UNIVERSITY OF MINNESOTA

ST. ANTHONY FALLS HYDRAULIC LABORATORY

Technical Paper No. 52, Series B

\title{
Supercavitating Flat-Plate with an Oscillating Flap at Zero Cavitation Number
}

by

C. S. SONG

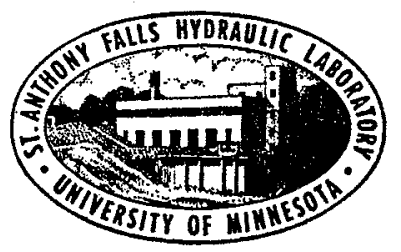

Prepared for OFFICE OF NAVAL RESEARCH

Department of the Navy Washington, D.C. under

Contract Nonr 710(24), Task NR 062-052

November 1965

Minneapolis, Minnesota 


\section{Supercavitating Flat-Plate with an Oscillating Flap at Zero Cavitation Number}

by

C. S. SONG

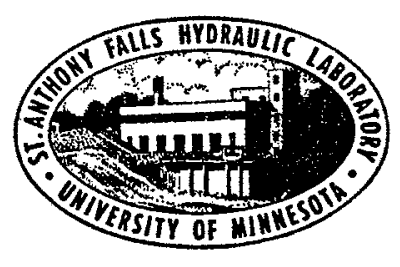

Prepared for OFFICE OF NAVAL RESEARCH

Department of the Navy Washington, D.C. under

Contract Nonr 710(24), Task NR 062-052

November 1965

Minneapolis, Minnesota 
u

Reproduction in whole or in part is permitted for any purpose of the United States Government 


\section{ABSTRACT}

The results of experimental and theoretical investigations on a supercavitating flat-plate with an oscillating flap at zero cavitation number are presented. The experiment was carried out in a vertical free-jet water tunnel using 3 in. chord and 2 in. chord flat-plate hydrofoils, both having flap-chord ratios of 0.29 . Various relative locations of the free surfaces were used and the reduced frequency range of zero to four was covered. Amplitude and phase angle of lift, drag, and moment as well as the surface wave speed were measured.

The problem was also solved analytically by means of a first order perturbation theory using complex acceleration potential. Numerical values were obtained for the cases of infinite fluid, symmetrical jet, and zero spray thickness using three flap-chord ratios $(0.25,0.30,0.40)$.

Fairly good agreement between the experimental data and the analytical results was obtained. 
CONTENTS

Page

Abstract ..................... i i ...

Iist of Iliustrations ................... vii

List of symbols ..................... ix

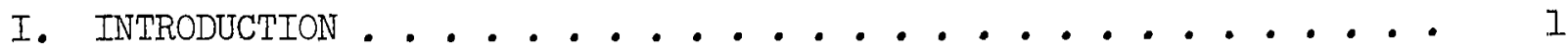

II. IINEAR THEORY . . . . . . . . . . . . . . . . . 2

A. The Boundary Value Problem and Its Solution...... 2

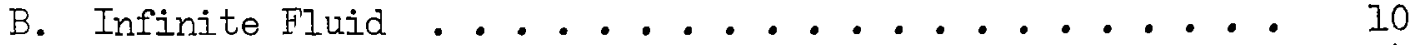

C. Symmetrical Jet............... 14

D. Zero Submergence ..................... 17

III. EXPERIMENTAL EQUIPMENT AND PROCEDURE . . . . . . . . . I8

A. Free-Jet Water Tunnel ................ 18

B. Dynamometer and Test Bodies ............ 18

C. Dynamic Properties of the System .......... 19

D. Experimental Procedure............ 20

IV. EXPERIMENTAL RESULTS AND COMPARISON WITH THEORY . . . . . . 23

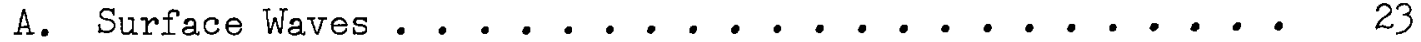

B. Oscillating Force and Moment in Symmetrical Jet.... 23

C. Oscillating Force and Moment in Non-Symmetrical Jet ... 24

D. Second Harmonic of Oscillating Drag........ 25

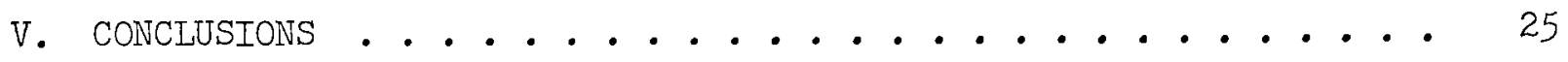

Iist of References . . . . . . . . . . . . . 27

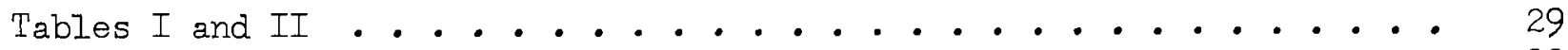

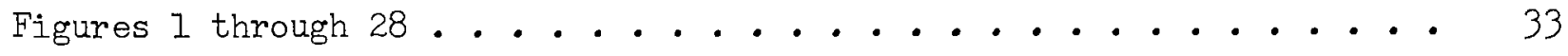




\section{IIST OF ILLUSTRATIONS}

Figure

I Flow Diagram and the Mapping Planes . . . . . . . . . 33

2 Frequency Response Function ............. . . 34

3 Oscillatory Lift Coefficient in Infinite Fluid . . . . . . . 35

4 Oscillatory Moment Coefficient About Leeding Edge in Infinite

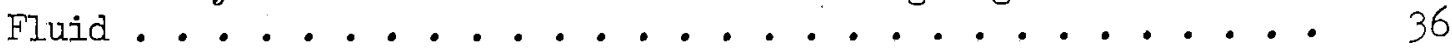

5 Effect of the Moment Center on the Oscillatory Moment

Coefficient . . . . . . . . . . . . . 37

6 Term by Term Comparison of First and Second Harmonies of

Drag Coefficient . . . . . . . . . . . 38

7 Comparison of First and Second Harmonics of Drag Coefficient. • 39

8 Free-Surface Correction Factor . . . . . . . . . . 40

9 Free-Surface Effect on the Amplitude of Iift Coefficient . . . 41

10 Free-Surface Effect on the Phase Angle of Iift Coefficient. . . 42

11 Lift Coefficient at Zero Submergence . . . . . . . . . 43

12 The Two-Dimensional Free-Jet Water Tunnel . . . . . . . . 44

Schematic Drawing of Two-Dimensional Test Section and
Appurtenances . . . . . . . . . . . . 45

14 The Dynamometer . . . . . . . . . . . . . 46

15 Construction Details of Test Bodies . . . . . . . . . 47

16 Foil and Driving Mechanism . . . . . . . . . . 48

17 System Response to Step Load Application. . . . . . . . . . 49

18 Dynamic Response of the System to Flap Oscillation, 3 in.

19 Typical Oscillograph Records . . . . . . . . . . 51

20 Photographs of Cavity Surface Waves in Non-Symmetrical Jet. . . 52

21 Photographs of Cavity Surface Waves in Symmetrical Jets . . . 53 
22 Amplitude of Oscillating Lift and Drag Coefficient in Symmetrical Jets . . . . . . . . . . . . . . 54

23 Phase Angle of Oscillating Lift Coefficients in Symmetrical Jets . . . . . . . . . . . . . . . . 55

24 Amplitude of Oscillating Moment Coefficient in Symmetrical Jets . . . . . . . . . . . . . . . . 56

25 Phase Angle of Oscillating Moment Coefficient in Symmetrical Jets ........................ . . 5 ?

26 Effect of Suction-Side Free Surface on Amplitude of Oscillating Force and Moment . . . . . . . . . . . 58

- Effect of Suction-Side Free Surface on Phase Angle of Oscillating Force and Moment . . . . . . . . . . . 59

28 Effect of Pressure-Side Free Surface on Oscillatory Force and Moment . . . . . . . . . . . . . . . . . . 


\section{LIST OF SYMBOLS}

$$
\begin{aligned}
& \text { A, A' - frequency response function } \\
& a_{n} \text { - coefficient of series expansion } \\
& \text { B - free-surface correction factor } \\
& \text { b - half jet width }
\end{aligned}
$$

$b_{1}, b_{2}$ - distance from the leading edge to free surfaces $b_{1}^{\prime}, b_{2}^{\prime}$ - thickness of divided free-jet at far downstream $C_{L}, C_{D}, C_{M}-$ lift, drag, and moment coefficients $\widetilde{C}_{L}, \widetilde{C}_{D}, \widetilde{C}_{M}$ - unsteady part of lift, drag, and moment coefficients $\overline{\mathrm{C}}_{\mathrm{L}}, \overline{\mathrm{C}}_{\mathrm{D}}, \overline{\mathrm{C}}_{\mathrm{M}}$ - steady part of lift, drag, and moment coefficients $\left(\widetilde{C_{D}}\right)_{I}$ - first harmonic of drag coefficient $\left(\widetilde{C}_{D}\right)_{2}$ - second harmonic of drag coefficient c - chord $\widetilde{D i}$ - amplitude of drag measured in air $\widetilde{|D|}$ - amplitude of drag measured in water e - flap-chord ratio

$G_{L}, G_{D}, G_{M}$ - integrands for lift, drag, and moment integrals $I, I_{0}, I_{1}, I_{2}$ - integrals related with lift $I^{\prime}, I_{0}^{\prime}, I_{1}^{\prime}, I_{2}^{\prime}$ - integrals related with drag

i - unit imaginary number with regard to space $J_{0}, J_{1}, J_{2}$ - integrals related with the frequency response function $J_{0}^{\prime}, J_{1}{ }^{\prime}$ - integrals related with the frequency response function $j$ - unit imaginary number with regard to time $K$ - integrand related with the frequency response function $k$ - reduced frequency based on full chord length k' - modified reduced frequency due to free-surface effect 


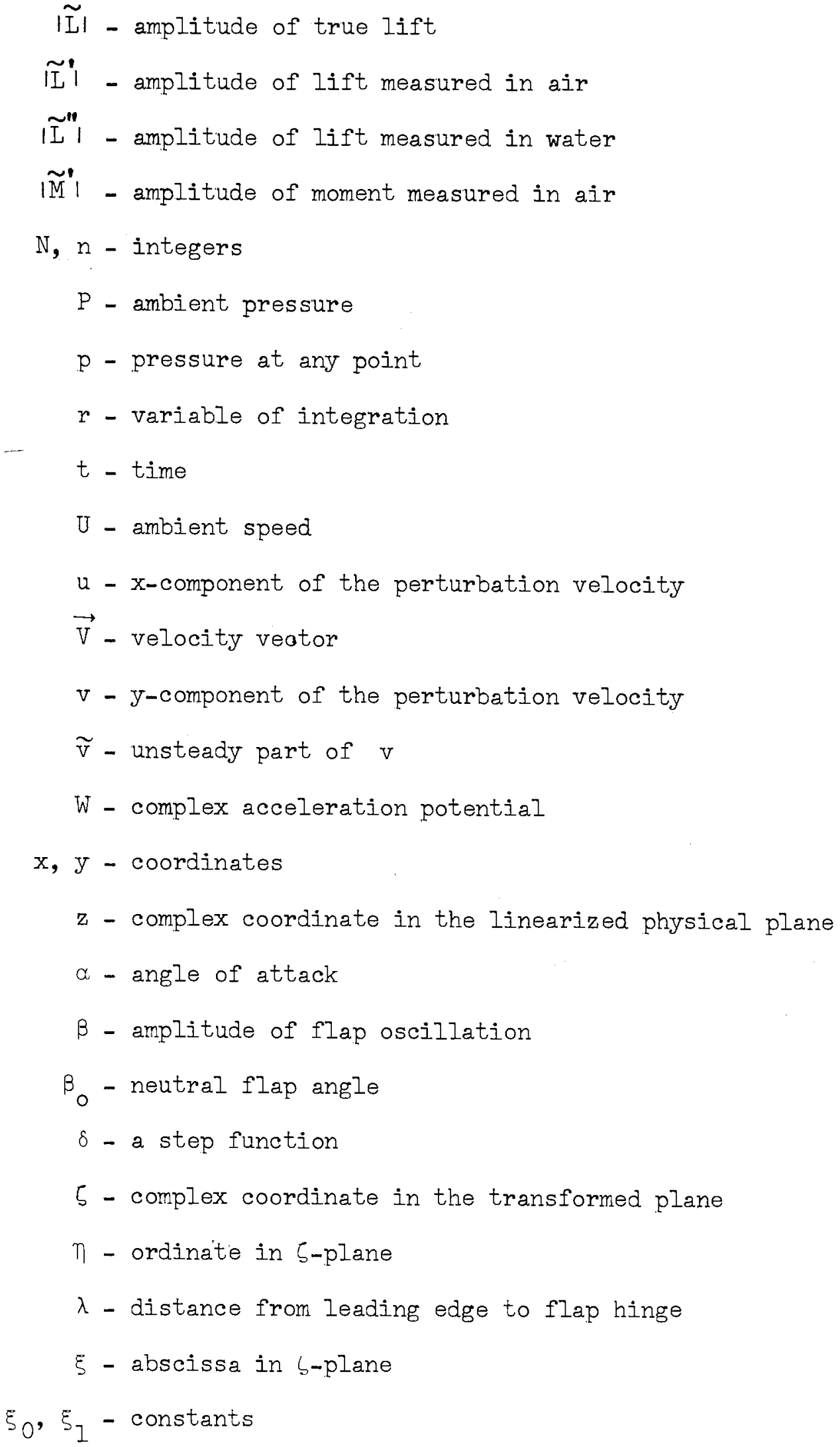




$$
\begin{aligned}
& \rho \text { - fluid density } \\
& \tau \text { - variable of integration } \\
& \varnothing \text { - acceleration potential }
\end{aligned}
$$

$\psi, \psi_{1}, \psi_{2}$ - imaginary part of the complex acceleration potential $\tilde{\psi}$ - amplitude of the unsteady part of $\psi$ $\omega$ - angular speed of flap oscillation 


\section{INTRODUCTION}

It is generally known that the oscillatory force on a supercavitating hydrofoil due to a small amplitude oscillation of the foil or the attached solid flap mainly depends on the reduced frequency. This statement is valid only if the oscillation does not result in instability of the flow. For example, if the cavity is ventilated and the cavitation number is not equal to zero, then the oscillation is found to alter the cavity pressure $[1]^{*}$. In this case the oscillatory force will depend on the cavitation number and the ventilation coefficient as well. The recent experimental studies carried out at the St. Anthony Falls Hydraulic Laboratory have revealed various instability phenomena concerning flow at small but non-zero cavitation numbers. Some of these phenomena were reported in previous papers $[1,2]$ and additional results will be reported in future papers.

The present paper concerns the flow about a flat-plate at zero cavitation number wherein the oscillation does not result in an instability. It is well known that in an ideal infinite and gravity-free field, zero cavitation number results in an infinitely long cavity wherein the pressure is equal to the pressure at infinity. Thus, once the cavitation number reaches zero it will remain zero regardless of the flap oscillation. The same statement also applies for the case when the flow field is bounded by one or two free surfaces. Because of its inherent simplicity, a great majority of papers available in the current literature are concerned with flows at zero cavitation number. Unfortunately, flows at zero cavitation number are very difficult to simulate experimentally. In fact, the author is not aware of any experimental data at zero cavitation number covering a sufficiently wide range of reduced frequency so that the existing theories may be compared with the experiment.

During the past few years the St. Anthony Falls Hydraulic Laboratory has been engaged in both theoretical and experimental investigations of unsteady supercavitating flow problems. The free-jet water tunnel at the Laboratory has been used to simulate unsteady supercavitating flows in gravity-free fields at zero cavitation number. Some of the data concerning the flow due to an oscillating flat-plate was reported in Reference [1]. Due to a mechanical 
difficulty it was not possible to obtain data at reasonably high reduced frequencies. The experimental program has since been modified and a trailing edge solid flap, instead of the foil itself, was oscillated. With the new arrangement, which will be described later, the reduced frequency based on the chord was increased to nearly four. The purpose of the present paper is to report the experimental findings and the comparison with an analytical result.

In a recent paper Hsu [3] has reported his analytical results concerning the unsteady force due to an oscillating flat-plate and that due to an oscillating flap under a free surface. However, there appear to be errors in the latter part of his analysis and the result does not compare favorably with : the experimental data.

This research has been supported by the Office of Naval Research of the U. S. Department of the Navy under Contract Nonr 710(24), Task NR 062-052. The author gratefully acknowledges the assistance of Messrs. John Almo, Harold Pearson, and Donald Ramsey, who have carried out the details of experimental observation and data analysis. He is also indebted to Dr. John W. Hayden, who has set up a computer program for the numerical integrations necessary for the analytical solution and to Dr. R. Oba for his useful discussions. The author is also grateful to Marjorie Olson and Patricia McNelly, who prepared the manuscript for publication.

\section{LINEAR THEORY}

A. The Boundary Value Problem and Its Solution

The problem under consideration is the perturbation of an otherwise uniform two-dimensional jet of constant speed $U$ due to a flat-plate hydrofoil fitted with an oscillating solid flap. An infinitely long trailing cavity with fixed and known separation points is always assumed to exist. Furthermore, the flow is considered to be incompressible and irrotational. The chord which is defined as the distance from the leading edge of the foil to the trailing edge of the flap is taken as unity and the following nomenclature completes the geometrical description:

$$
\begin{aligned}
e & =\text { flap-chord ratio } \\
b_{1}= & \text { distance from the leading edge to the undisturbed free } \\
& \text { surface on the cavity side } \\
b_{1}{ }^{\prime}= & \text { cavity side jet width far downstream }
\end{aligned}
$$


$b_{2}=$ distance from the leading edge to the undisturbed free surface on the wetted side

$\mathrm{b}_{2}{ }^{\prime}=$ wetted-side jet width far downstream

$\alpha=$ angle of attack

$\beta_{0}+\operatorname{Re}\left(\beta e^{j \omega t}\right)=$ flap angle

where $j$ is the unit imaginary number associated with time and $\beta_{0}, \beta$, and $\omega$ are, respectively, neutral flap angle, amplitude, and frequency of the flap oscillation. The flow is shown schematically in Fig. I(a).

Consideration will be given only to those cases wherein the perturbation velocity is an order of magnitude smaller than $U$ everywhere except within a few isolated small areas. Specifically, the case of small attack angle and small flap angle, which is of considerable practical importance, will be considered in this paper. For the special type of flow considered herein, the method of complex acceleration potential is applicable [4].

It has been shown that there exists an acceleration potential which satisfies the Laplace equation up to the first order of the perturbation velocity. The acceleration potential $\phi$ is defined as

$$
\phi=\frac{P-p}{\rho \mathrm{J}^{2}}
$$

where $P$ is the ambient pressure, $p$ is the pressure at any point, and $\rho$ is the density of the fluid. It follows that the complex acceleration potential

$$
W=\phi+i \psi
$$

is an analytic function of the complex coordinate

$$
z=x+i y
$$

The perturbation velocity components $u$ and $v$ are defined as

$$
\vec{V}=U(I+u, v)
$$

It has also been shown that either the real part or the imaginary part of $W$ can be calculated from known boundary conditions and the problem is reducible to a mixed boundary value problem of analytic functions. However, the problem is extremely complex because of the nature of the boundary profile. For simplicity, the boundary profile also needs to be linearized and suitably placed on the z-plane. The linearized boundary representing the foil and the cavity surfaces is, as usual, placed on the positive x-axis. The best locations for 
the remaining two free-surface boundaries are not so obvious. The presence of the foil and the cavity results in a division of the flow into two parts not necessarily according to the ratio $b_{1}: b_{2}$ and, hence, $b_{1} \neq b_{1}{ }^{\prime}$ and $b_{2} \neq b_{2}{ }^{\prime}$. Since the force characteristics depend mainly on the flow near the foil, $b_{1}^{\prime}$ and $b_{2}^{\prime}$ rather than $b_{1}$ and $b_{2}$ should be chosen as the representative dimensions and the linearized free surfaces are placed as shown in Fig. $l(b)$. Of course the differences between the two sets of dimensions $\left(b_{1}, b_{2}\right)$ and $\left(b_{1}{ }^{\prime}, b_{2}{ }^{\prime}\right)$ become less important as $b_{1}$ and $b_{2}$ increase.

The linearized $\mathrm{z}$-plane is then mapped onto the upper half 5 -plane by the following transformation formula:

$$
z=\frac{b_{1}^{\prime}}{\pi} \ln \left(\frac{\xi_{1}}{\xi_{1}-\zeta}\right)+\frac{b_{2}{ }^{\prime}}{\pi} \ln \left(\frac{b_{2}{ }^{\prime} \xi_{1}}{b_{2}{ }^{\prime} \xi_{1}+b_{1}{ }^{\prime} \zeta}\right)
$$

where $\zeta=\xi+i \eta$, and $\xi_{1}$ is a root of

$$
1=\frac{b_{1}^{\prime}}{\pi} \ln \left(\frac{\xi_{1}}{\xi_{1}+1}\right)+\frac{b_{2}^{\prime}}{\pi} \ln \left(\frac{b_{2}^{\prime} \xi_{1}}{b_{2}{ }^{\prime} \xi_{1}-b_{1}^{\prime}}\right)
$$

The S-plane is shown in Fig. I(c).

The boundary conditions are as follows:

1. The pressure on the free-surfaces is constant and equal to P. Thus,

$$
\phi=0 \text { on } \xi<-1, \eta=0 \text { and } \xi>0, \eta=0
$$

2. The fluid cannot penetrate into the solid boundary. If the boundary profile is given by $y=Y(x, t)$, then it has been shown that, to first order accuracy $[5,6]$,

$$
\psi=-\frac{1}{U^{2}} \int \frac{\partial^{2} Y}{\partial t^{2}} d x-\frac{2}{U} \frac{\partial Y}{\partial t}-\frac{\partial Y}{\partial x}+\Psi(t, \delta)
$$

where $\Psi(t, \delta)$ is an arbitrary function of integration and $\delta$ is a step function defined as

$$
\delta= \begin{cases}0 & 0<x<\lambda \\ 1 & \lambda<x<1\end{cases}
$$

Unlike the problems considered in Refs. [5] and [6], this problem requires a singularity at the flap hinge and, hence, 
the function of integration contains a step function with the step located at the flap hinge. For the specific problem under consideration

$$
Y(x, t)= \begin{cases}-\alpha x, & 0<x<\lambda \\ -\alpha x-(x-\lambda)\left(\beta_{0}+\beta_{e}^{j \omega t}\right), & \lambda<x<1\end{cases}
$$

where $\alpha$ is the angle of attack and $\lambda=1-e$. It then follows that:

$$
\psi= \begin{cases}\psi_{1}, & 0<x<\lambda \\ \psi_{2}, & \lambda<x<1\end{cases}
$$

where

$\psi_{1}=\alpha+\beta A e^{j \omega t}$

$\psi_{2}=\alpha^{+} \beta_{0}+\beta\left[1+A^{\prime}+2 j k(x-\lambda)-k^{2} x\left(\frac{1}{2} x-\lambda\right)\right] e^{j \omega t}$

and $A$ and $A '$ are complex constants to be determined later. Because of the step change indicated in Eq. (6) the two constants are not equal.

3. The flow at upstream infinity is not affected by the presence of the hydrofoil. That is

$$
\psi=0, \quad x \longrightarrow-\infty
$$

4. To obtain a unique solution, it is necessary to relate the acceleration field with the velocity field. This relationship is furnished by the general integral of the linearized equation of motion along the $y$-axis. For an oscillatory motion, it is written as

$$
\widetilde{v}(x, y)-\widetilde{v}_{I}\left(x_{1}, y_{I}\right)=-e^{-j k x} \int_{x_{I}}^{x} e^{j k t} \frac{\partial \psi}{\partial \tau} d \tau
$$

where $\widetilde{v}(x, y)=$ amplitude of the unsteady part of $v$,

$$
\begin{aligned}
\widetilde{\psi}(\mathrm{x}, \mathrm{y}) & =\text { amplitude of the unsteady part of } \psi \text {, and } \\
\mathrm{k} & =\frac{\omega . \mathrm{I}}{\mathrm{U}}, \text { reduced frequency }
\end{aligned}
$$

The detailed derivation of $\mathrm{Eq}$. (9) is given in Refs. [4] and $[?]$. 
It seems most convenient to express the solution of the problem in an integral form following Chen and Rott's method [8]. The following expression can readily be shown to satisfy the first three boundary conditions.

$$
W(\zeta)=\frac{1}{\pi} \sqrt{\frac{\zeta+1}{-\zeta}}\left[\int_{-1}^{-\xi_{0}} \psi_{2}(\tau, t)+\int_{-\xi_{0}}^{0} \psi_{1}(\tau, t)\right] \sqrt{\frac{-\tau}{\tau+1}} \frac{d \tau}{\tau-\zeta}(10
$$

where $\xi_{0}$ is the coordinate of the flap hinge on the $\zeta$-plane and is a root of

$$
\lambda=\frac{b_{1}^{\prime}}{\pi} \ln \left(\frac{\xi_{1}}{\xi_{1}+\xi_{0}}\right)+\frac{b_{2}^{\prime}}{\pi} \ln \left(\frac{b_{2}^{\prime} \xi_{1}^{\prime}}{b_{2}{ }^{\prime} \xi_{1}-b_{1}^{\prime} \xi_{0}}\right)
$$

It is now necessary to determine the constants $A$ and $A^{\prime}$ by using Eq. (9). First, it should be noted that

$$
\begin{aligned}
& \tilde{v}= \begin{cases}0, & \text { as } x \longrightarrow-\infty \\
0, & \text { on } 0<x<\lambda, y=0^{-} \\
-\beta[1+j k(x-\lambda)], & \text { on } \lambda<x<1, y=0^{-}\end{cases} \\
& \tilde{\psi}= \begin{cases}0, & \text { as } x \longrightarrow-\infty \\
\beta A & \text { at } x=\lambda^{-}, y=0^{-} \\
\beta\left(1+A^{\prime}-\frac{1}{2} \lambda^{2} k^{2}\right), & \text { at } x=\lambda^{+}, y=0^{-}\end{cases}
\end{aligned}
$$

On account of the singularity exhibited by $\tilde{v}$ and. $\tilde{\psi}$ at the flap hinge $(\lambda, 0)$, it is necessary that $A$ is not equal to $A^{\prime}$. Applying Eq. (9) across this singular point, it follows that

$$
A^{\prime}=A-\frac{1}{2} \lambda^{2} k^{2}
$$

This equation gives $A=A^{\prime}$ when $\lambda=0$ which is to be expected. The fact that the singularity at the flap hinge should be so chosen as to satisfy Eq. (9) was overlooked by Hsu [3]. The remaining constant A may be determined by applying Eq. (9) between $(-\infty, 0)$ and $\left(0^{+}, 0^{-}\right)$. Since the integral is independent of the path (it depends only on the end points), it is advantageous 
to choose the $\eta$-axis as the path of integration unless $b_{1}{ }^{\prime}=0$ and the negative $\mathrm{x}$-axis falls on $\xi$-axis. After some lengthy computations, $A$ is reduced to

$$
A=j k \frac{J_{1}+J_{2}}{1+j k J_{0}}
$$

where

$$
\begin{aligned}
& J_{0}=\int_{-\infty}^{0}\left(\sqrt{\frac{r+1}{2}}-1\right) e^{j k x} d x \\
& J_{I}=\frac{1}{\pi} \int_{-\infty}^{0} \sqrt{\frac{r-1}{2}} \int_{\xi_{0}}^{1} K(\tau) \sqrt{\frac{\tau}{1-\tau}} \frac{\eta_{d \tau}}{\tau^{2}+\eta_{1}^{2}} e^{j k x} d x, \\
& J_{2}=\frac{1}{\pi} \int_{-\infty}^{0} \sqrt{\frac{r+1}{2}} \int_{\xi_{0}}^{1} K(\tau) \sqrt{\frac{\tau}{1-\tau}} \frac{\tau d \tau}{\tau^{2}+\eta_{i}^{2}} e^{j k x} d x \\
& r=\frac{\sqrt{1+\eta^{2}}}{\eta} \text { and } K(\tau)=1+2 j k[x(\tau)-\lambda]-\frac{1}{2} k^{2}[x(\tau)-\lambda]^{2}
\end{aligned}
$$

When $b_{1}^{\prime}=0$ (zero spray thickness), then the negative $x$-axis coincides with the positive $\xi$-axis and it is best to integrate along the negative $x$-axis. The resulting equation for $A$ is

$$
A=j k \frac{J_{1}^{\prime}}{1+j k J_{0}^{\prime}}
$$

where

$$
\begin{gathered}
J_{0}^{\prime}=\int_{-\infty}^{0}\left(\sqrt{\frac{F+1}{\xi}}-1\right) e^{j k x} d x \\
J_{I}^{\prime}=-\frac{1}{\pi} \int_{-\infty}^{0} \sqrt{\frac{\xi+1}{\xi}} \int_{\xi_{0}}^{1} K(\tau) \sqrt{\frac{\tau}{1-\tau}} \frac{d \tau}{\tau+\xi} e^{j k x} d x
\end{gathered}
$$


The lift coefficient, up to the first order terms, is given by the real part of the following expression:

$$
\begin{aligned}
C_{L}= & \frac{2}{\pi}\left[\left(\alpha+\beta A e^{j \omega t}\right) I+\left(\beta_{0}+\beta e^{j \omega t}\right) I_{0}\right. \\
& +2 j k \beta e^{j \omega t} I_{I}-\frac{I}{2} k^{2} \beta e^{j \omega t} I_{2}
\end{aligned}
$$

where

i:

$$
\begin{aligned}
& I=\int_{0}^{I} G_{I} \sqrt{\frac{T}{I-T}} d \tau \\
& I_{0}=\int_{\xi_{0}}^{I} G_{L} \sqrt{\frac{T}{1-\tau}} d \tau \\
& I_{1}=\int_{\xi_{0}}^{I}[x(-\tau)-\lambda] G_{L} \sqrt{\frac{\tau}{1-\tau}} d \tau \text {, } \\
& I_{2}=\int_{\xi_{0}}^{1}[x(-\tau)-\lambda]^{2} G_{L} \sqrt{\frac{\tau}{1-\tau}} d \tau \text {, and } \\
& G_{L}=\frac{b_{1}{ }^{\prime} b_{2}^{\prime}}{b_{2}{ }^{\prime} \xi_{1}-b_{1}^{\prime} \tau} \sqrt{\frac{b_{2}^{\prime} \xi_{1}-b_{1}}{b_{2}^{\prime} \xi_{1}}}-\frac{b_{1}^{\prime}}{\xi_{1}+\tau} \sqrt{\frac{1+\xi_{1}}{\xi_{1}}}
\end{aligned}
$$

Using the mapping function, Eq. (4), it can be shown that

$$
\mathrm{b}_{2}{ }^{\prime} \xi_{1}=\mathrm{b}_{1}{ }^{\prime} \xi_{2}>\mathrm{b}_{1}{ }^{\prime}
$$

and $G_{L}$ is always real.

The drag coefficient is given by the real part of the following expression:

$$
C_{D}=\alpha C_{L}+\left(\beta_{0}+\beta e^{j \omega t}\right) C_{L}^{\prime}
$$


where $C_{L}$ ' has the same functional form as $C_{I}$ given by Eq. (20) through Eq. (25) except $G_{L}$ is replaced by $G_{D}$ as follows:

$$
\begin{aligned}
& G_{\dot{D}}=\frac{1}{2} G_{L}+\frac{b_{1}{ }^{\prime}}{U}\left(\frac{1}{\xi_{I}+\tau}-\frac{b_{2}{ }^{\prime}}{b_{2}{ }^{\prime} \xi_{I}-b_{1}{ }^{\prime} \tau}\right) \sqrt{\frac{1-\tau}{\tau}} \ln \frac{\left[\sqrt{(1-\tau) \xi_{0}}+\sqrt{\tau\left(1-\xi_{0}\right)}\right]^{2}}{\left|\tau-\xi_{0}\right|} \\
& +\frac{b_{1}^{\prime}}{\pi\left(\xi_{1}+\tau\right)} \sqrt{\frac{1+\xi_{1}}{\xi_{1}}} \sin ^{-1} \frac{\xi_{0}+2 \xi_{0} \xi_{1}-\xi_{1}}{\xi_{0}+\xi_{1}} \\
& +\frac{b_{1}^{\prime} b_{2}^{\prime}}{\pi\left(b_{2}^{\prime} \xi_{1}-b_{1}^{\prime} \tau\right)} \sqrt{\frac{b_{2}^{\prime} \xi_{1}-b_{1}^{\prime}}{b_{2}^{\prime} \xi_{1}}} \sin ^{-1} \frac{b_{2}^{\prime} \xi_{1}+b_{1}^{\prime} \xi_{0}-2 b_{2}^{\prime} \xi_{1} \xi_{0}}{b_{2}^{\prime} \xi_{1}-b_{1}^{\prime} \xi_{0}}
\end{aligned}
$$

The moment coefficient referred to the leading edge, tail up positive, is given by the real part of the following expression:

$$
\begin{aligned}
C_{M} & =\frac{2}{\pi}\left[\left(\alpha+\beta A e^{j^{\omega t}}\right) L+\left(\beta_{0}+\beta e^{j^{\omega} t}\right) I_{0}\right. \\
& \left.+2 j k \beta e^{j \omega t} I_{I}-\frac{1}{2} k^{2} \beta e^{j \omega t} L_{2}\right]
\end{aligned}
$$

where $I, I_{0}, I_{1}$, and $I_{2}$ have the same expression as $I, I_{0}, I_{1}$, and $I_{2}$, respectively, except that $G_{I}$ is replaced by $G_{M}$ as follows:

$$
G_{M}=\frac{b_{1}^{\prime}}{\pi} \int_{0}^{1} x(-\xi) \quad \sqrt{\frac{1-\xi}{\xi}}\left(\frac{\xi_{1}}{\xi_{1}^{\prime}+\xi}-\frac{b_{2}^{\prime}}{b_{z_{2}}^{\prime} \xi_{1}-b_{1} \xi}\right) \frac{d \xi}{\xi-T}
$$

The hinge moment coefficient, tail up positive, is

$$
C_{M}^{\prime}=C_{M}\left(G_{M}^{\prime}\right)
$$

where $C_{M}\left(G_{M}^{\prime}\right)$ means replacing $G_{M}$ in Eq. (28) by $G_{M}^{\prime}$, defined as

$$
G_{M}^{\prime}=\frac{b_{1}{ }^{\prime}}{\pi} \int_{\xi_{0}}^{I}[x(-\xi)-\lambda] \sqrt{\frac{1-\xi}{\xi}}\left(\frac{1}{\xi_{ \pm}+\xi}-\frac{b_{2}^{\prime}}{b_{2}{ }^{\prime} \xi_{1}-b_{1}{ }^{\prime} \xi}\right) \frac{d \tau}{\xi-\tau}
$$


It should be noted that the oscillatory part of the drag coefficient as indicated by Eq. (26) consists of the first two harmonics whereas the lift and moment coefficients given by Eqs. (20) and (28) include only the first harmonic. It is readily seen that the order of magnitude of the first and the second harmonics of the drag coefficient are $\alpha \beta$ and $\beta^{2}$ respectively. Therefore, unless $\beta<<\alpha$, the second harmonic is of the same order of magnitude as the first harmonic. On the contrary, the second harmonic is always an order of magnitude smaller than the first harmonic for the lift and moment coefficients.

The evaluation of the improper integrals $\mathrm{J}_{0}, \mathrm{~J}_{1}, \mathrm{~J}_{2}, \mathrm{~J}_{0}^{\prime}$, and $\mathrm{J}_{1}{ }^{\prime}$ is very time-consuming. The difficulty is partly due to the singularity at the origin and partly due to the fact that the integrals converge very slowly at large $x$. For this reason, only a few special cases have been computed and the results are compared with the experimental data.

\section{B. Infinite Fluid}

For this special case we may let $b_{1}^{\prime}=b_{2}{ }^{\prime} \rightarrow \infty$ and the mapping function is simplified to

$$
z=\zeta^{2}
$$

It then follows that $\xi_{0}=\sqrt{\lambda}, \quad \xi_{1}=\xi_{2} \rightarrow \infty$ such that

$$
\frac{b_{1}{ }^{\prime}}{\xi_{1}{ }^{2}}=\frac{b_{2}{ }^{\prime}}{\xi_{2}^{2}} \rightarrow \pi
$$

The integrals $J_{0}, J_{1}$, and $J_{2}$ were numerically integrated for the case of the flap-chord ratio $e=0.25,0.30$, and 0.40 by means of an electronic computer (Control Data 1604). In conjunction with the numerical integrations, it should be noted that $J_{1}$ and $J_{2}$ may be reduced to single integrals by analytically performing the inside integrals. However, the resulting integrands expressed inclosed form are singular at $\mathrm{x}=0$ as well as at $|x| \rightarrow \infty$. The singularity at $x=0$ is obvious from Eqs. (15) and (16). The 
singularity at large $|x|$ arises because the closed form expression of the integrands turned out to be the sum of two functions, each unbounded at infinity, which approaches to zero as $|x| \rightarrow \infty$. For this reason the numerical integrations were performed in two steps. The first step was the integration covering the lower range of $|x|$ wherein the integrands were expressed in the exact closed form. The second step was to integrate for large $|x|$ wherein the integrands were expanded asymptotically, in the following form:

$$
x^{-\frac{3}{4}}(\sqrt{x+1}+\sqrt{x})^{-\frac{1}{2}} \sum_{n=0}^{N} a_{n} x^{-n}
$$

The computed frequency response function $A$ is listed in Table $I$ and also plotted in Fig. 2. The numerical error int: lved is believed to be less than 0.1 per cent of the correct value.

Once the frequency response function has been determined the lift, drag, and moment coefficients may be determined without difficulty. As a check, it may be shown that the steady flow solution for a flat plate by Tulin and Burkhart [9] is obtained by setting $\beta=\beta_{0}=0$. The contribution of the flap to the steady state lift and moment coefficients is

$$
\begin{aligned}
& \bar{C}_{L}\left(\beta_{0}\right)=\frac{2}{\pi} \beta_{0} I_{0} \\
&=\left[(1+2 \sqrt{\lambda}) \sqrt{\sqrt{\lambda}(1-\sqrt{\lambda})}+\frac{\pi}{2}-\tan -\sqrt{\frac{\sqrt{\lambda}}{1-\sqrt{\lambda}}}\right] \beta_{0} \quad(32) \\
& \bar{C}_{M}\left(\beta_{0}\right)=\frac{2}{\pi} \beta_{0} I_{0} \\
&=\left[\left(\lambda^{3 / 2}+\frac{1}{2} \lambda+\frac{3}{8} \sqrt{\lambda}+\frac{5}{16}\right) \sqrt{\sqrt{\lambda(1-\sqrt{\lambda}})}+\frac{5}{32}\left(\pi-2 \tan \frac{-1}{\sqrt{1-\sqrt{\lambda}}}\right)\right] \beta_{0}
\end{aligned}
$$

which can be shown to agree with. Tulin and Burkhart's result given in Ref. [9]. The steady drag coefficient due to the plate and the flap is

$$
\begin{aligned}
& \bar{C}_{D}\left(\alpha, \beta_{0}\right)=\frac{\pi}{2} \alpha^{2}+\frac{\beta_{0}^{2}}{\pi}\left[\sqrt{\sqrt{\lambda}(1-\sqrt{\lambda})}+\frac{\pi}{4}-\tan ^{-1} \sqrt{\frac{\sqrt{\lambda}}{1-\sqrt{\lambda}}}\right]^{2} \\
&+\beta_{0} a\left[(1-2 \sqrt{\lambda}) \sqrt{\sqrt{\lambda}(1-\sqrt{\lambda})}+\frac{\pi}{2}-\tan ^{-1} \sqrt{\frac{\sqrt{\lambda}}{1-\sqrt{\lambda}}}\right]
\end{aligned}
$$


12

which includes a term indicating interaction between the angle of attack and the flap angle. This fact is also well known [10].

The unsteady part of the lift and moment coefficients are given, respectively, by the real parts of the following equations.

$$
\begin{aligned}
& \frac{\widetilde{C}_{L}}{\beta}=\frac{2}{\pi}\left(A I+I_{0}+2 j k I_{I}-\frac{I}{2} k^{2} I_{2}\right) e^{j \omega t} \\
& \widetilde{C}_{M}=\frac{2}{\pi}\left(A I+I_{0}+2 j k I_{I}-\frac{I}{2} k^{2} I_{2}\right) e^{j \omega t}
\end{aligned}
$$

a:

where

$$
\begin{aligned}
& I=\frac{\pi^{2}}{4}, \\
& I_{0}=\frac{\pi}{2}\left[(1+2 \sqrt{\lambda}) \sqrt{\sqrt{\lambda}(1-\sqrt{\lambda})}+\frac{\pi}{2}-\tan ^{-1} \sqrt{\frac{\sqrt{\lambda}}{1-\sqrt{\lambda}}}\right] \text {, } \\
& I_{1}=\frac{\pi}{4}\left[\frac{15}{8}+\frac{5}{4} \sqrt{\lambda}-\lambda-2 \lambda^{3 / 2}\right) \sqrt{\sqrt{\lambda}(1-\sqrt{\lambda})}+\left(\frac{15}{16}-\lambda\right)\left(\pi-2 \tan ^{-1} \sqrt{\left.\frac{\sqrt{\lambda}}{1-\sqrt{\lambda}}\right)},\right. \\
& I_{2}=\pi\left[\left(\frac{105}{256}+\frac{35}{128} \sqrt{\lambda}-\frac{23}{32} \lambda-\frac{7}{16} \lambda^{3 / 2}+\frac{1}{6} \lambda^{2}+\frac{1}{3} \lambda^{5 / 2}\right) \sqrt{\sqrt{\lambda}(1-\sqrt{\lambda})}\right. \\
& \left.+\left(\frac{105}{512}-\frac{15}{32} \lambda+\frac{1}{4} \lambda^{2}\right)\left(\pi-2 \tan ^{-1} \sqrt{\frac{\sqrt{\lambda}}{1-\sqrt{\lambda}}}\right)\right], \\
& I=\frac{5}{64} \pi^{2} \\
& I_{0}=2 \pi \int_{\sqrt{\lambda}}^{0}\left(\tau^{3}-\frac{1}{2} \tau^{2}-\frac{1}{8} \tau-\frac{1}{16}\right) \sqrt{\frac{T}{1-\tau}} d \tau, \\
& I_{1}=2 \pi \int_{\sqrt{\lambda}}^{1}\left(\tau^{2}-\lambda\right)\left(\tau^{3}-\frac{1}{2} \tau^{2}-\frac{1}{8} \tau-\frac{1}{16}\right) \sqrt{\frac{\tau}{1-\tau}} d \tau \text {, and } \\
& I_{2}=2 \pi \int_{\sqrt{\lambda}}^{1}\left(\tau^{2}-\lambda\right)^{2}\left(\tau^{3}-\frac{1}{2} \tau^{2}-\frac{1}{8} \tau-\frac{1}{16}\right) \sqrt{\frac{\tau}{1-\tau}} d \tau \text {. }
\end{aligned}
$$


Here, moment is referred to the leading edge and counter-clockwise rotation is regarded as positive rotation. For the purpose of comparison with data it is more convenient to rewrite Eqs. (35) and (36) in the following forms wherein amplitudes and phase angles appear explicitly.

$$
\begin{aligned}
& \operatorname{Re}\left\{\frac{\widetilde{C}_{I}}{\beta}\right\}=\left|\frac{\widetilde{C}_{L}}{\beta}\right| \cos \left(\omega t+\phi_{L}\right) \\
& \operatorname{Re}\left\{\frac{\widetilde{C}_{M}}{\beta}\right\}=\left|\frac{\widetilde{C}_{M}}{\beta}\right| \cos \left(\omega t+\phi_{M}\right)
\end{aligned}
$$

The amplitude and the phase angle of the lift coefficient were computed for three flap-chord ratios, $e=0.25,0.30$, and 0.40 , and the results are plotted in Fig. 3.

Since moment oscillation is affected by the magnitude as well as the location of the resulting force, its characteristic may be different from that of lift oscillation. Figure 4 shows the amplitude and phase angle of the oscillatory moment about the leading edge given by Eq. (38) for the three flapchord ratios. Figure 5 shows the same oscillatory moment, nose up as positive, referred to several different points on the chord for the case $\mathrm{e}=0.30$. Noteworthy is the fact that the phase angle curves as well as the amplitude curves are widely separated for various conditions indicating that the location of the force does not oscillate in a simple harmonic manner.

The unsteady part of the drag coefficient is the real part of the following equation:

$$
\widetilde{C}_{D}=\left(\widetilde{C}_{D}\right)_{1}+\left(\widetilde{C}_{D}\right)_{2}
$$

where $\left(\widetilde{C}_{D}\right)_{1}$ and $\left(\widetilde{C}_{D}\right)_{2}$ are the first and the second harmonies respectively. They are

$$
\begin{gathered}
\left(\widetilde{C}_{D}\right)_{I}=\alpha \widetilde{C}_{I}+\frac{2}{\pi} \beta\left[\left(\alpha+\beta_{0} A\right) I^{\prime}+2 \beta_{0} I_{0}^{\prime}+2 j k \beta_{0} I_{I}^{\prime}-\frac{I}{2} k^{2} \beta_{0} I_{2}^{\prime}\right] e^{j \omega t} \\
\left(\widetilde{C}_{D}\right)_{2}=\frac{2}{\pi} \beta^{2}\left(A I^{\prime}+I_{0}^{\prime}+2 j k I_{I}^{\prime}-\frac{I}{2} k^{2} I_{2}^{\prime}\right) e^{2 j \omega t}
\end{gathered}
$$

where 


$$
\begin{aligned}
& \begin{array}{l}
I^{\prime}=\frac{\pi}{2}\left[(1-2 \sqrt{\lambda}) \sqrt{\sqrt{\lambda}(1-\sqrt{\lambda})}+\frac{\pi}{2}-\tan ^{-1} \sqrt{\frac{\sqrt{\lambda}}{1-\sqrt{\lambda}}}\right] \\
I_{0}^{\prime}=\left[\sqrt{\sqrt{\lambda}(1-\sqrt{\lambda})}+\frac{\pi}{2}-\tan ^{-1} \sqrt{\frac{\sqrt{\lambda}}{1-\sqrt{\lambda}}}\right]^{2}
\end{array} \\
& I_{I}^{\prime}=(I-\lambda) I_{0}^{\prime}-\frac{I}{4 \pi^{2}}\left(I^{\prime}\right)^{2} \\
& I_{2}^{\prime}=\int_{\sqrt{\lambda}}^{I} \sqrt{\frac{\tau}{I-\tau}}\left(\tau^{2}-\lambda\right) \mathrm{d} \tau \int_{\sqrt{\lambda}}^{I} \sqrt{\frac{\tau}{1-\tau}}\left(2-\lambda-\tau^{2}\right) \mathrm{d} \tau-2 \int_{\sqrt{\lambda}}^{1} \sqrt{\tau(1-\tau)} \mathrm{d} \tau \int_{\sqrt{\lambda}}^{I} \sqrt{\tau(1-\tau)}\left(\tau^{2}-\lambda\right) \mathrm{d} \tau
\end{aligned}
$$

When the neutral flap angle $\beta_{0}$ is zero, then the first harmonic of the drag coefficient is reduced to

$$
\left(\widetilde{C}_{D}\right)_{1}\left(\beta_{0}=0\right)=\frac{2}{\pi} \alpha \beta\left[\left(A I+\left(I_{0}+I^{\prime}\right)+2 j k I_{1}-\frac{1}{2} k^{2} I_{2}\right)\right] e^{j \omega t}
$$

Term by term comparison of Eqs. (41) and (42) should give an indication of the relative order of magnitude between the first and the second harmonics. For example, the ratio $\left(I_{0}+I^{\prime}\right) / I_{0}^{\prime}$ indicates the ratio of the first harmonic to the second harmonic at the limiting case of zero frequency. The ratios of all corresponding terms $I_{0}^{\prime} /\left(I_{0}+I^{\prime}\right), I^{\prime} / I, I_{1}^{\prime} / I_{1}$, and $I_{2}^{\prime} / I_{2}$ are plotted as functions of the flap-chord ratio in Fig. 6. Observe that the relative magnitude of the second harmonic is an increasing function of the flapchord ratio. It should also be noted that the influence of the unsteady terms ( $k$ and $k^{2}$ terms) on the second harmonic is greater than that of the quasisteady term. The amplitude and the phase angle of the first and second harmonics of the drag coefficient are computed for the three cases ( $e=0.25$, $0.30,0.40$ ) and the results are plotted in Fig. 7 as functions of the reduced frequency.

\section{Symmetrical Jet}

The importance of determining the free surface effect, or the solid boundary effect as the case may be, in the interpretation of experimental data is well recognized. The purpose of this section is to calculate the effect of free surfaces on force ano moment when the leading edge of the foil is situated on the centerline of the jet, i. e., $b_{1}=b_{2}=b$. For simplicity it will be further assumed that $b_{1}{ }^{\prime}=b_{2}{ }^{\prime}=b$ in the following analysis. This assumption will make the analysis inaccurate when $b$ is small. 
The mapping function for the summetrical case is reduced to

$$
\mathrm{z}=\frac{\mathrm{b}}{\pi} \ln \frac{\xi_{1}{ }^{2}}{\xi_{I}{ }^{2}-\zeta^{2}}
$$

where

$$
\xi_{1}=\frac{1}{i-\exp \left(-\frac{\pi}{b}\right)}
$$

It can also be shown that

$$
\xi_{0}^{2}=\xi_{1}^{2}\left[1-\exp \left(-\frac{\pi \lambda}{b}\right)\right]
$$

The main difficulty now lies in the evaluation of the frequency response function given by Eq. (13). An exact calculation of $J_{1}$ and $J_{2}$ would involve double integrations of singular and slowly converging functions. However, if we limit our concern to a relatively wide jet (large b), then it is possible to estimate the frequency response function by an asymptotic expansion.

Consider first the integral $J_{0}$ given by Eq. (14). The path of integration is on the line $-\infty<x<0$ or $0<\eta<\infty$. On this line, the mapping formula may be expanded, asymptotically, into the following form.

$$
-x \approx \frac{b \eta^{2}}{\pi \xi_{I}^{2}} \sum_{n=0}^{\infty} \frac{(-1)^{n}}{n+1}\left(\frac{\eta}{\xi_{I}}\right)^{2 n}
$$

The expansion is only asymptotic because Eq. (43) does not converge for $\eta>\xi_{I}$. If only the first term is retained, we have

$$
-\mathrm{x} \approx \frac{\mathrm{b}}{\pi \xi_{I}^{2}} \eta^{2}=\mathrm{B} \eta^{2}
$$

where $B$ varies from 0 to $I$ when $b$ changes from 0 to $\infty$. Substitution of Eq. (43a) into Eq. (14) clearly leads to 


$$
k J_{0} \approx B k \int_{-\infty}^{0}\left(\sqrt{\frac{r+1}{2}}-1\right) e^{-j B k \eta^{2}} d\left(-\eta^{2}\right)
$$

or in an abbreviated form

$$
k \cdot J_{0}(k, b) \approx k^{\prime} J_{0}(k, \infty)
$$

where $k^{\prime}=B k$.

Next, consider the inner integrals of $J_{1}$ and $J_{2}$. The path of the integrals is on the line $0<x<\lambda$ or $\xi_{0}<\tau<1$. In this case the first term of the asymptotic expansion is

$$
\mathrm{x} \approx \mathrm{B} \tau^{2}, \quad \xi_{0}<\tau<1
$$

Therefore, it can be readily shown that

$$
\int_{\xi_{0}}^{l} K(k, x-\lambda, b) \cdot M(\tau) d \tau \approx \int_{\sqrt{\lambda}}^{l} K\left(k^{\prime}, \tau^{2}-\lambda, \infty\right) M(\tau) d \tau
$$

where $M(\tau)$ is a function of $\tau$.

After substituting Eqs. (43a) and (45) into Eqs. (15) and (16), it follows that

$$
k J_{n}(k, b) \approx k^{\prime} J_{n}\left(k^{\prime}, \infty\right)
$$

where $\mathrm{n}=0,1,2$.

Finally, if Eq. (46) is substituted into Eq. (13) it results in

$$
\mathrm{A}(\mathrm{k}, \mathrm{b}) \approx \mathrm{A}\left(\mathrm{k}^{\prime}, \infty\right)
$$

Since the frequency response function has been computed for the infinite fluid case, Eq. (47) makes the estimation particularly simple for a finite symmetrical jet. The coefficient $B(b)$ which characterizes the free-surface effect is plotted in Fig. 8. All other remaining integrals are single integrals, 
some of which may be expressed in closed form, and others can be evaluated by means of an electronic computer without resort to the process of asymptotic representation.

The amplitude and the phase angle of the lift coefficient for the case $e=0.30$ were computed for various jetwidths and plotted in Figs. 9 and 10, respectively. The curves shown in these figures are remarkably close to parallel curves indicating that the free surface effect on the unsteady lift is almost independent of the reduced frequency. It should also be noted that when $k$ is set equal to zero the known quasi-steady solution is recovered from the unsteady solution

D. Zero Submergence

In this case, $b_{1}^{\prime}=0, b_{2} \rightarrow \infty$, and the mapping function is reduced to

$$
2=-\zeta
$$

It can also be shown that $\xi_{0}=-\lambda, \xi_{1}=0$, and $\xi_{2} \rightarrow \infty$.

The integral $J_{0}^{\prime}$ is reducible to Hankel's function. The other integral, $J_{1}$ ', can be evaluated by means of an electronic computer in much the same way as that for $J_{1}$ and $J_{2}$. The resulting frequency response function is tabulated in Table II. The frequency response function for the zero submergence case is plotted in Fig. 2 together with the infinite fluid case. The procedure used in the infinite fluid case is also applicable here for the calculation of lift, drag, and moment coefficients. For example, the oscillatory part of the lift coefficient is expressible by Eq. (35). Here, the integrals $I, I_{0}, I_{1}$, and $I_{2}$ are expressible in closed forms as follows:

$$
\begin{aligned}
& I=\frac{\pi^{2}}{2}, I_{0}=\pi\left[\frac{\pi}{2}-\tan ^{-1} \sqrt{\frac{\lambda}{1-\lambda}}+\sqrt{\lambda(1-\lambda)}\right] \\
& I_{1}=\pi\left[( \frac { 3 } { 4 } - \lambda ) \left(\frac{\pi}{2}-\tan ^{-1} \sqrt{\left.\frac{\lambda}{1-\lambda}\right)}+\left(\frac{3}{4}-\frac{\lambda}{2} \sqrt{\lambda(1-\lambda)}\right]\right.\right. \\
& I_{2}=\pi\left[\left(\frac{5}{8}-\frac{3}{4} \lambda+\lambda^{2}\right)\left(\frac{\pi}{2}-\tan ^{-1} \sqrt{\frac{\lambda}{1-\lambda}}\right)+\left(\frac{5}{8}-\frac{13}{12} \lambda+\frac{\lambda^{2}}{3}\right) \sqrt{\lambda(1-\lambda)}\right]
\end{aligned}
$$

The amplitude and the phase angle of the lift coefficient are computed for the case of $e=0.25,0.30$, and 0.40 and the results are shown in Fig. 11 . 


\section{EXPERIMENTAL EQUIPMENT AND PROCEDURE}

A. Free-Jet Water Tunnel

The experimental studies have been conducted in the two-dimensional test section of the free-jet water tunnel at the St. Anthony Falls Hydraulic Laboratory [10]. The tunnel is a free-falling, nonrecirculating type utilizing river water and having a vertical test section. The test section is transparent to promote visualization and photography. An overall view of the tunnel test section area is shown in Fig. 12, and the principal interior dimensions and some other features of the test section are illustrated in Fig. 13.

The-tunnel test section is designed to produce a rectangular jet 5 in. thick and of variable width and location. The thickness of the jet is maintained by two vertical walls while the two free surfaces are independently controlled by two sharp-edged gates. By moving a free surface close to the centerline of the test section while keeping the other free surface relatively far away, it is possible to simulate the flow under a free surface. Since the jet is bounded by two solid walls and two free surfaces, it simulates a gravity-free field except for the two boundary layers adjacent to the walls. The working velocity of the jet is between $20 \mathrm{fps}$ and $50 \mathrm{fps}$. Any pressure between vapor pressure and atmospheric pressure can be created at the test section. Velocity and pressure are controlled together by bleeding air into the testsection space at both sides of the jet, while velocity alone can also be controlled to some extent by a water inlet valve. A pressure equalization ring immediately downstream of the test section is used to balance the test section ambient pressure or ambient velocity; zero cavitation number is obtained through equalizing the cavity pressure and the ambient pressure.

B. Dynamometer and Test Bodies

Two identical dynamometer units, one for the front face and one for the rear face of the tunnel, are used. Each unit is built around a heavy brass cup which fits into $3 . ?$ in. diameter holes in opposite faces of the test section. The joint is sealed with an "O" ring. Figure 14 shows photographically some details of a dynamometer unit.

Each unit is of the displacement type, small displacements being measured by strain gages cemented to tension fibers. There are two pairs each 
of lift fibers and a pair of drag fibers so arranged as to produce minimum mutual interferences. The voltage output from the strain gages are amplified by a carrier amplifier and recorded on paper or tape depending on the purpose. A more detailed description of the dynamometer is given in Reference [12].

Flat-plate hydrofoils of $3 \mathrm{in}$, and $2 \mathrm{in}$. chord and $5 \mathrm{in}$. span were used in the experiment. Each foil is fitted with a trailing solid flap hinge supported at the upstream edge and spring supported at the trailing edge. Pertinent dimensions of the test bodies are shown in Fig. 15. The flap oscillation is accomplished by varying the oil pressure inside a bellows attached to the flap and the foil. This bellows is connected to another bellows located outside of the water tunnel through a plastic pipe. The outside bellows is driven by a variable speed electric motor. A photograph of the 3 in. foil with its driving mechanism attached is shown in Fig. 16. This photograph shows that the oil pipe enters the bellows through the trailing edge of the foil along the chord line. For the purpose of checking the undesirable effect of the external force on the foil through the oil pipe, the oil pipe is made to enter the $2 \mathrm{in}$. foil from the side along the spanwise direction.

\section{Dynamic Properties of the System}

Since it is desired to measure the true hydrodynamic force on a stationary foil due to an oscillating flap covering a wide range of reduced frequency, the dynamic properties of the system have to be evaluated. The response of the system in air to a step load change was first examined. The test was carried out in the tunnel test section with all the test components in the operating condition. A step load change was applied to the foil by cutting a string which exerted a constant force on the foil prior to the cutoff. The first record in Fig. 17 shows the system's response to a step drag force applied on the $2 \mathrm{in}$. foil. It is readily seen that the resulting motion is along the longitudinal direction only. The natural frequency and the damping factor of such a motion were approximately $220 \mathrm{cps}$ and 0.04 respectively. It can therefore be concluded that the system is adequate to measure the amplitude as well as the phase angle of the drag oscillation within the range of frequency used in the subsequent experiment; the maximum frequency tested was about $40 \mathrm{cps}$. Much the same result was also obtained for the 3 in. foil. 
In Fig. I7(b) a similar record due to a step lift application is shown. Here, although a pure lift force was applied, the resulting motion was not solely along the lift direction; both drag and moment records registered vibration. It was difficult to obtain the damping factor from this record. It was then decided to carry out a harmonic calibration. A spring of known elastic property was attached to the foil and it was driven at a constant amplitude. The dynamic calibration was carried out in this manner for different frequencies up to $38 \mathrm{cps}$ and the result indicated no measurable frequency effect.

A test similar to that described above was also carried out at an operating condition when the hydrofoil was in a planing condition (unsymmetrical jet) so that the jet could not interfere with the driving rod. This test also indicated no measurable frequency effect up to the maximum frequency tested. Based on the results of the dynamic tests, it was thought safe to use the dead weight calibration for the subsequent data analysis.

The next question to be answered was the magnitude of the external force acting on the foil through the oil and the oil pipe. For the purpose of estimating the extemal force the flap was oscillated in air at different frequencies and the resulting lift, drag, and moment records were analyzed. The amplitudes per unit flap angle deflection of lift $\left(L^{\prime} / \beta\right), \operatorname{drag}\left(D^{\prime} / \beta\right)$, and moment $\left(M^{\prime} / \beta\right)$ for the 3 in. foil are shown in Fig. 18 as functions of frequency. Here $L^{\prime}, D^{\prime}$, and $M^{\prime}$ are, respectively, the amplitude of lift, drag, and moment oscillations.

There was a constant, 180 degrees, phase difference between the flap angle and the system response for all frequencies tested.

Similar tests conducted for the 2 in. foil indicated no appreciable response to the flap oscillation in air. It appears, therefore, that the oil pipe does exert some oscillatory force on the foil along the axis of the pipe. Since the oil pipe was parallel to the span for the 2 in. foil, it did not produce lift, drag, and moment. The external force was, of course, taken into account in a manner described in the next section.

\section{Experimental Procedure}

The first concern prior to the experiments was whether data can be successfully obtained for a reasonably high reduced frequency range. For this 
reason the hydrofoil with the larger chord ( 3 in.) was first constructed and extensively tested. The flap-chord ratio was measured to be approximately 0.29. The angle of attack was set at $16^{\circ}$ which resulted in a clear separation at the leading edge. Good quality flap angle oscillation, which is almost free from any higher frequency components, was obtained for primary frequencies as high as $40 \mathrm{cps}$ at $3^{\circ}$ amplitude. This maximum frequency at the minimum water velocity corresponds to a reduced frequency of 4.0 , which is sufficiently high for most practical purposes. For the first few muns, no attempt was made to seal off the gap around the flap hinge and there was visible leakage through the gap. Later the gap was sealed off by rubber cement and the data thus obtained were compared with the data with leakage. No significant difference was found as far as the unsteady part of the force and moment are concerned.

Typical oscillographic records of flap angle, lift, drag, and moment are shown in Fig. 19. It should be noted that the amplitude of the high frequency noise increases with the frequency of the flap oscillation. The noise level became equivalent to the magnitude of the oscillatory force being measured at the flap frequency of about $50 \mathrm{cps}$. It should also be noted that the average lift of the best bellows available on the market becomes very short when the flap frequency exceeds $40 \mathrm{cps.} \mathrm{Thus,} \mathrm{the} \mathrm{maximum} \mathrm{flap} \mathrm{fre-}$ quency was limited to $40 \mathrm{cps}$ in the reported experiments.

Amplitude and phase angle of the oscillating forces and moment were read from oscillographic records such as those shown in Fig. 19. The raw data thus obtained were then corrected for the external. force due to the oil pipe. Denoting the uncorrected values by double prime, the corrected values are given by the following formulas:

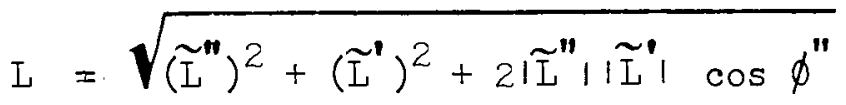

$$
\begin{aligned}
& \phi=\sin ^{-1} \frac{1 L^{\prime \prime} \sin \phi^{\prime \prime}}{\sqrt{\left(\tilde{L}^{\prime \prime}\right)^{2}+\left(\widetilde{L}^{\prime}\right)^{2}+2 \tilde{I}\|\tilde{L}\| \cos \phi^{\prime \prime}}}
\end{aligned}
$$

The experiment was carried out in free-jets of various sizes and relative positions. Motion pictures of the cavity walls were also taken for the purpose of studying the surface waves. 
To obtain data at larger submergence conditions and al so to check the data, expecially with reference to the external force, a 2 in. foil having approximately the same flap-chord ratio but a different oil pipe connection was tested briefly.

As was shown by the theory, the second harmonic of the drag oscillation may not be negligible when $\beta$ is not very small compared with $\alpha$. To clarify this problemitwas necessary to take data for a relatively small angle of attack and large flap oscillation. The angle of attack was reduced to $14^{\circ}$, the minimum angle at which the cavity surface clears the foil surface, and the flap was oscillated at $7^{\circ}$ amplitude. The data were first stored in a tape record and then fed into a frequency analyzer.

In general it is very difficult to obtain accurate and reliable experimental data of the kind reported herein. There are many instrumentation problems as well as data processing problems. Although utmost carewas given to instrumentation and method of experiment, there still remain some uncertainties as to whether the data represent the ideal condition which it was attempted to establish. Among other difficulties, for example, the line separating the moving part and the stationary part near the flap hinge was a zig-zag line causing an unknown amount of local disturbances. The noise, especially the part corresponding to the natural frequency of the foil-dynamometer system (approximately $200 \mathrm{cps}$ ), was believed to be another major source of error especially at high frequencies. It is quite possible that for some data the error could be as high as 20 per cent of the true value. On the low frequency range a slow drift of the steady value as can be observed from Fig. 19 causes more serious error. This slow drift of the steady value is due to the basically unsteady characteristic of the supposedly steady ambient flow and the cavity flow. For the reasons stated above scatter of data in the whole frequency range may be expected. The accuracy of the moment data is believed to be considerably lower than that of the lift data. 


\section{EXPERIMENTAI RESUITS AND COMPARISON WITH THEORY}

\section{A. Surface Waves}

Some photographs of cavity surface waves at various reduced frequencies and constant amplitude are shown in Figs. 20 and 21 . While there are surface waves of significant amplitude on the pressure side of the cavity surface, the waves on the suction side of the cavity surfaces are hardly noticeable. The waves appear to grow and become sharp crested as they travel downstream. Although the current photographs do not permit observation far downstream, there is reason to believe that the wave may eventually break far downstream. The phase velocity (in this case, equal to the group velocity) was measured from motion pictures and was found to be identical to the average water speed $U$ within the accuracy of the measurement for all flow conditions and frequencies.

The agreement between the measured wave speed and the average water speed should be regarded as an important confirmation of the linear theory which concludes that the trailing vortices, or for that matter all small disturbances, move with an average speed U. The fourth boundary condition, Eq. (9), is a mathematical expression of this principle.

B. Oscillating Force and Moment in Symmetrical Jet

Amplitudes of the oscillating lift and drag coefficients per degree slap angle change are plotted as functions of reduced frequency in Fig. 22. The corresponding phase angle change of the lift coefficient is plotted in Fig. 23. There was practically no measurable phase difference between lift and drag. Also included in Figs. 22 and 23 are predicted curves based on a first order perturbation theory as described in the previous section. It should be noted that the theoretical curves are for the $e=0.30$ case but the experimental data are for $e=0.29$ and, hence, small discrepancies are to be expected. In the author's opinion the agreement between the data and the predicted values is good for all jet widths shown in these figures considering the inherent uncertainties and approximations. It may be of practical importance to note that the amplitudes of lift and drag are almost independent of the reduced frequency when the reduced frequency is less than two. 
The amplitude and phase angle of moment coefficient referred to mid chord, nose up as positive, are plotted in Figs. 24 and 25 respectively. For the purpose of comparison, two sets of theoretical curves for the infinite fluid case were selected from Fig. 5 and plotted in Figs. 24 and 25. It seems that the agreement is better between the data and the theoretical curves for the case when the axis of rotation is taken at 0.45 chord measured downstream from the leading edge.

C. Oscillating Force and Moment in Non-Symmetrical Jet

Various combinations of $b_{1}$ and $b_{2}$ were used in this phase of the experiment. The first set of data in Fig. 26 shows the amplitude of lift, drag, and moment coefficients for a fixed $b_{2}$ ( 3 chords) and $b_{1}$ equal to 1 , $1 / 2, \quad 0$, and $-1 / 3$. It should be noted that the spray thickness is always larger than $b_{1}$, and even when $b_{1}=0$ there is still a substantial amount of spray on the suction side. In order to completely eliminate the suctionside spray $b_{1}$ has to be considerably less than $-1 / 3$ at $16^{\circ}$ angle of attack. When $b_{1}$ is reduced below $-1 / 3$, however, the end effect becomes intolerable; the flow near the ends of the span where the flow is retarded due to the presence of the tunnel walls may detach from the foil and the fllow becomes unstable. It can be observed that the free-surface effect is insignificant until $b_{1}$ becomes less than 1/2. There seemed to be a rapid increase in amplitude when $b_{1}$ was reduced below zero.

Since the linear theory does not take into account the free-surface deflection and the variation of the spray thickness with $b_{1}$ it is difficult to make a direct comparison between the theoretical prediction and the experimental data. The solid line shown in Fig. 26(d) is the theoretical lift coefficient for the case when $b_{1}^{\prime}=0$ and $b_{2}^{\prime}=\infty$. The data points appear to fall near the predicted curve. Similar data and a theoretical curve for the phase angles are shown in Fig. 27. Here the discrepancy between theory and data is greater, especially in the low frequency range. In an attempt to study the effect of the pressure-side free surface, data were also taken at constant $b_{1}$ and variable $b_{2}$ and are shown in Fig. 28. No definite conclusion could be drawn from the limited amount of data shown in this figure. 


\section{Second Harmonic of Oscillating Drag}

An attempt was also made to verify the theoretical prediction concerning the second harmonic of oscillating drag. This would require the foil to be operated at small $\alpha$ and the flap to be oscillated at large $\beta$. Unfortunately, the angle of attack was limited by the minimum value required for the suction-side cavity surface to clear the foil, and the flap oscillation was limited by the capacity of the bellows. It was very difficult to generate a pure harmonic flap oscillation when the amplitude was increased. For this reason this experiment was not very successful although a considerable amount of second harmonic component was detected from the drag records.

\section{CONCLUSIONS}

The results of experimental and theoretical investigations on a supercavitating flat-plate with an oscillating flap at zero cavitation number are presented. Unsteady flow data for a sufficiently wide range of reduced frequency have been obtained to permit a comparison with an analytical result, thus facilitating the understanding of a complicated flow mechanism. In general, reasonable agreement between the experimental data and the analytical result has been obtained.

Following is a list of conclusions which may be drawn from the present study.

1. It appears that the first order perturbation theory correctly predicts the general trend of unsteady lift and drag on a supercavitating flat plate due to an oscillating flap in aravitation-free field when the cavitation number is zero. In spite of the severely deflected free surfaces the linear theory seems to be applicable, in the case of a symmetrical jet, for jet width as small e.s one.

2. Waves are created on the cavity surfaces by an oscillating flap. These waves move downstream with the same speed as the average fluid speed. This is an important and direct confirmation of an assumption often used in linear unsteady flow theories. 
3. The change in amplitude of force and moment is not significant for reduced frequencies (based on full chord) between 0 and 2 whereas phase angle may change considerably within the same frequency range, especially in the case of a non-symmetrical jet and small spray thickness.

4. In symmetrical jets the free-surface effect becomes significant when the half jet width becomes less than 5 chords. The free-surface effect seems to be almost independent of the reduced frequency, at least up to $\mathrm{k}=4$.

5. In the case of non-symmetrical jets with large $b_{2}$, the free-surface effect may become significant only when the submergence is less than one chord. For such a small submergence, the spray thickness is considerably larger than the submergence. Under this circumstance the submergence, $b_{1}$ should be replaced by the spray thickness $b_{1}$ in theoretical computation.

6. The drag due to an oscillating flap is composed of two harmonics. The magnitude of the second harmonic is not necessarily negligible compared with the first harmonic when the amplitude of the flap oscillation is not very small compared with the angle of attack.

7. The characteristics of the oscillatory moment due to an oscillating flap may appear considerably different depending on the location of the moment axis. Moment iș also the quantity most difficult to measure accurately. For these reasons, more experimental work involving different flap-chord ratios and moment axes is needed to obtain more conclusive results concerning oscillatory moment. 
[1] Song, C. S., Measurements of the Unsteady Force on Cavitating Hydrofoils in a Free Jet, University of Minnesota, St. Anthony Falls Hydraulic Laboratory, Technical Paper No. 49, Series B, June 1964,55 pages.

[2] Silberman, E., and Song, C. S., "Instability of Ventilated Cavities," Journal of Ship Research, Vol. 5, No. 1, June 1961.

[3] Hsu, C. C., Fully Cavitating Hydrofoils in Non-steady Motion under a Free Surface, Hydronautics, Report 119-5, August 1963.

[4] Parkin, B. R., Fully Cavitating Hydrofoils in Non-Steady Motion, California Institute of Technology, Pasadena, California, Engineering Division Report No. 85-2, July 1957.

[5] Wu, T. Y., "Unsteady Supercavitating Flows," Second Symposium on Naval Hydrodynamics, Washington, D. C., August 1958, pages 296-315.

[6] Song, C. S., "Two-Dimensional Supercavitating Plate Oscillating under a Free-Surface," Journal of Ship Research, Vol. 9, No. 1, June 1965.

[7] Fung, Y. C., An Introduction to the Theory of Aeroelasticity, John Wiley and Sons, Inc., New York, 1955.

[8] Cheng, H. K., and Rott, N., "Generalization of the Inversion Formula of Thin Airfoil Theory," Journal of Rational Mechanics and Analysis, Vol. 3, No. 3, Indiana University, Bloomington, Indiana 1954 .

[9] Tulin, M. P. and Burkhart, M. P., Linearized Theory for Flows About Lifting Foils at Zero Cavitation Number, David Taylor Model Basin, Report C-638, February 1955.

[10] Auslaender, J., "Supercavitating Foils with Flaps Beneath a Free Surface," Journal of Basic Engineering, Vol. 86, Series D, No. 2, June 1964 .

[11] Silberman, E. and Ripken, J. F., The St. Anthony Falls Hydraulic Laboratory Free-Jet Water Tunnel, University of Minnesota, St. Anthony Falls Hydraulic Laboratory, Technical Paper No. 24, Series B, August 1959, 45 pages.

[12] Silberman, E., Experiments on a Jet Flap in Supercavitating Flow, University of Minnesota, St. Anthony Falls Hydraulic Laboratory, Technical Paper No. 46, Series B, January 1964, 71 pages. 


\section{TABLE I}

Frequency Response Function, $A(k, e)$, in Infinite Fluid

\begin{tabular}{|c|c|c|c|c|c|c|c|c|c|c|c|}
\hline Reduced & equency, $\mathrm{k}$ & 0.1 & 0.2 & 0.4 & 0.6 & 0.8 & 1.0 & 1.5 & 2.0 & 3.0 & 4.0 \\
\hline$e=0.25$ & $\begin{array}{l}-100 \times \operatorname{ReA} \\
-100 \times \operatorname{ImA}\end{array}$ & $\begin{array}{l}1.4557 \\
2.7961\end{array}$ & $\begin{array}{l}2.6171 \\
4.2688\end{array}$ & & & & & $\begin{array}{r}7.7660 \\
12.5000\end{array}$ & & $\begin{array}{r}6.7893 \\
20.4350\end{array}$ & $\begin{array}{l}963 \\
980\end{array}$ \\
\hline$e=0.30$ & $\begin{array}{lll}-100 \times & \operatorname{ReA} \\
-100 \times & \operatorname{ImA}\end{array}$ & $\begin{array}{l}11 \\
09\end{array}$ & $\begin{array}{l}2.7699 \\
4.7119\end{array}$ & & $\begin{array}{l}5.7365 \\
8.6662\end{array}$ & $\begin{array}{r}6.5350 \\
10.1580\end{array}$ & $\begin{array}{r}7.0531 \\
11.5580\end{array}$ & $\begin{array}{r}7.5186 \\
14.9500\end{array}$ & $\begin{array}{r}7 . \\
18 .\end{array}$ & $\begin{array}{r}4 . \\
25 .\end{array}$ & $\begin{array}{l}8858 \\
330\end{array}$ \\
\hline$e=0.40$ & $\begin{array}{l}-100 \cdot x \operatorname{ReA} \\
-100 \times \operatorname{ImA}\end{array}$ & $\begin{array}{l}1.6873 \\
3.5248\end{array}$ & $\begin{array}{l}2.9673 \\
5.5141\end{array}$ & $\begin{array}{l}4.7338 \\
8.3924\end{array}$ & $\begin{array}{r}5.7974 \\
10.7290\end{array}$ & $\begin{array}{r}6.3897 \\
12.8720\end{array}$ & $\begin{array}{r}6.6379 \\
14.9460\end{array}$ & $\begin{array}{r}6.2012 \\
20.0960\end{array}$ & $\begin{array}{r}4.6824 \\
25.3400\end{array}$ & $\begin{array}{r}-0.7059 \\
36.1600\end{array}$ & $\begin{array}{l}-8.7003 \\
47.2760\end{array}$ \\
\hline
\end{tabular}

\section{TABLE II}

Frequency Response Function, $\mathrm{A}(\mathrm{k}, \mathrm{e})$, When $\mathrm{b}_{1}{ }^{\prime}=0, \mathrm{~b}_{2}^{\prime}=\infty$

\begin{tabular}{|c|c|c|c|c|c|c|c|c|c|c|c|}
\hline Reduced $F$ & requency, $k$ & 0.1 & 0.2 & 0.4 & 0.6 & 0.8 & 1.0 & .1 .5 & 2.0 & 3.0 & 4.0 \\
\hline$e=0.25$ & $\begin{array}{l}-10 x \operatorname{ReA} \\
-10 \times \operatorname{ImA}\end{array}$ & $\begin{array}{l}0.54009 \\
0.85949\end{array}$ & $\begin{array}{l}0.98579 \\
1.1930\end{array}$ & $\begin{array}{l}1.5724 \\
1.4793\end{array}$ & $\begin{array}{l}1.9097 \\
1.6268\end{array}$ & $\begin{array}{l}2.1128 \\
1.7509\end{array}$ & $\begin{array}{l}2.2387 \\
1.8784\end{array}$ & $\begin{array}{l}2.3753 \\
2.2398\end{array}$ & $\begin{array}{l}2.3812 \\
2.6529\end{array}$ & $\begin{array}{l}2.2023 \\
3.5684\end{array}$ & $\begin{array}{l}1.8625 \\
4.5452\end{array}$ \\
\hline$e=0.30$ & $\begin{array}{l}-10 \times \operatorname{ReA} \\
-10 \times \operatorname{ImA}\end{array}$ & $\begin{array}{l}0.58271 \\
0.94755\end{array}$ & $\begin{array}{l}1.0606 \\
1.3281\end{array}$ & $\begin{array}{l}1.6843 \\
1.6818\end{array}$ & $\begin{array}{l}2.0375 \\
1.8888\end{array}$ & $\begin{array}{l}2.2488 \\
2.0722\end{array}$ & $\begin{array}{l}2.3673 \\
2.2598\end{array}$ & $\begin{array}{l}2.4747 \\
2.7762\end{array}$ & $\begin{array}{l}2.4296 \\
3.3487\end{array}$ & $\begin{array}{l}2.0960 \\
4.5900\end{array}$ & $\begin{array}{l}1.5362 \\
5.8967\end{array}$ \\
\hline$e=0.40$ & $\begin{array}{l}-10 \times \operatorname{ReA} \\
-10 \times \operatorname{Im} A\end{array}$ & $\begin{array}{l}0.65178 \\
1.10800\end{array}$ & $\begin{array}{l}1.1789 \\
1.5822\end{array}$ & $\begin{array}{l}1.8535 \\
2.0840\end{array}$ & $\begin{array}{l}2.2201 \\
2.4285\end{array}$ & $\begin{array}{l}2.4193 \\
2.7498\end{array}$ & $\begin{array}{l}2.5192 \\
3.0776\end{array}$ & $\begin{array}{l}2.5238 \\
3.9528\end{array}$ & $\begin{array}{l}2.3223 \\
4.8919\end{array}$ & $\begin{array}{l}1.5322 \\
6.8768\end{array}$ & $\begin{array}{l}0.33077 \\
8.9334\end{array}$ \\
\hline
\end{tabular}


F $\underline{I} \underline{G} \underline{\mathrm{U}} \underline{\mathrm{E}} \mathrm{S}$

(I through 28) 


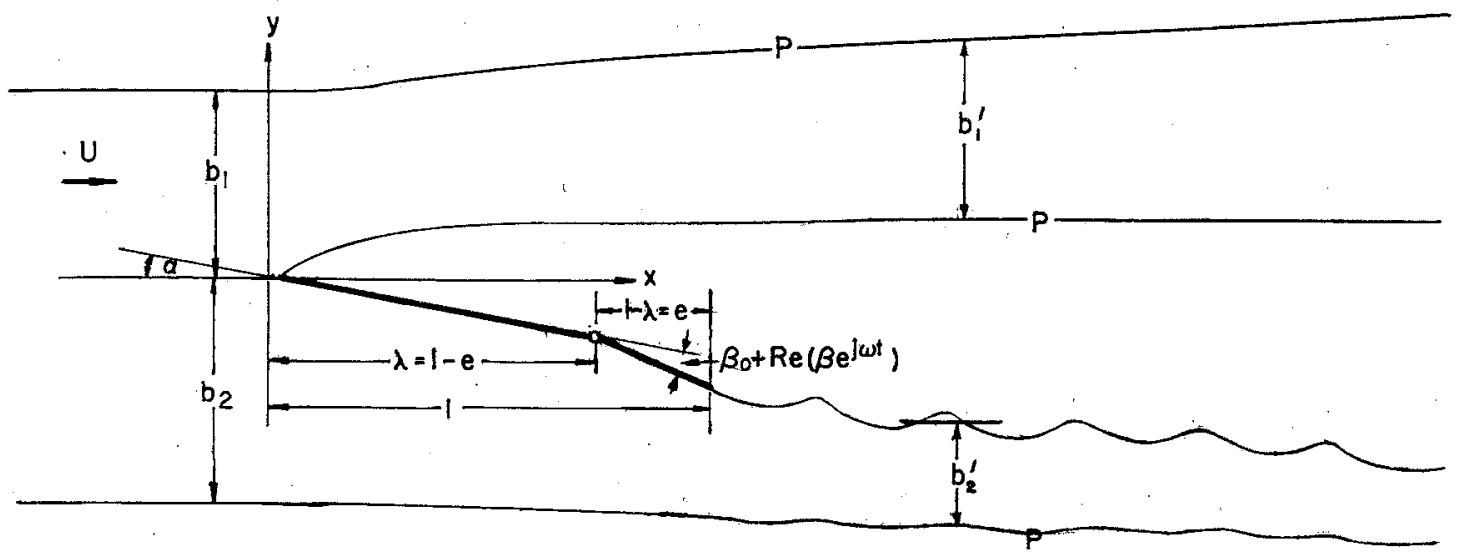

(a) Z-plane

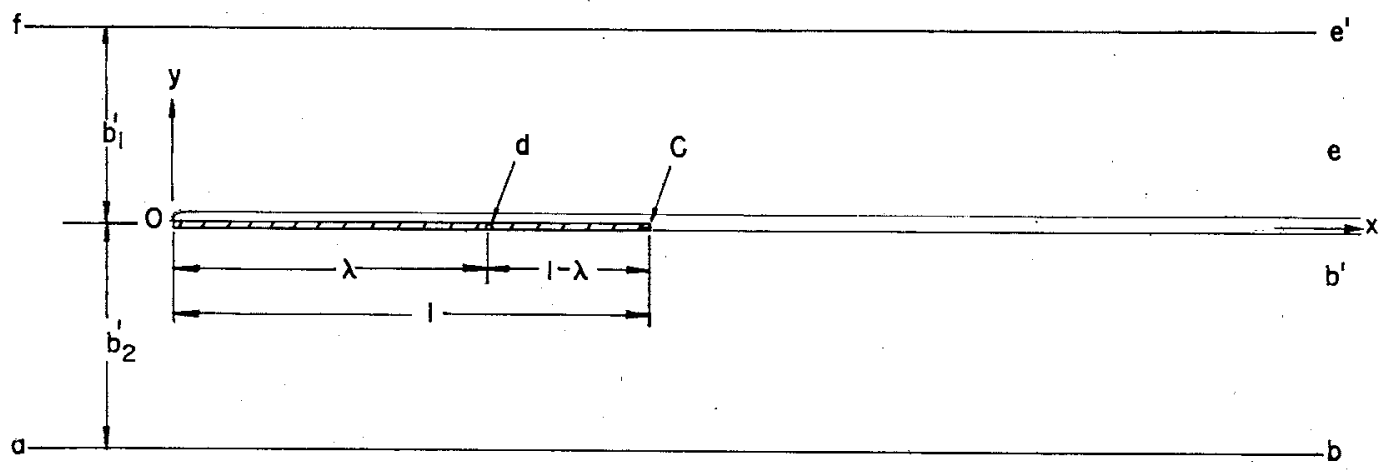

(b) Lineorized Z-plane

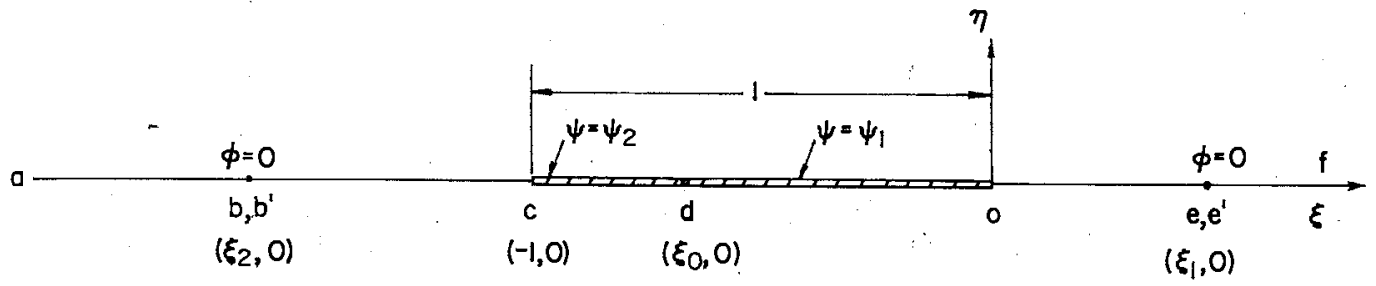

(c) 5-plane

Fig. 1 - Flow Diagram and the Mapping Planes 


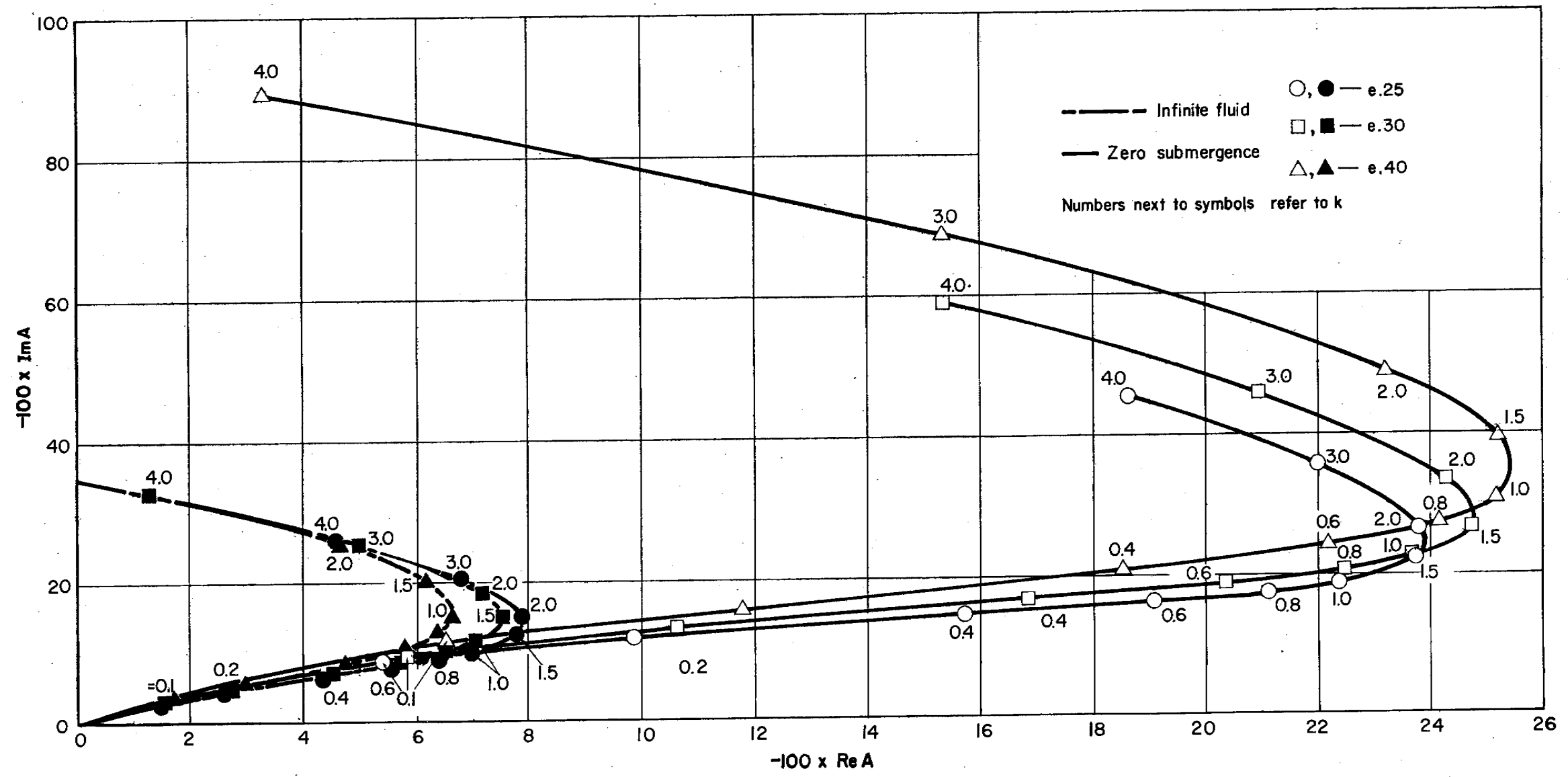

Fig. 2 - Frequency Response Function 


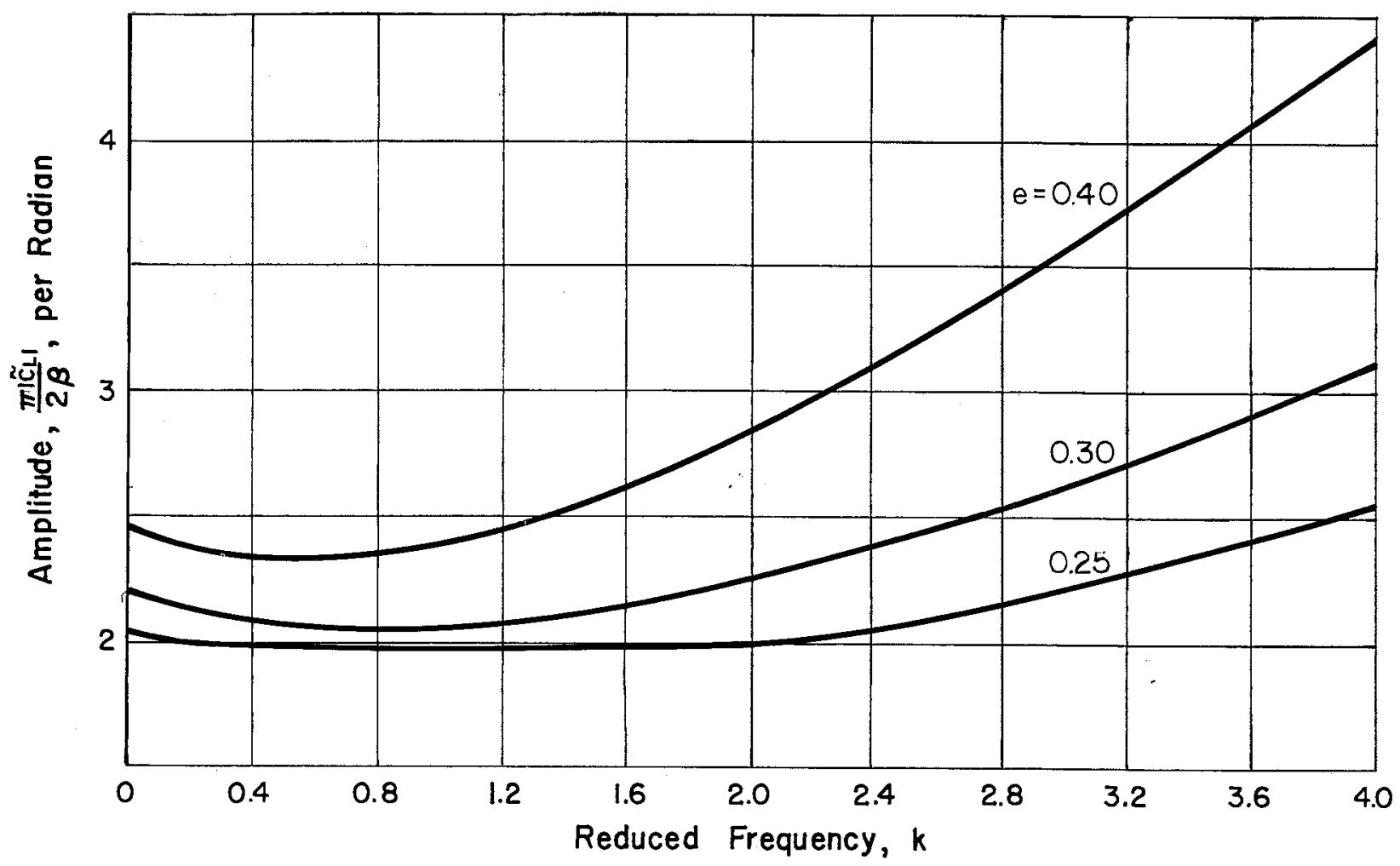

(a) Amplitude

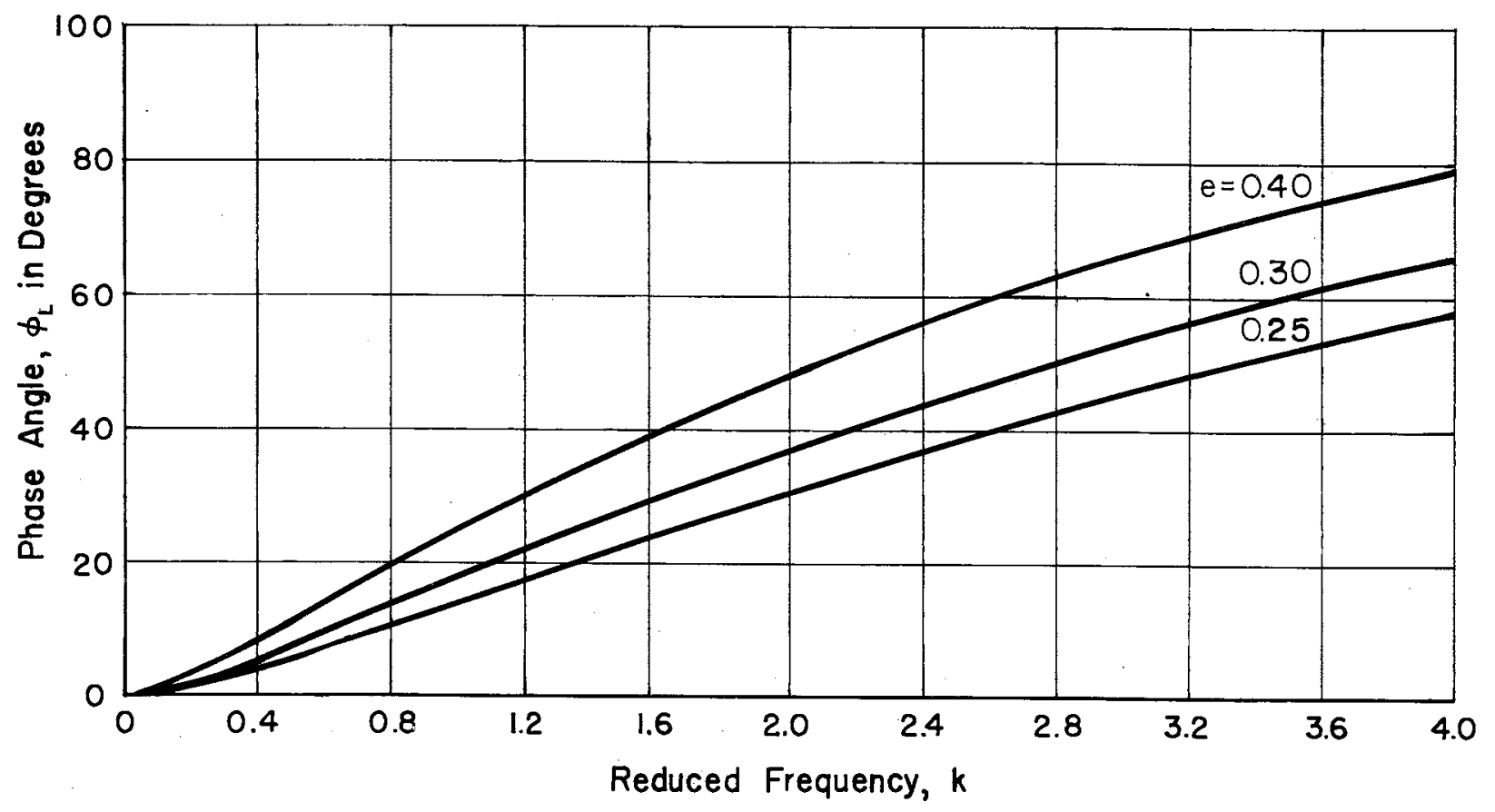

(b) Phase Angle

Fig. 3 - Oscillatory Lift Coefficient in Infinite Fluid 


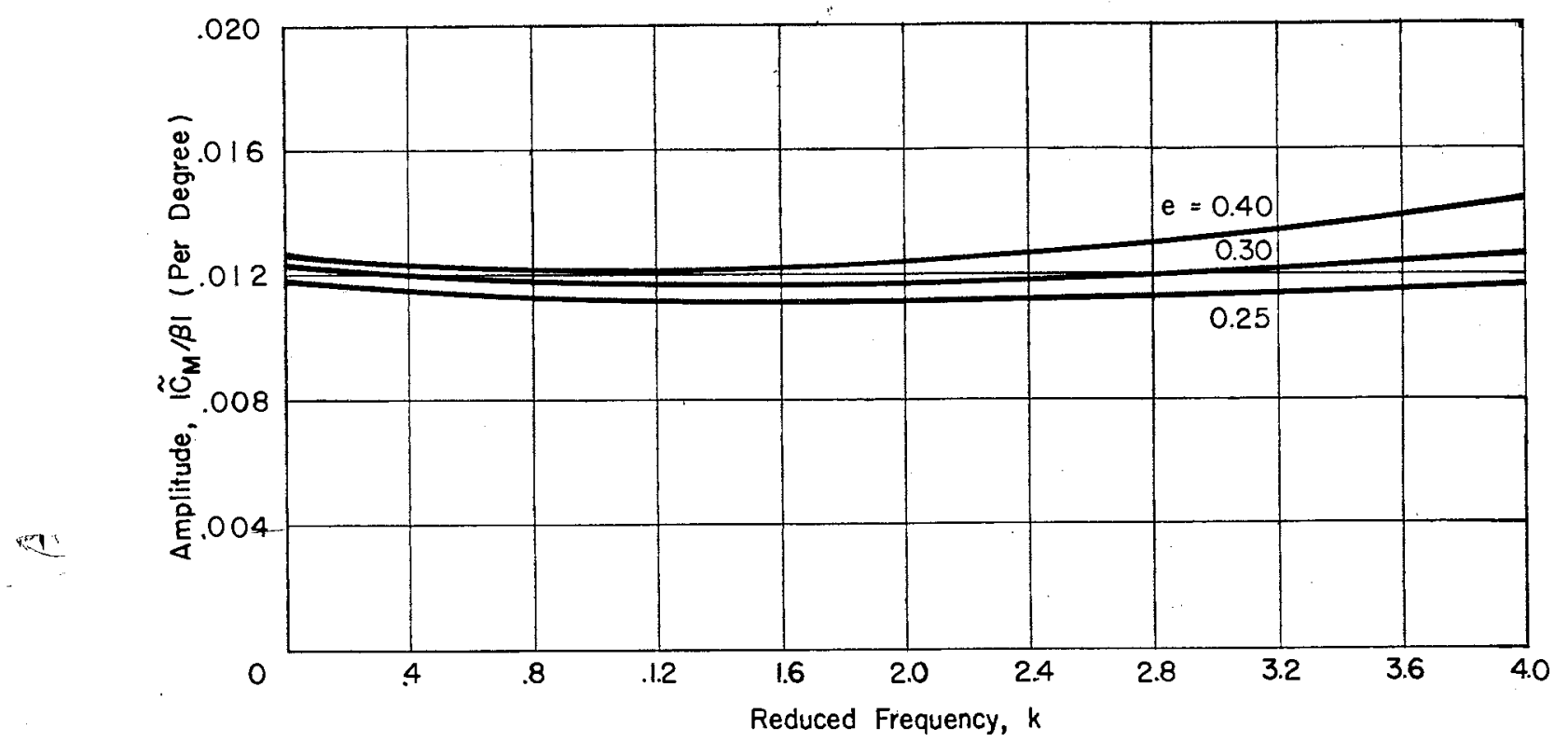

(a) Amplitude of Moment Coefficient Oscillation

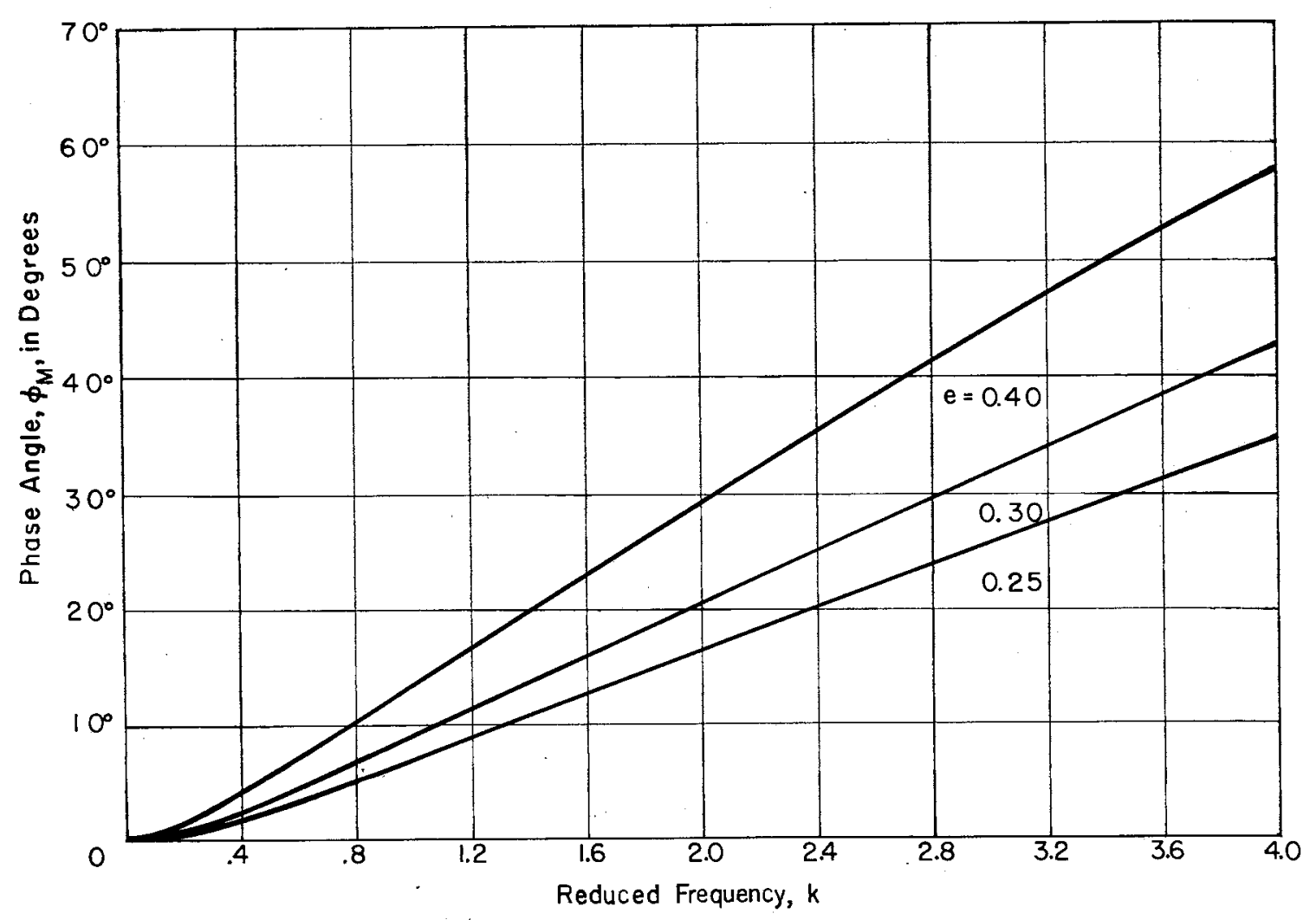

(b) Phase Angle of Moment Coefficient Oscillation

Fig. 4 - Oscillatory Moment Coefficient About Leading Edge in Infinite Fluid 


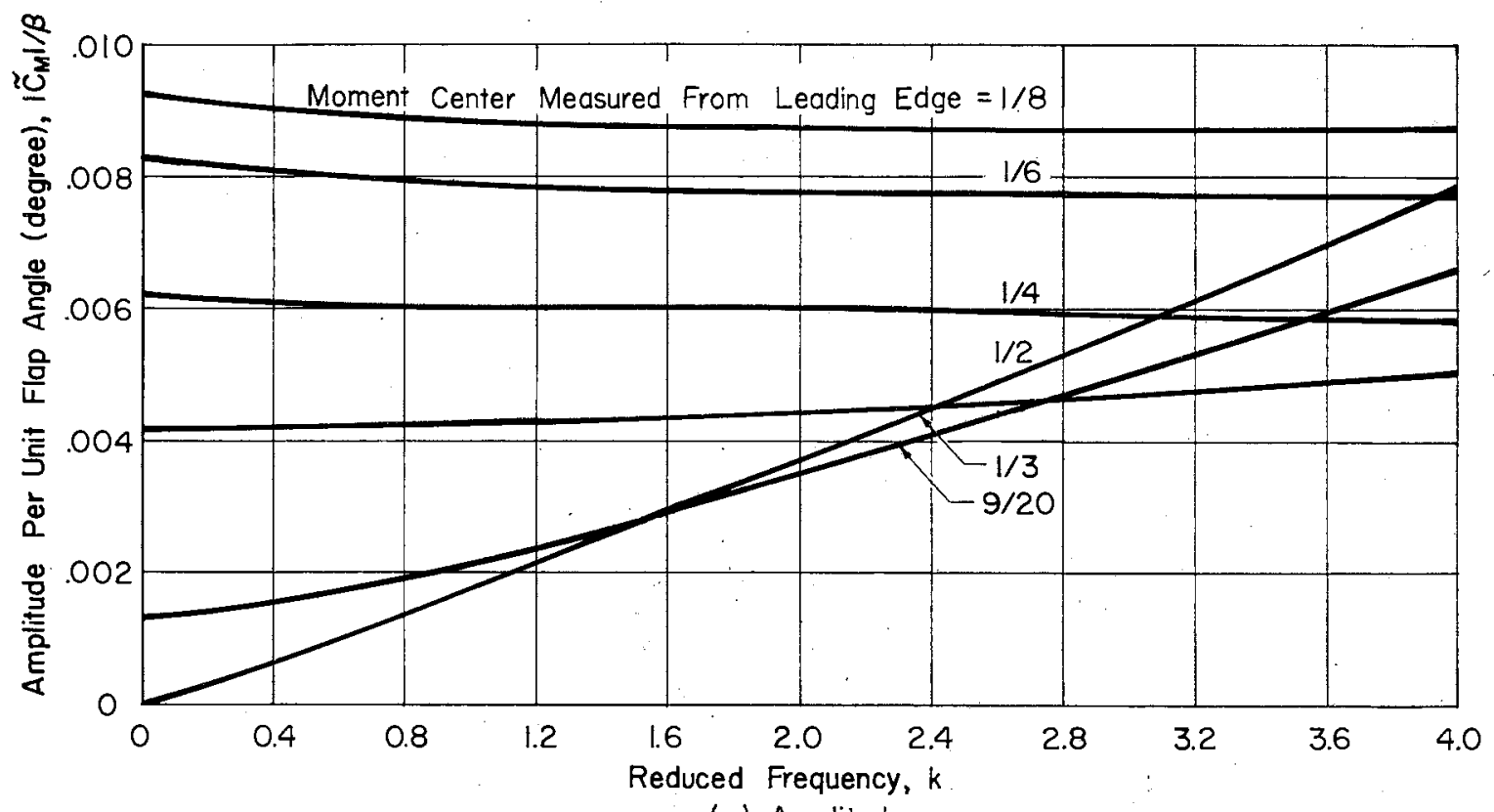

(a) Amplitude

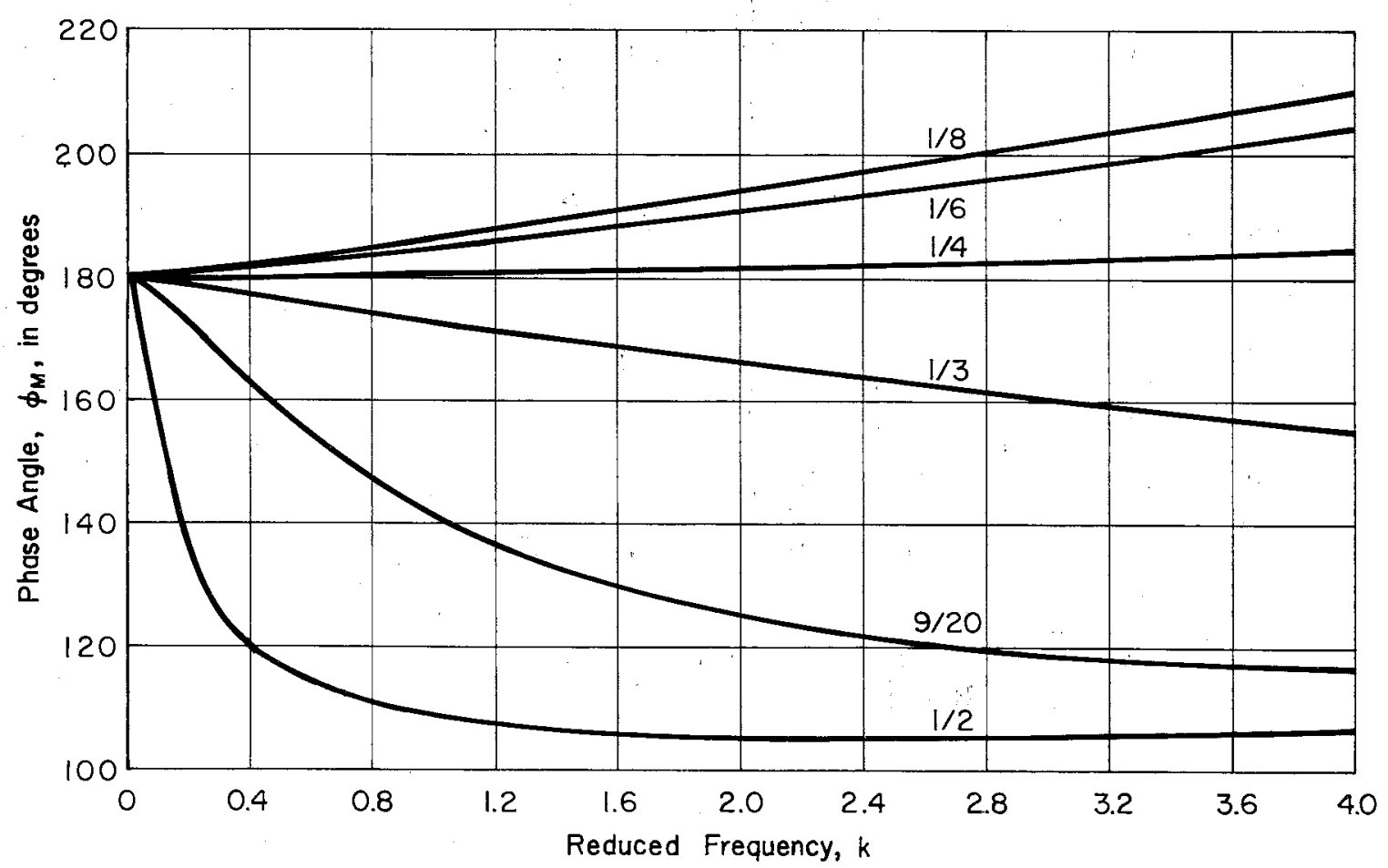

(a) Phase Angle

Fig. 5 - Effect of the Moment Center on the Oscillatory Moment Coefficient 


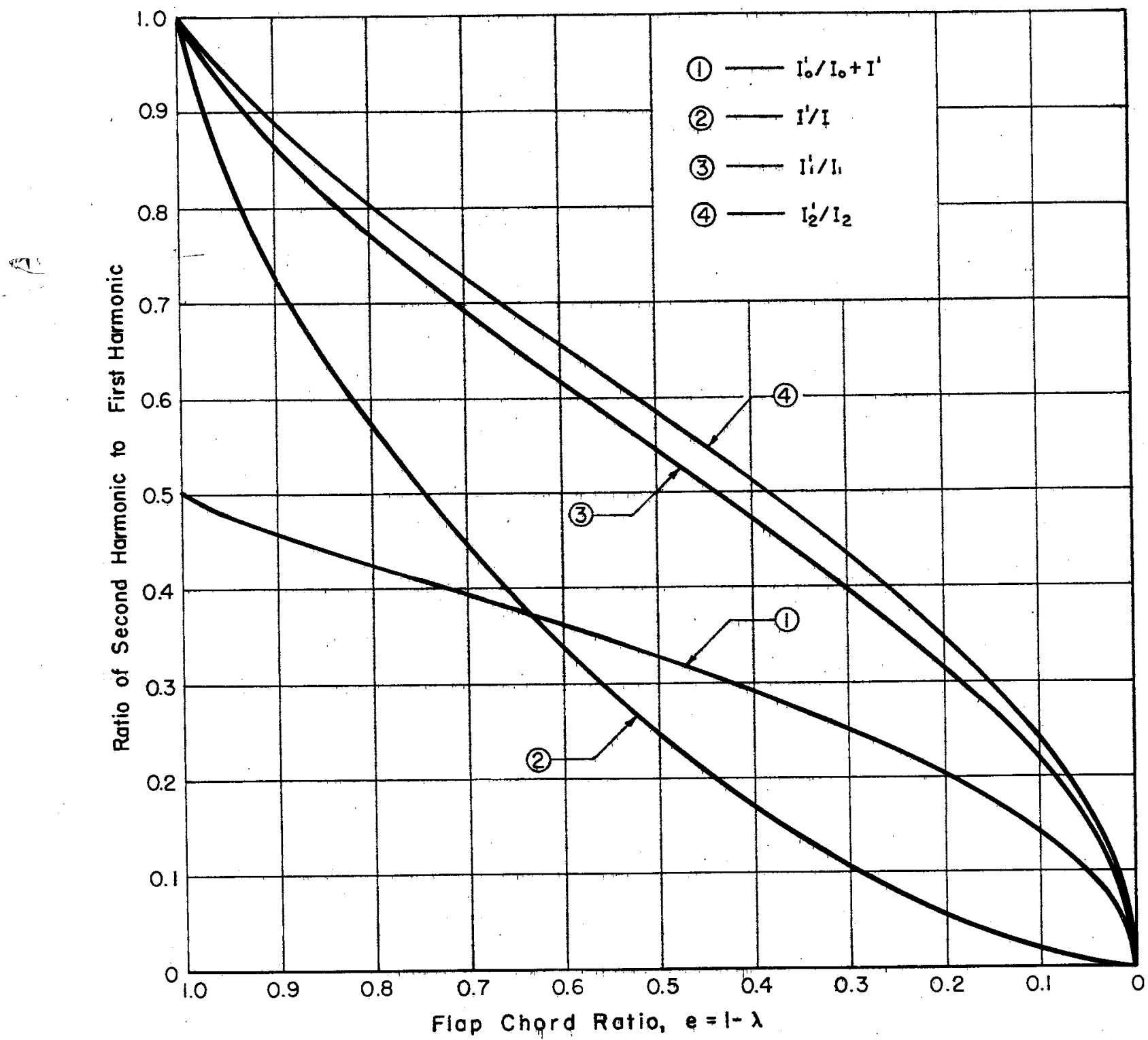

Fig. 6 - Term by Term Comparison of First and Second Harmonics of Drag Coefficient 


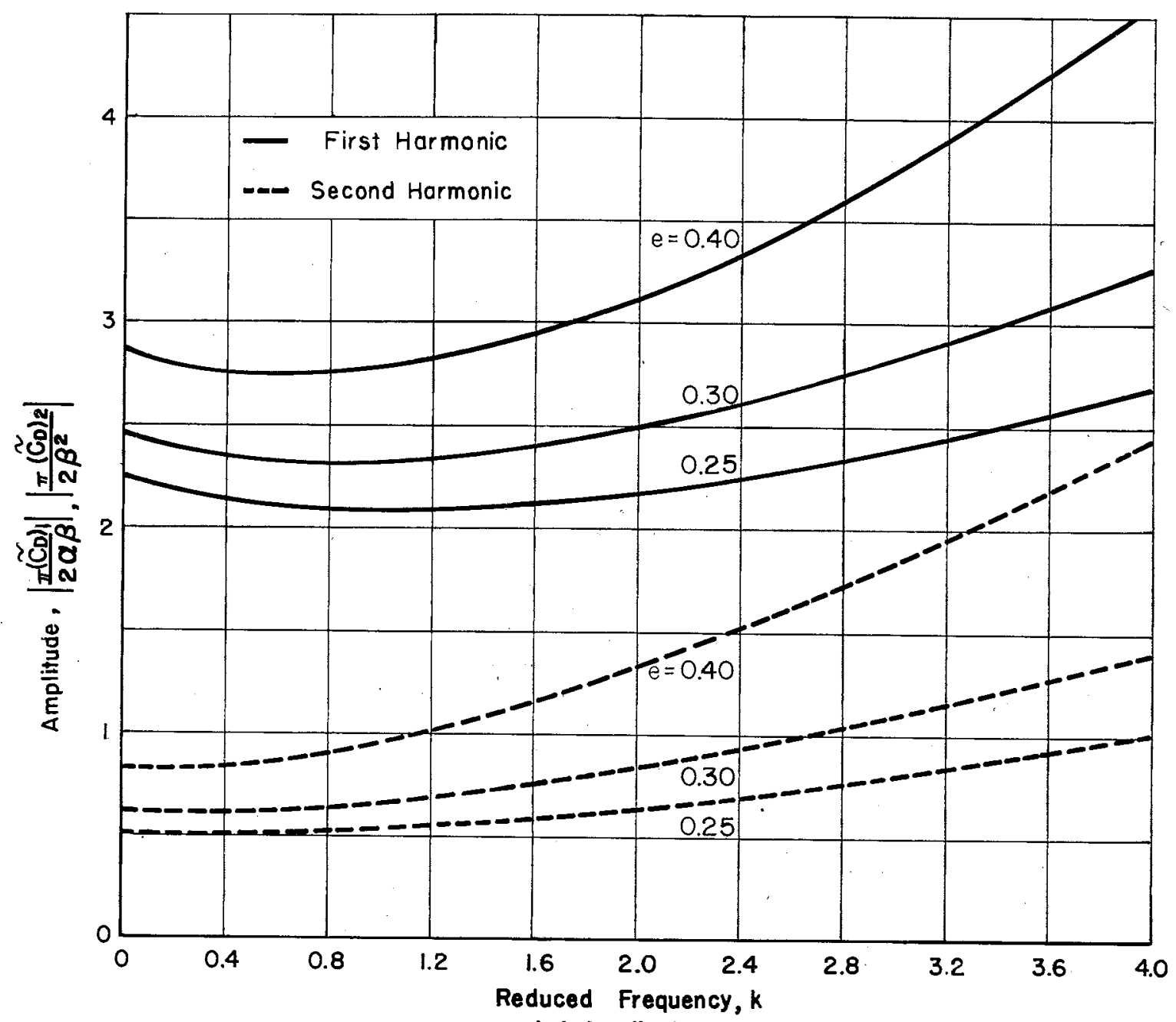

(a) Amplitude

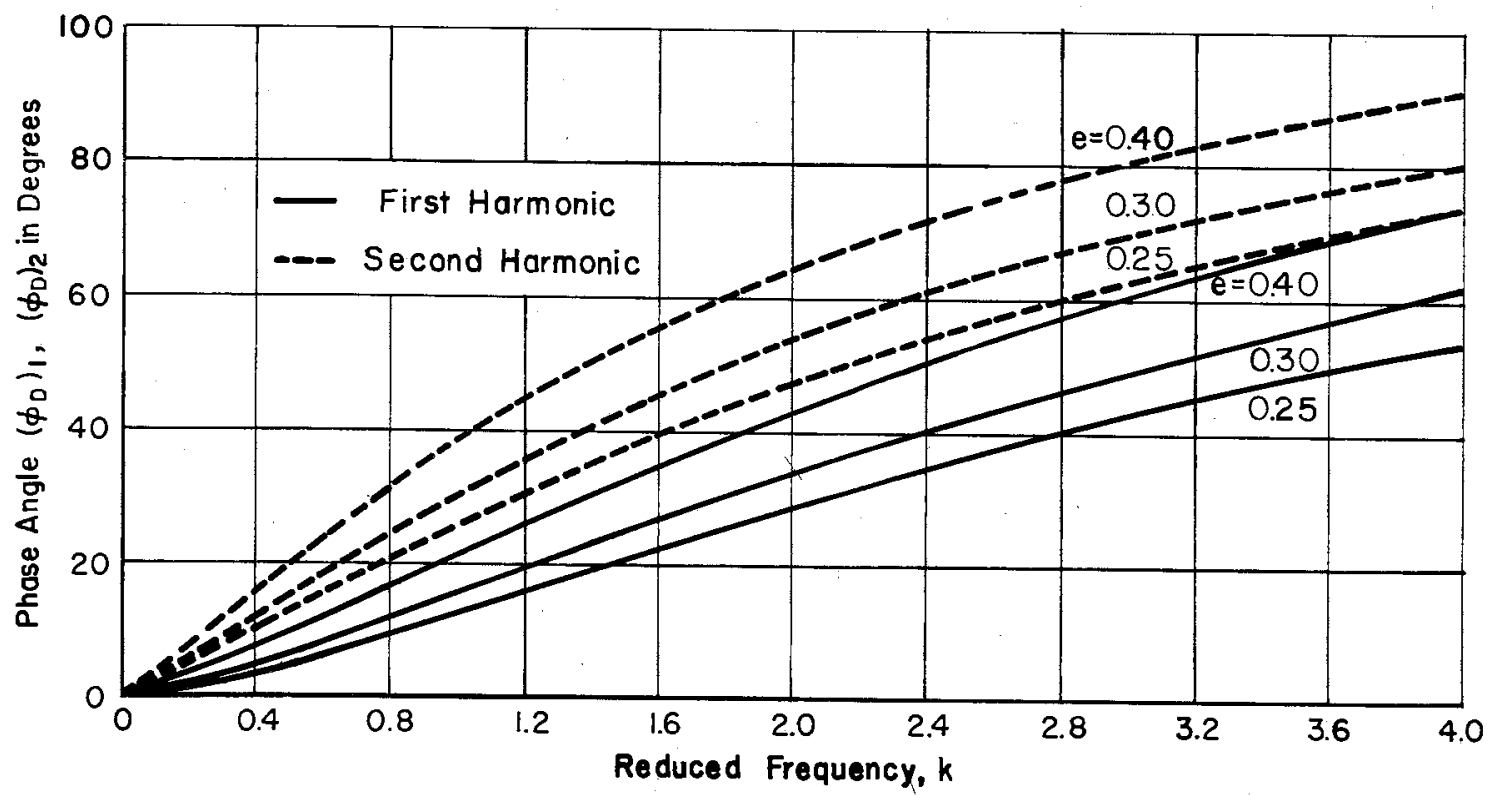

(b) Phase Angle

Fig. 7 - Comparison of First and Second Harmonics of Drag Coefficient 


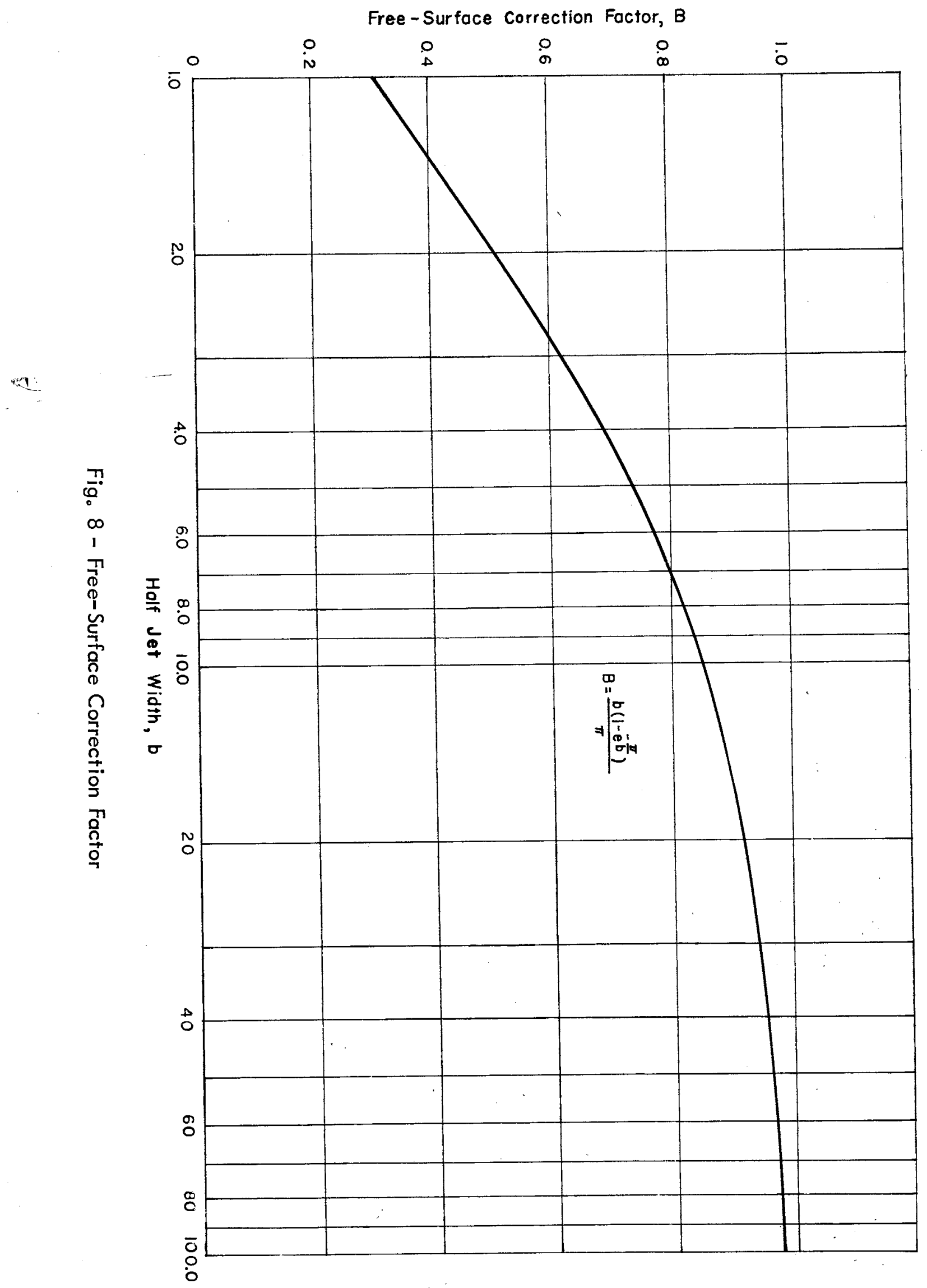




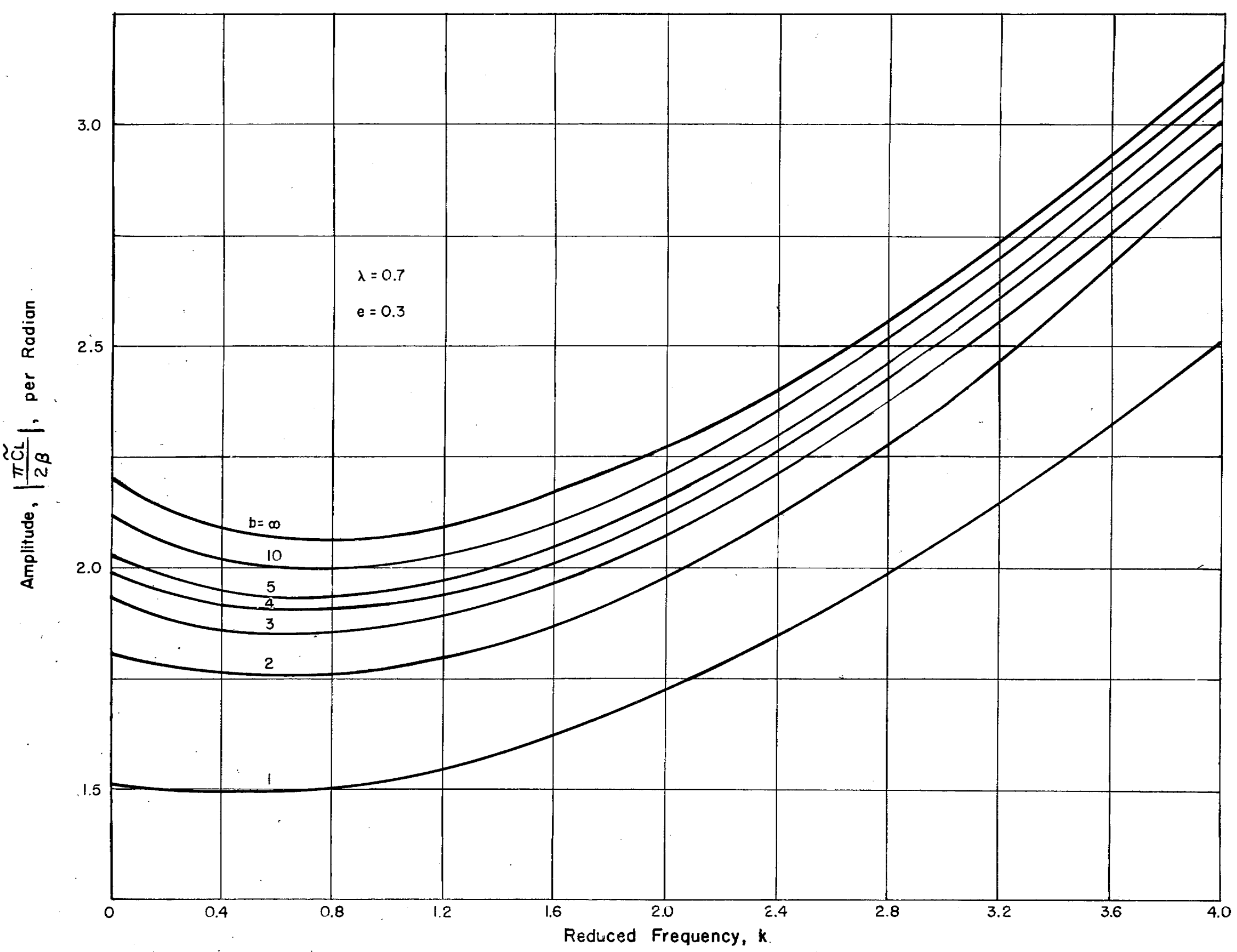

Fig。9 - Free-Surface Effect on the Amplitude of Lift Coefficient 
42

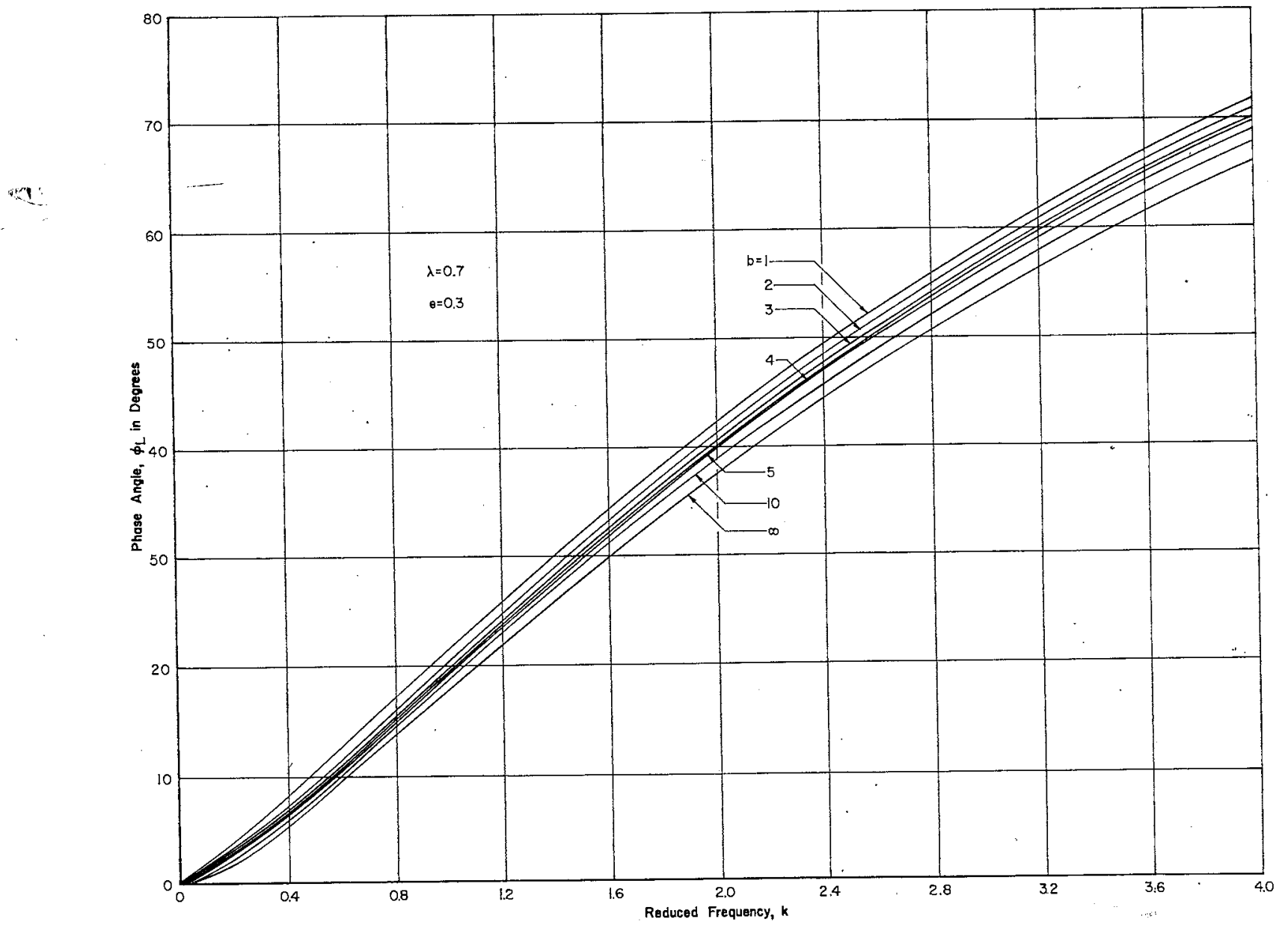

Fig. 10 - Free-Surface Effect on the Phase Angle of Lift Coefficient 


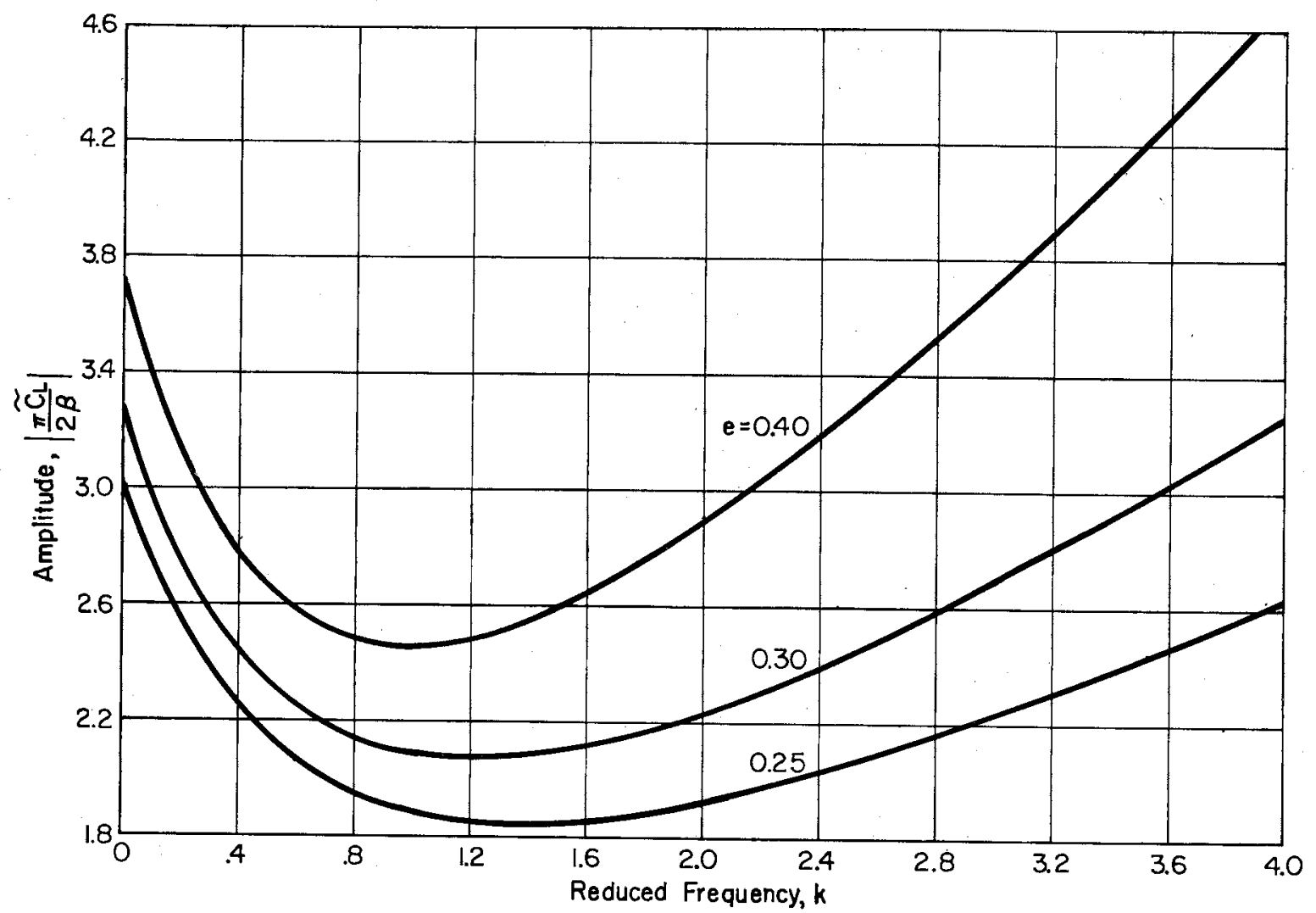

(a) Amplitude

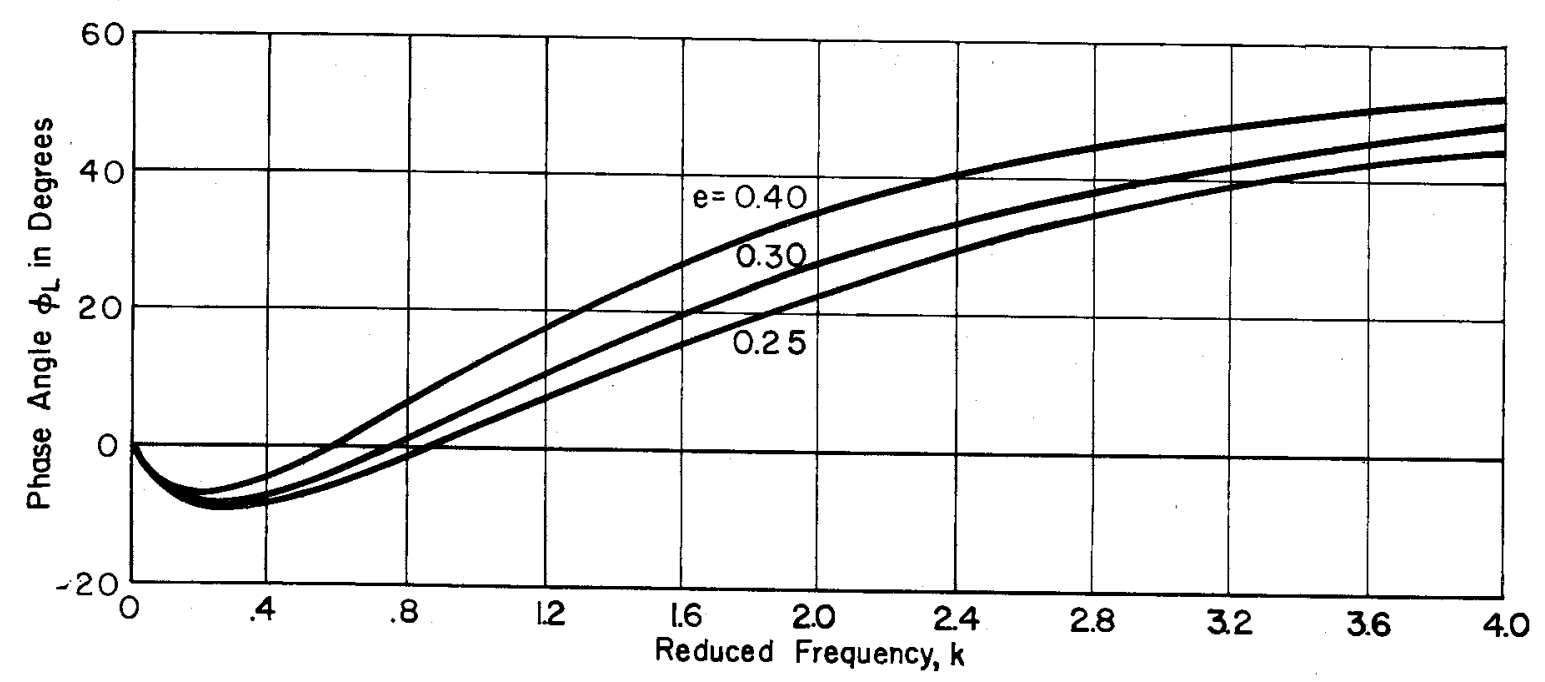

(b) Frequency

Fig. 11 - Lift Coefficient at Zero Submergence 


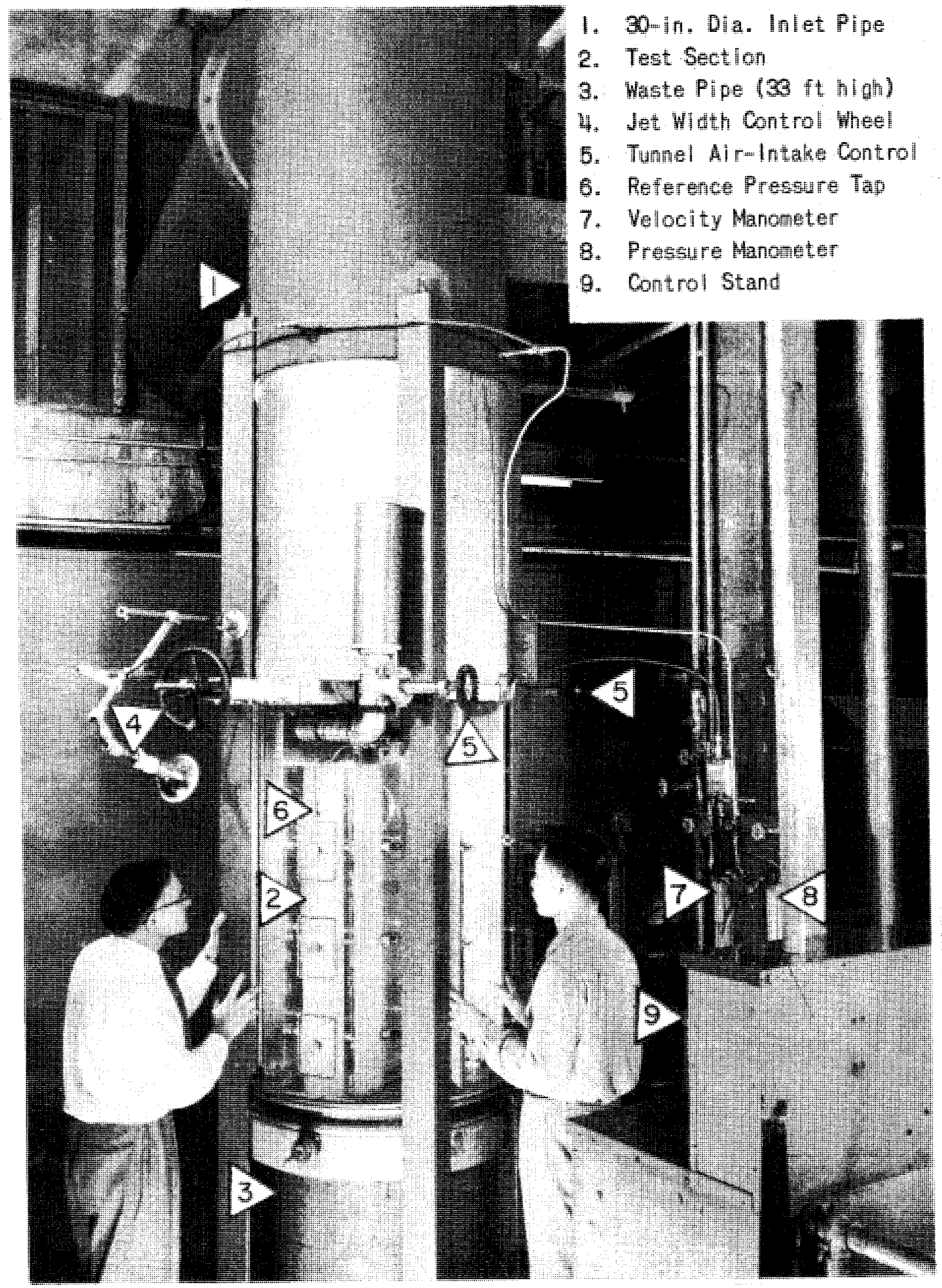

Fig. 12 - The Two-Dimensional Free-Jet Water Tunnel 


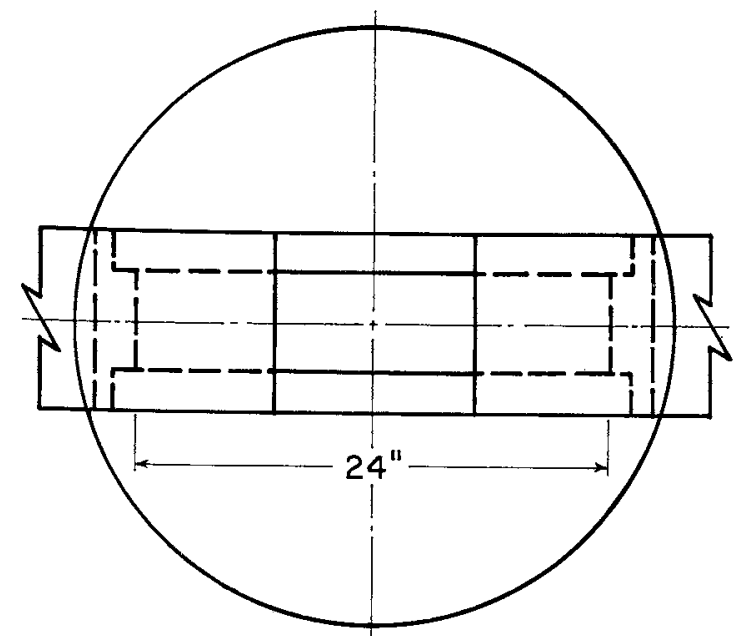

$$
\begin{gathered}
\text { Width of Jet } \\
\text { in Inches } \\
-3^{\prime \prime}<B_{1}<12^{\prime \prime} \quad-2^{\prime \prime}<b_{1}<9^{\prime \prime} \\
0^{\prime \prime}<B_{2}<12^{\prime \prime} \quad 0^{\prime \prime}<b_{2}<9^{\prime \prime}
\end{gathered}
$$
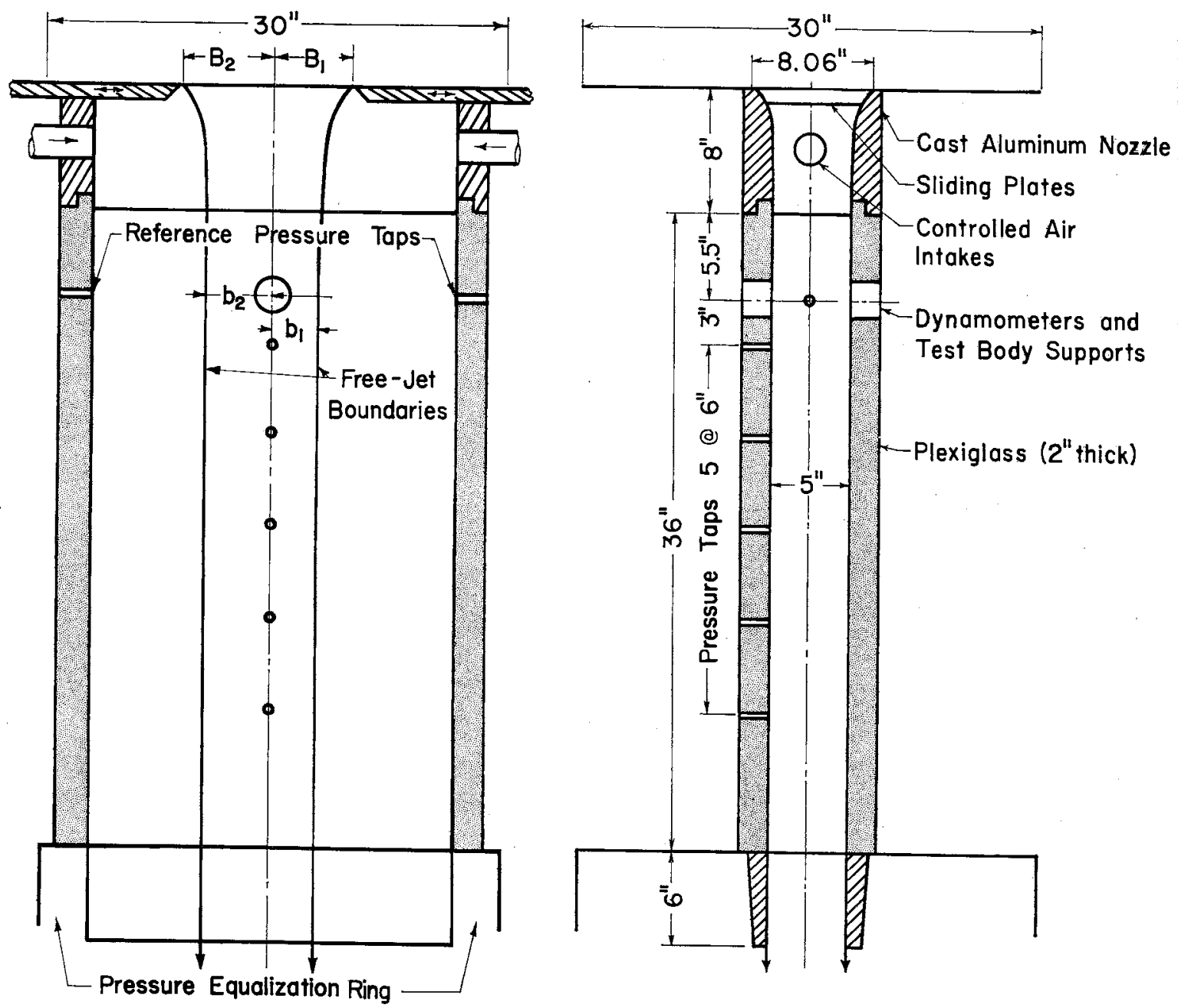

Fig. 13 - Schematic Drawing of Two-Dimensional Test Section and Appurtenances 


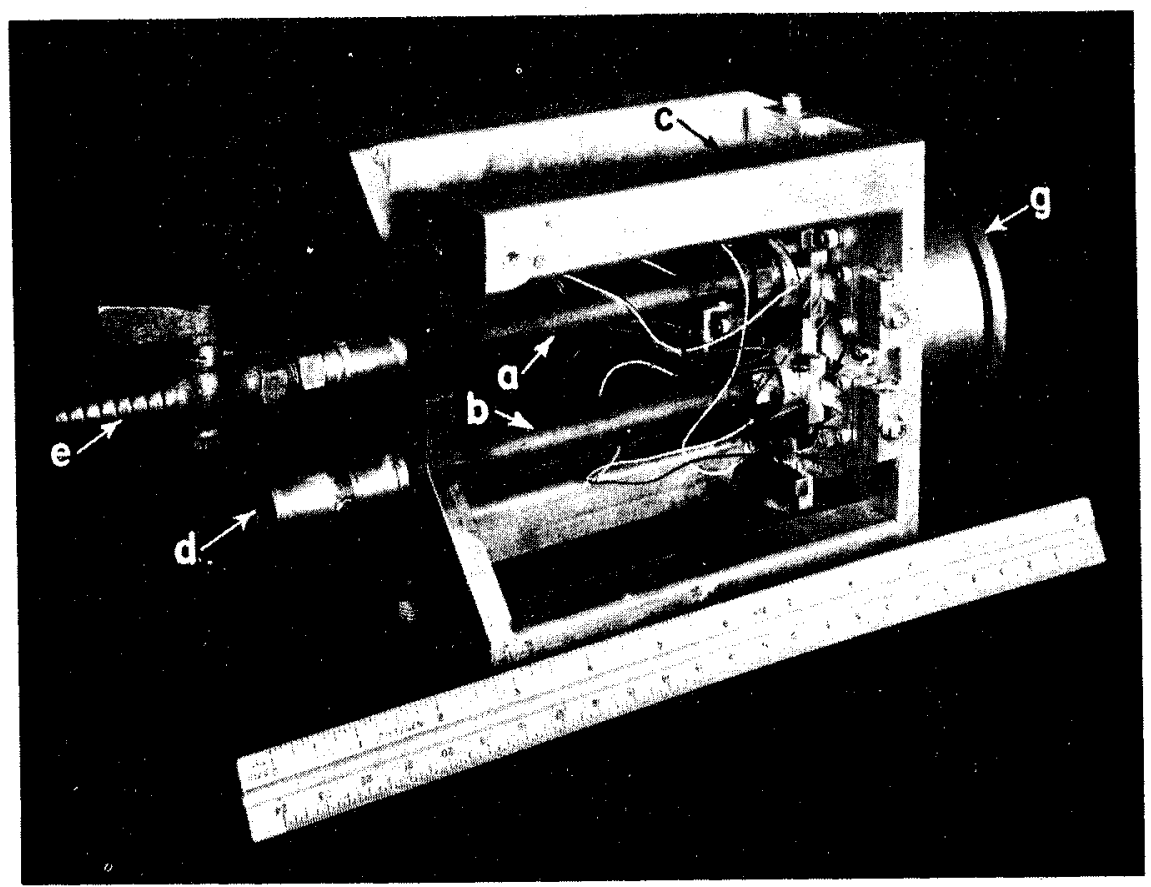

a. Dynamometer as seen from outside of tunnel

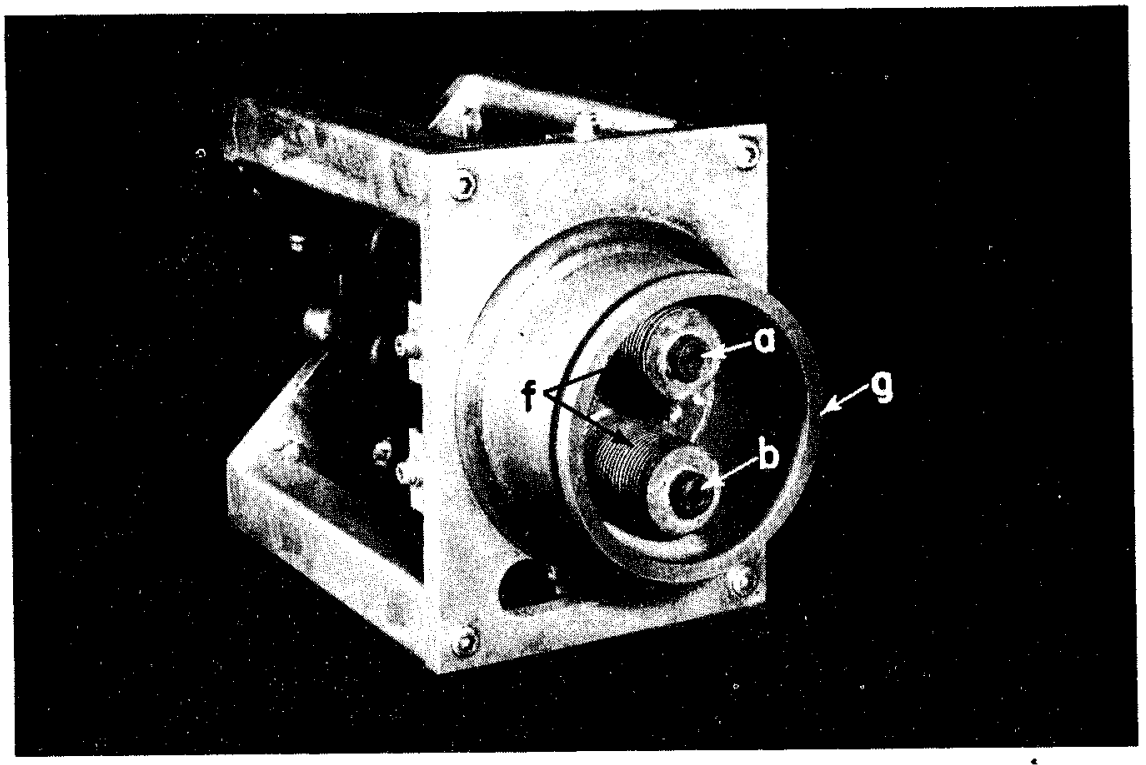

b. Dynamometer as seen from inside of tunnel

a. Upper beam

b. Lower beam

c. Tension fibers

d. Inlet for driving fluid e. Inlet for ventilation or for measuring cavity pressure

f. Bellows

g. Dynamometer cup (fits into 3.7 hole in test section wall) 


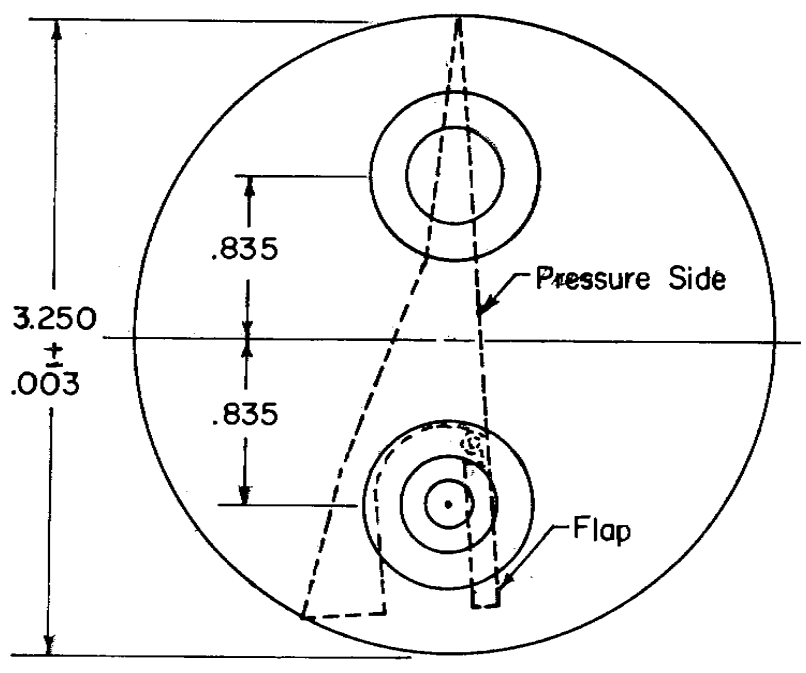

Note: I. All dimensions are in inches.

2. All parts fabricated from brass.

3. Dimensions in parenthesis are for $2^{\prime \prime}$ - foil, other dimensions ore for 3 "- foil: End Plate

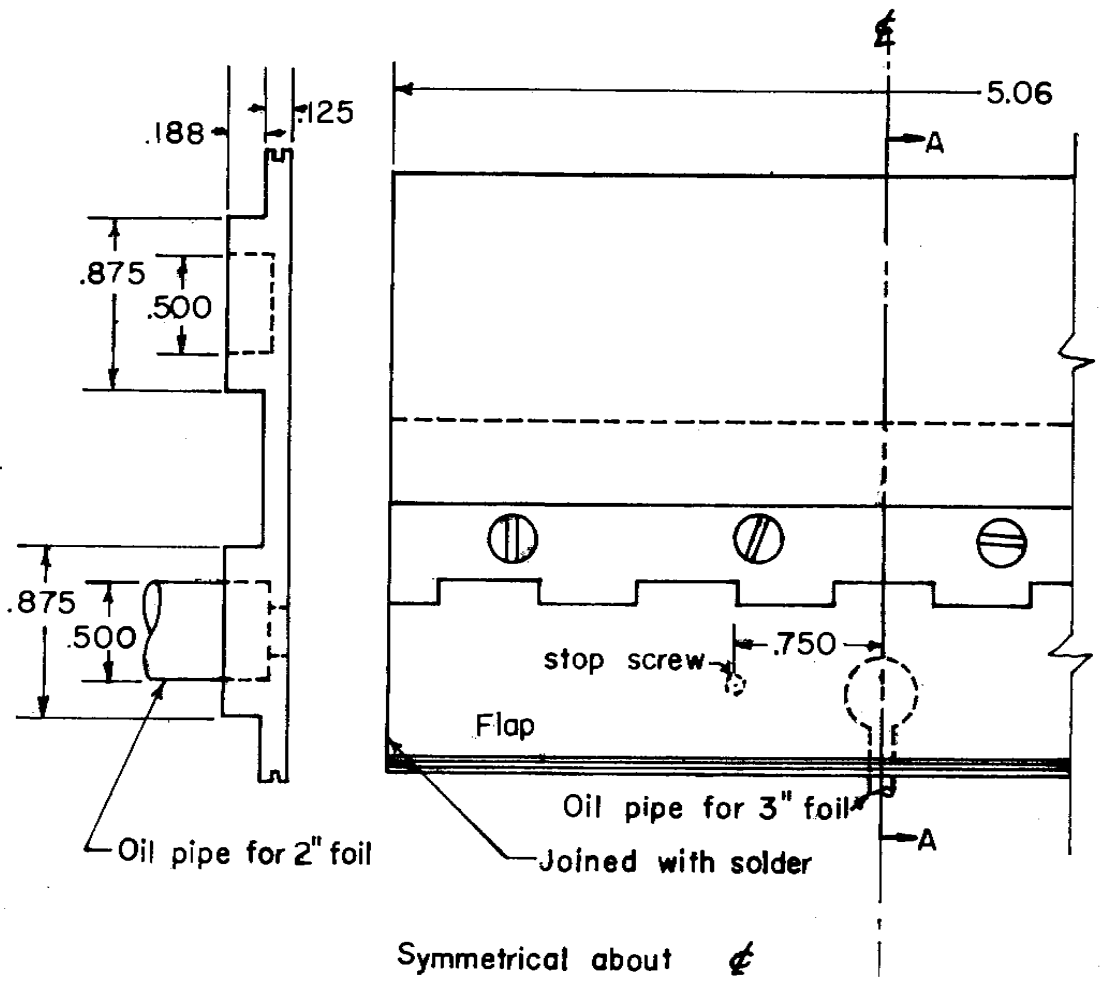

Foil

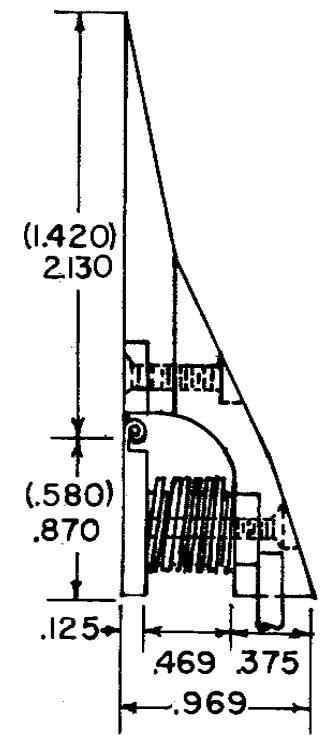

Section A-A

Fig. 15 - Construction Details of Test Bodies 


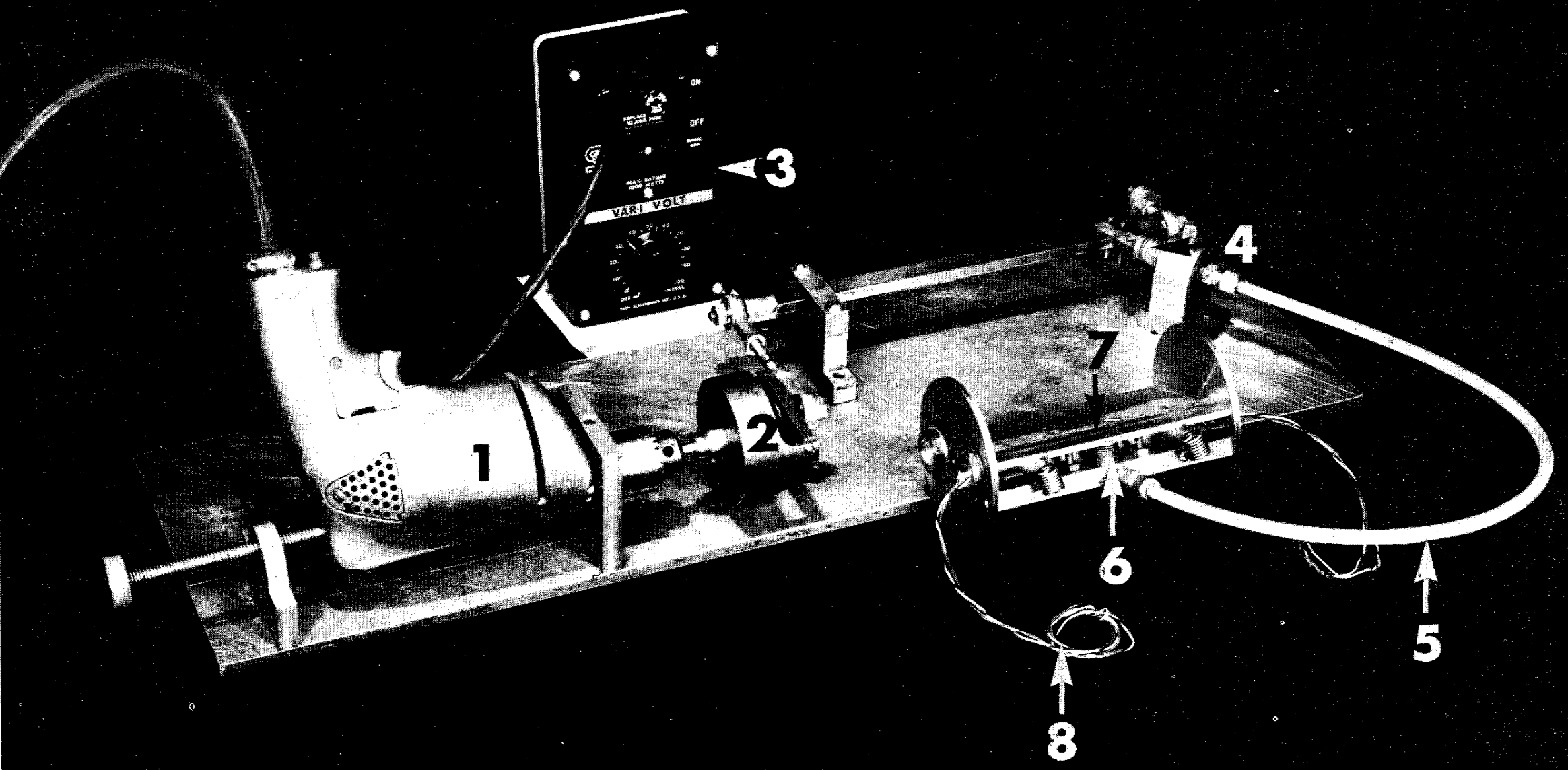

1 - Motor, 2 - Amplitude Control, 3 - Frequency Control,

4 - Driving Bellaws, 5 - Oil line, 6 - Receiving Bellows,

7. Solid Flap, 8 - Wiring for Fiap Angle Measurement

Fig. 16 - Foil and Driving Mechanism 


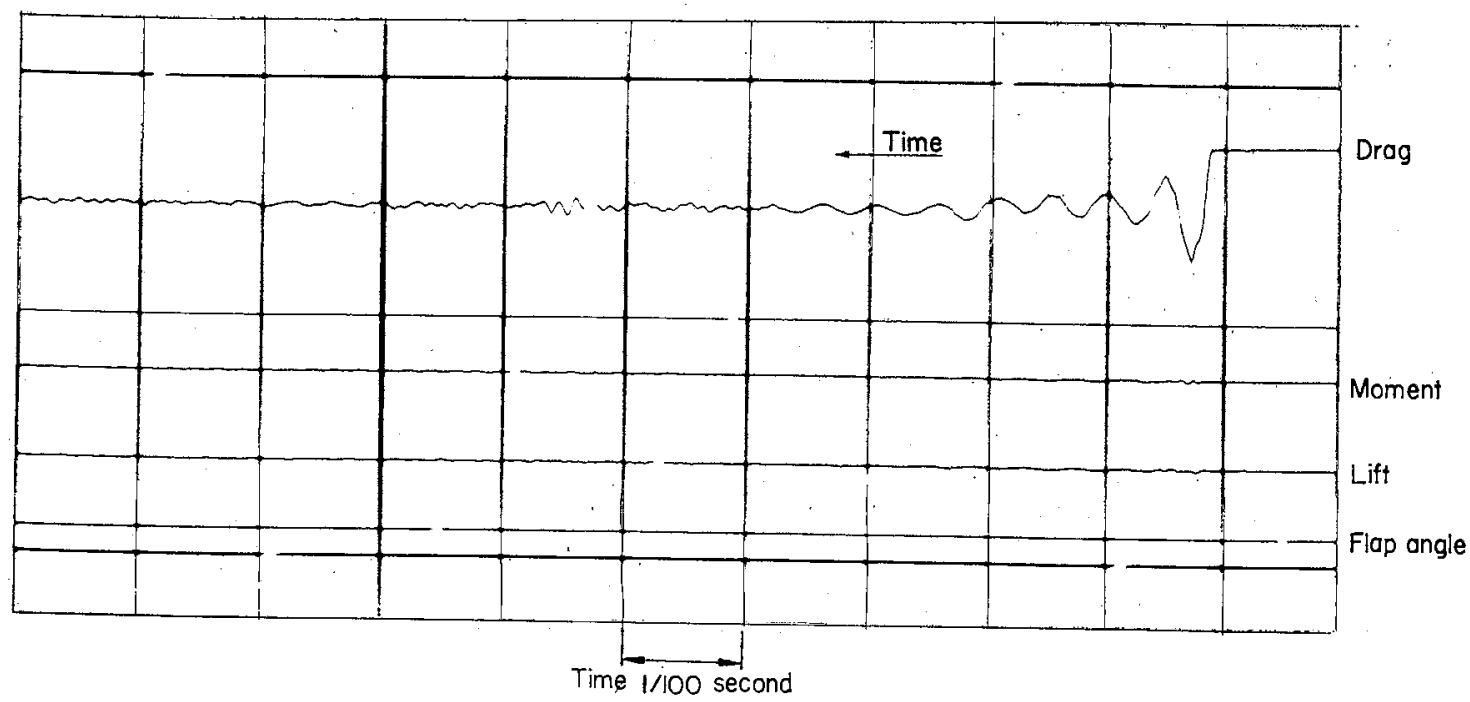

(a) System response to drag load step change in air

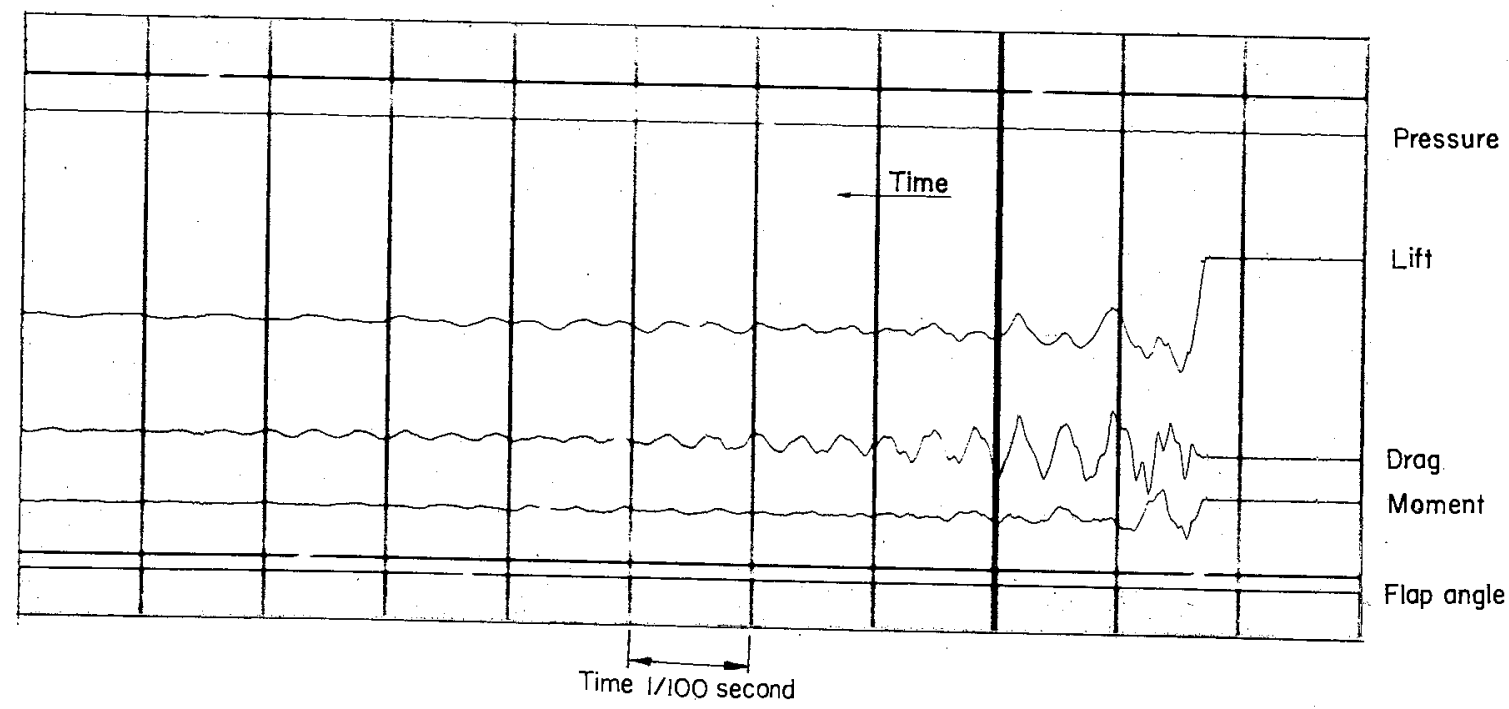

(b) System response to lift load step change in air

Fig. 17 - System Response to Step Load Application 


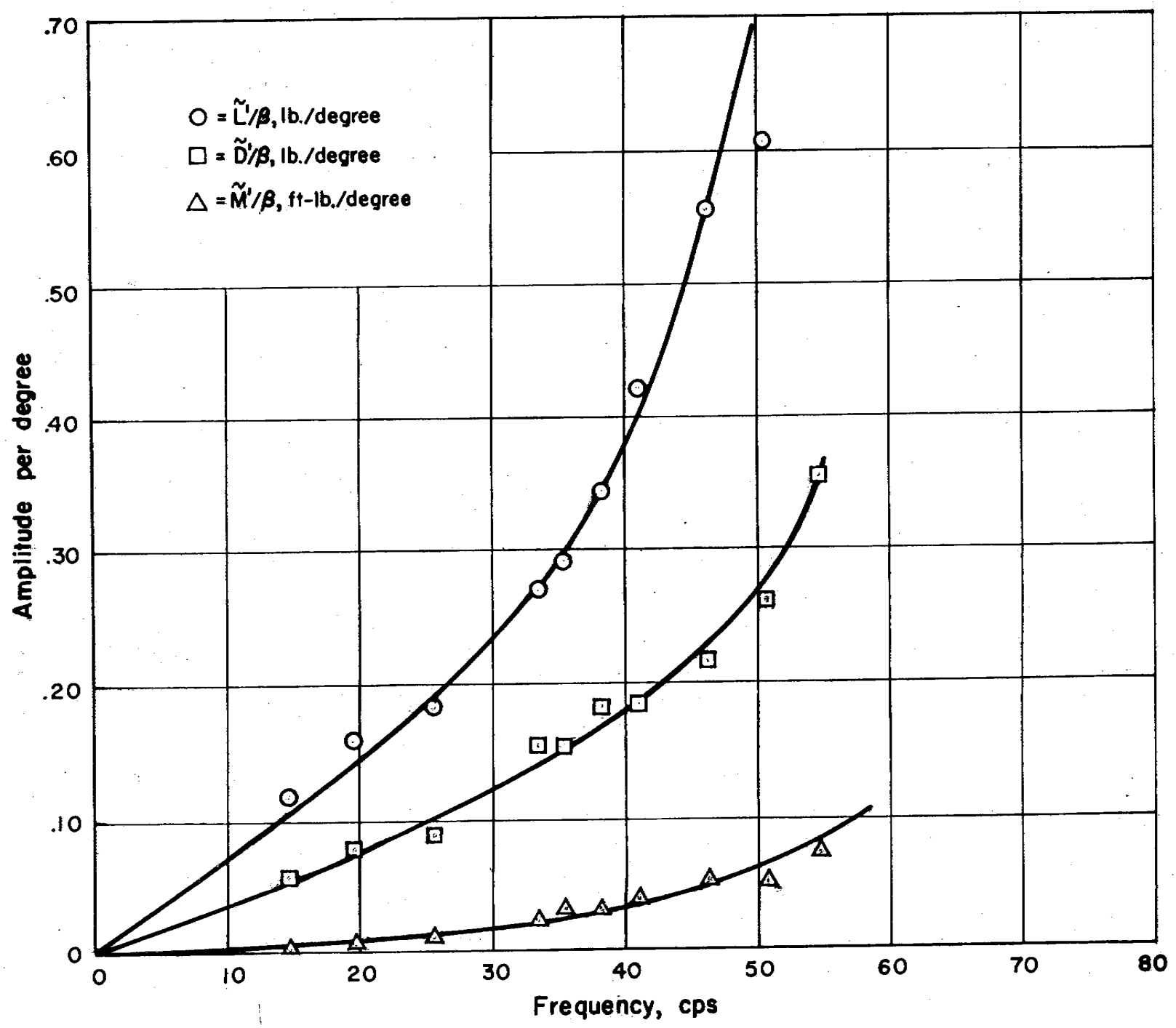

Fig. 18 - Dynamic Response of the System to Flap Oscillation, 3 in. Foil in Air 


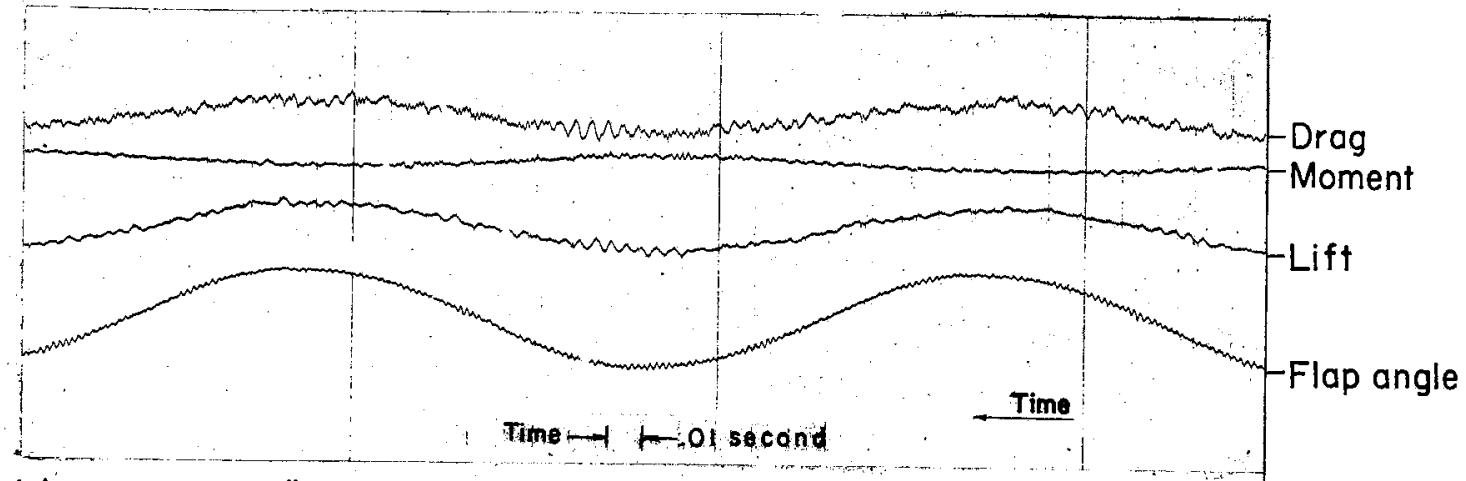

(a) $k=.350,\left|L^{\prime \prime}\right|=4.4 \mathrm{lbs},\left|D^{\prime \prime}\right|=.95 \mathrm{lbs},\left|M^{\prime \prime}\right|=.104 \mathrm{lbs}, \beta=4.3^{\circ}$

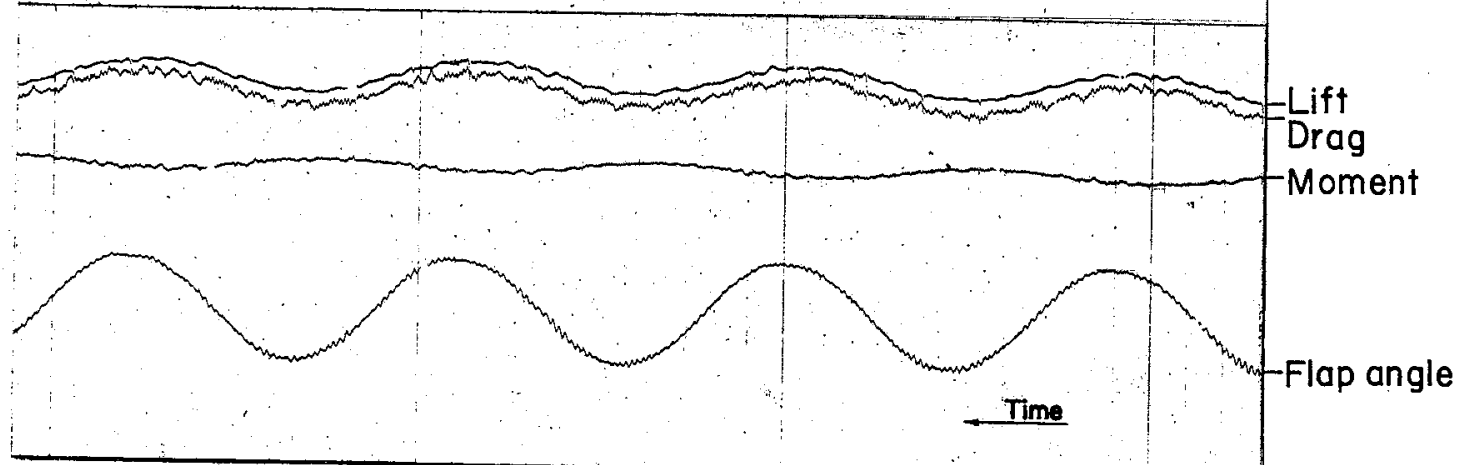

(b) $k=.720, \quad L^{\prime \prime}|=4.5 \mathrm{lbs}, \quad| D^{\prime \prime}|=1.33 \mathrm{lbs},| \mathrm{M}^{\prime \prime} \mid=.138 \mathrm{lbs}, \quad \beta=4.6^{\circ}$

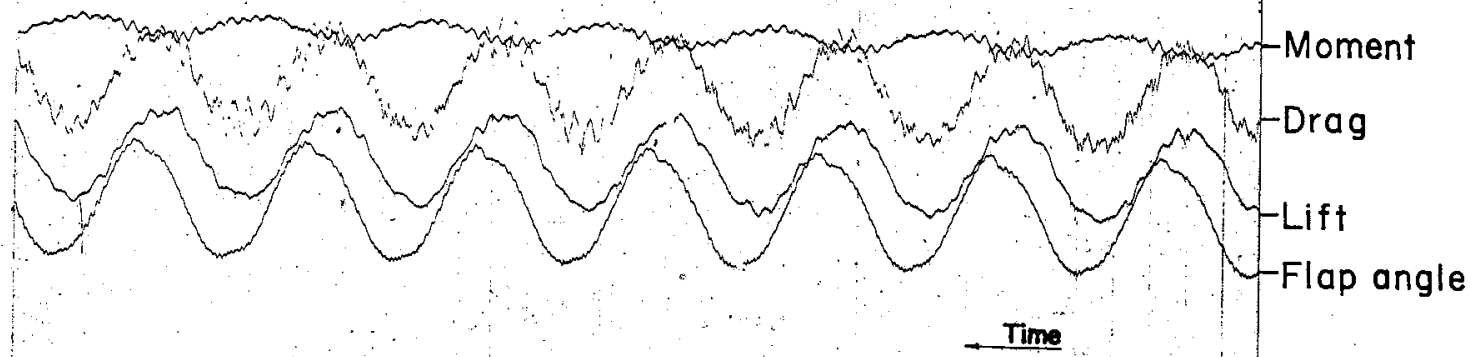

(c) $k=1.48, \quad L^{\prime \prime}|=9.2 \mathrm{lbs},| D^{\prime \prime}|=2.48 \mathrm{lbs},| \mathrm{M}^{\prime \prime} \mid=.276 \mathrm{lbs}, \quad \beta=5.5^{\circ}$

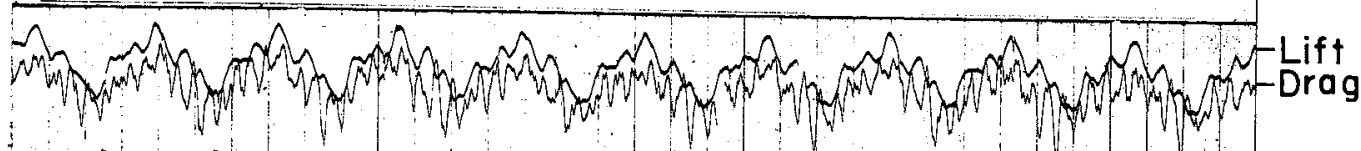

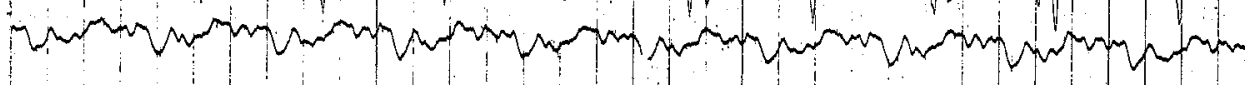

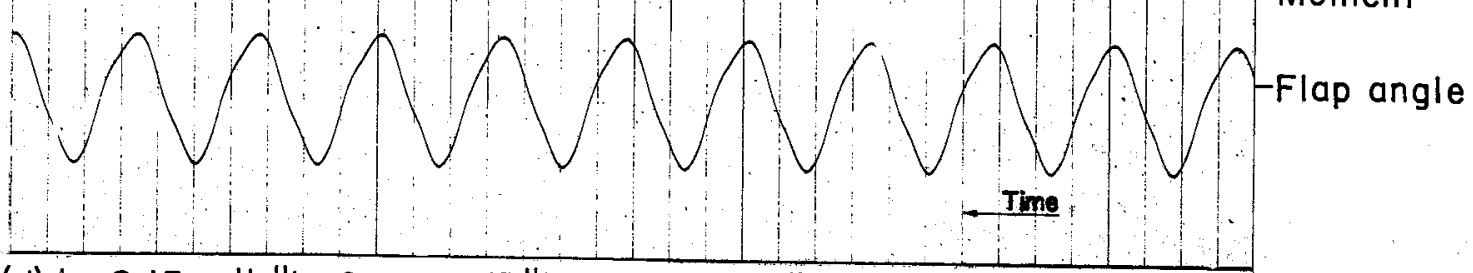

(d) $k=2.15,\left|L^{\prime \prime}\right|=6.0 \mathrm{lbs},\left|D^{\prime \prime}\right|=1.24 \mathrm{lbs},\left|\mathrm{M}^{\prime \prime}\right|=.253 \mathrm{lbs}, \quad \beta=5.8^{\circ}$

Fig. 19 - Typical Oscillograph Records 


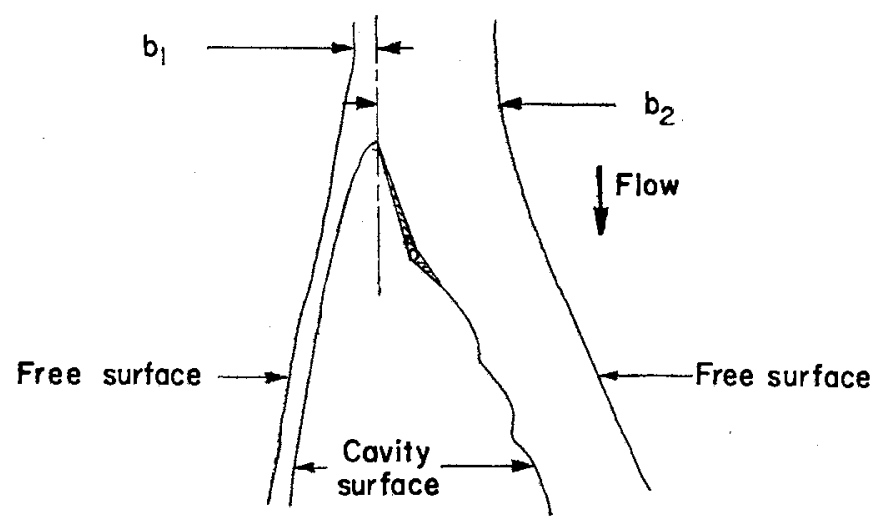

a

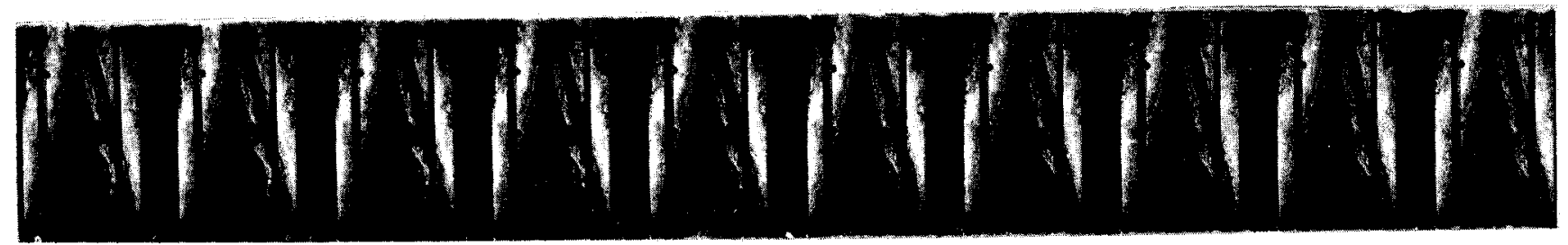

(a) $b_{1}=0, b_{2}=1, V=20.7 \mathrm{fps}, k=2.3$

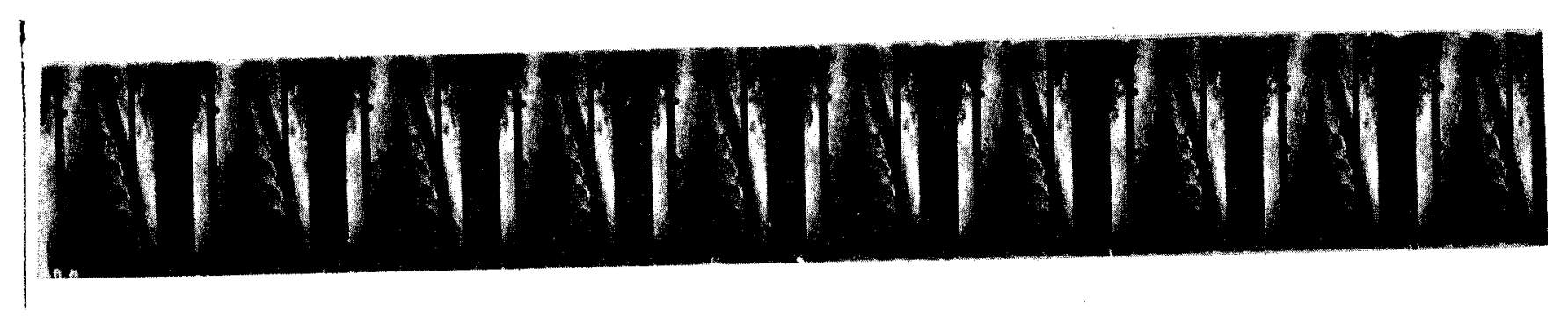

(b) $b_{1}=0, b_{2}=1, v=20.7 \mathrm{fps}, k=3.8$

Fig. 20 - Photographs of Cavity Surface Waves in Non-Symmetrical Jet 


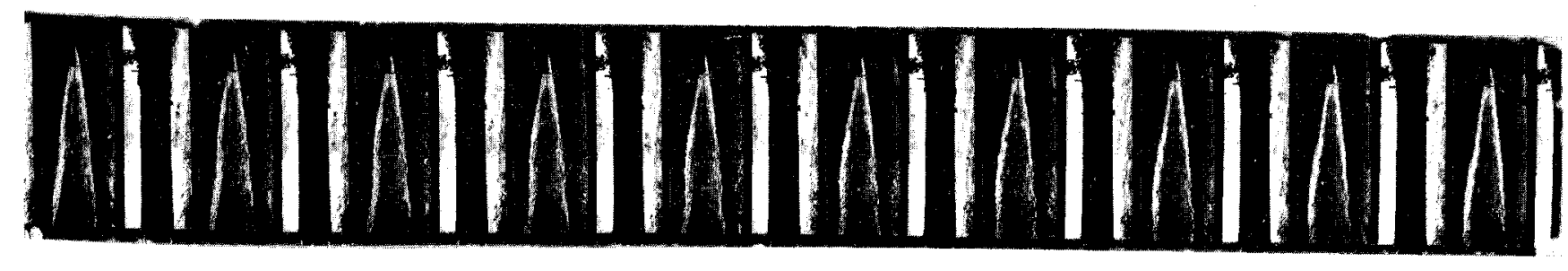

(a) $V=21.0 \mathrm{fps}, \quad k=0.965$

flap at left

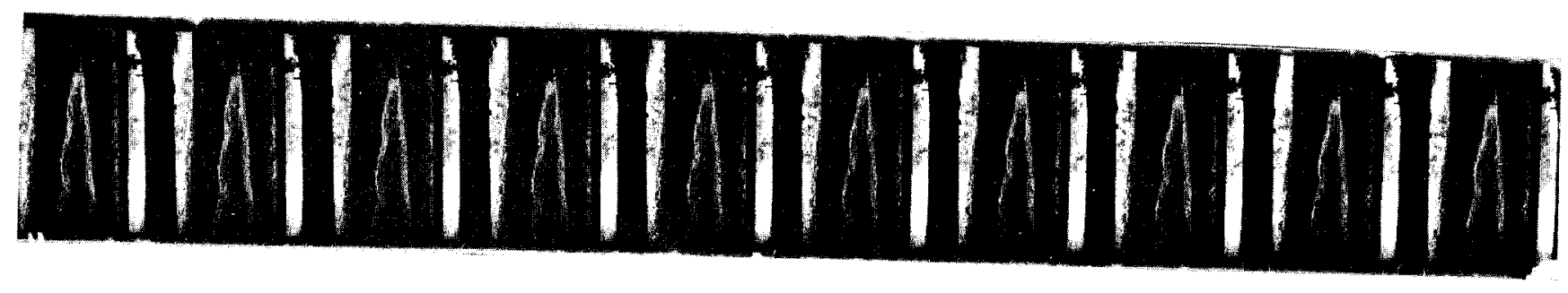

(b) $V=21.0 \mathrm{fps}, k=2.20$

flap at left

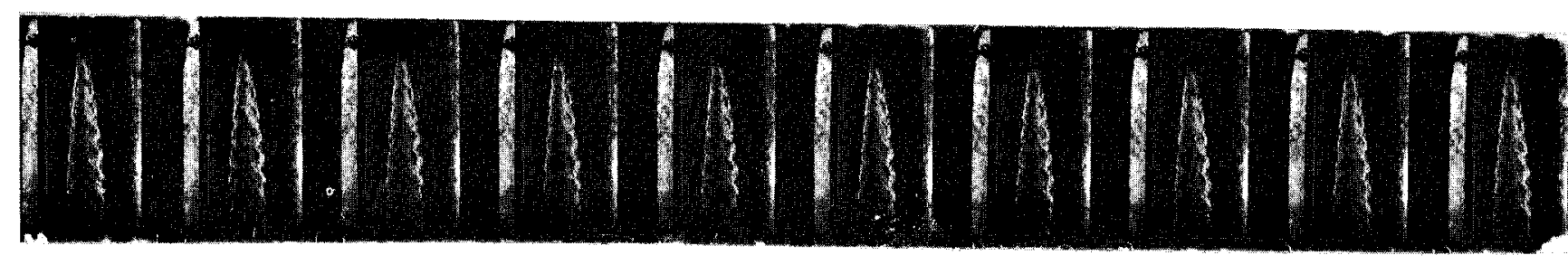

(c) $V=15.2$ fps, $k=5.0$

flap at right

Fig。 21 - Photographs of Cavity Surface Waves in Symmetrical Jets 


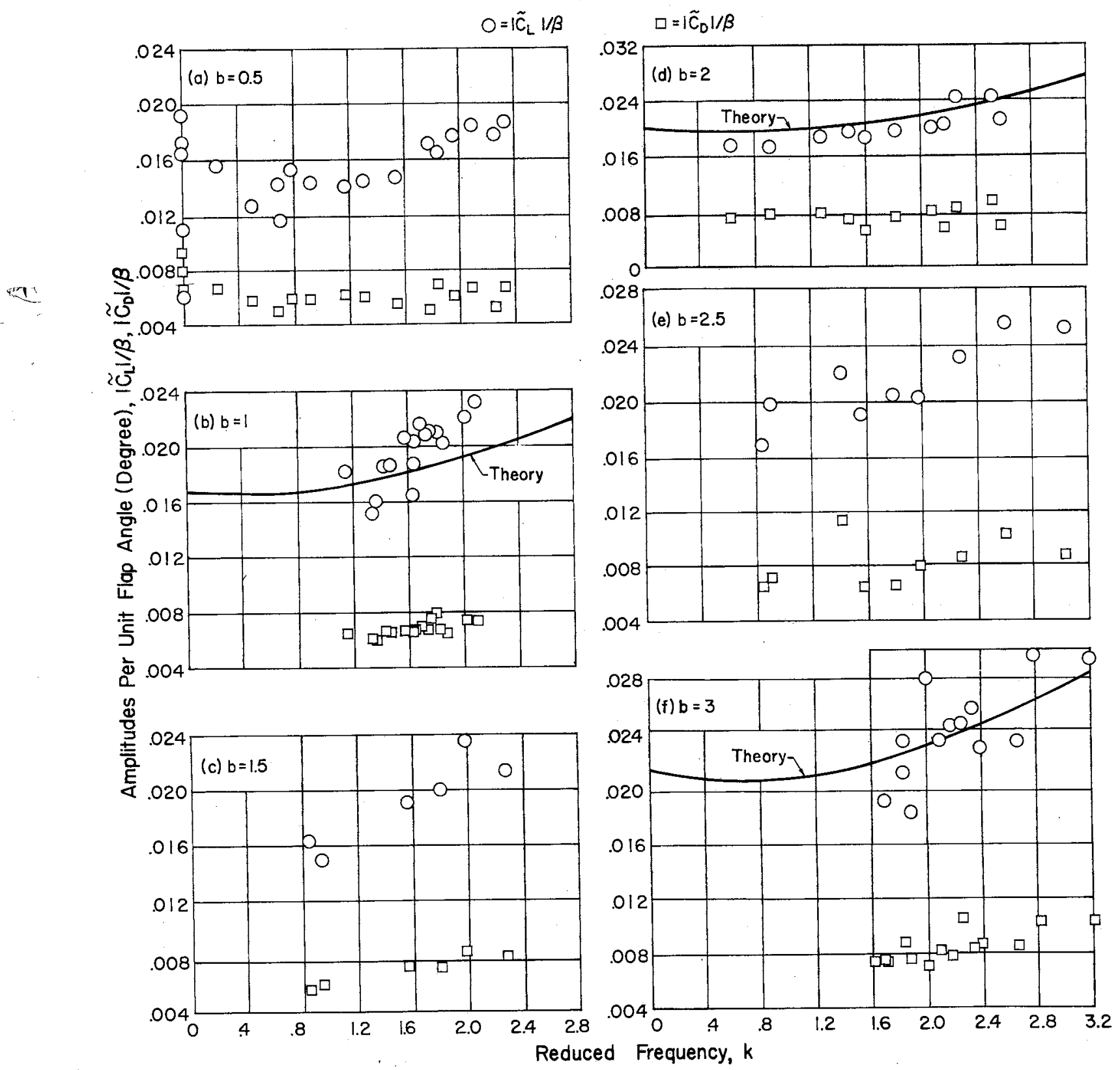

Fig. 22 - Amplitude of Oscillating Lift and Drag Coefficient in Symmetrical Jets 

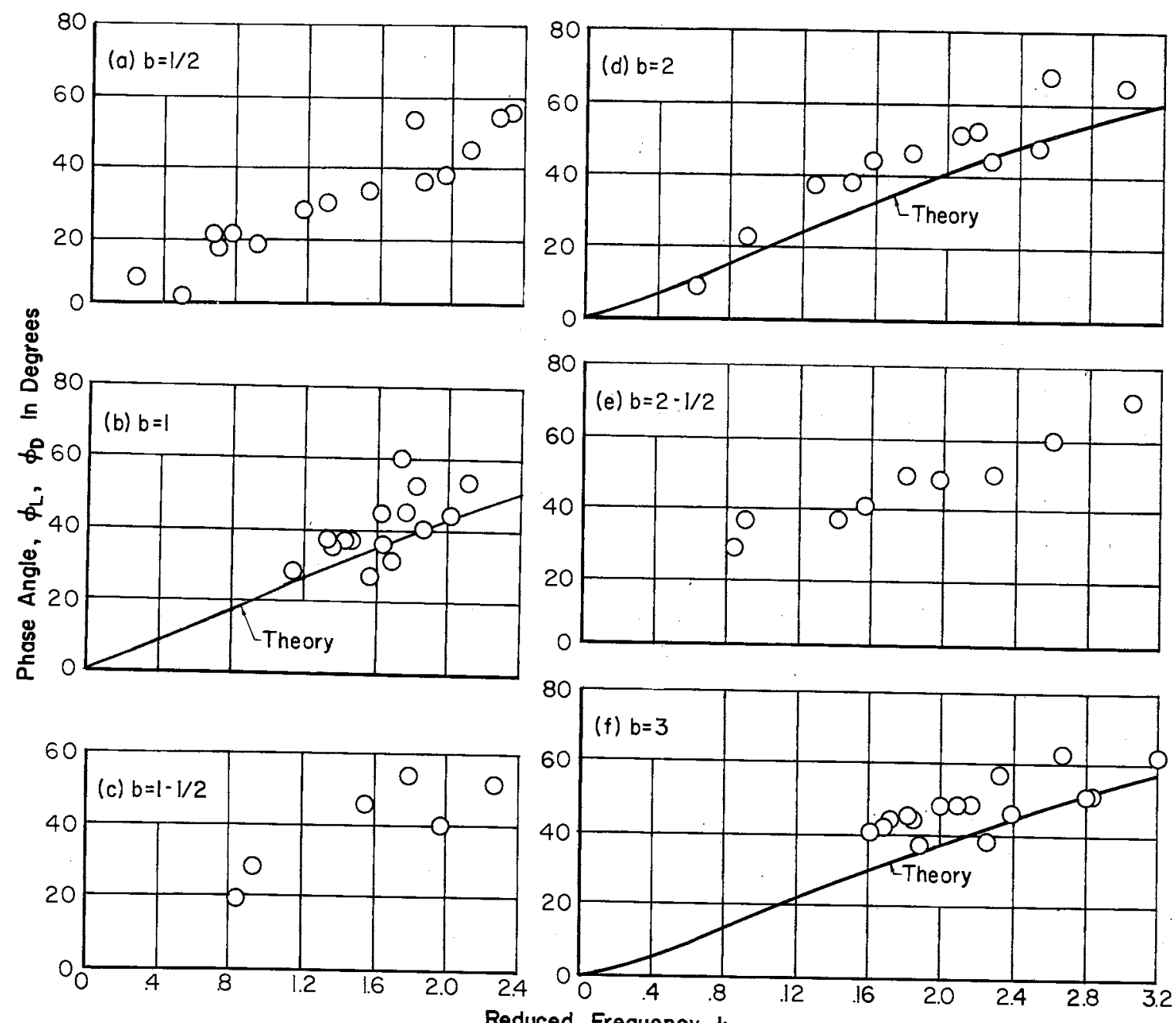

Fig. 23 - Phase Angle of Oscillating Lift Coefficient in Symmetrical Jets 


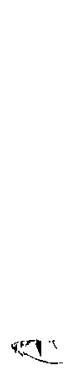

$\frac{n}{2}$
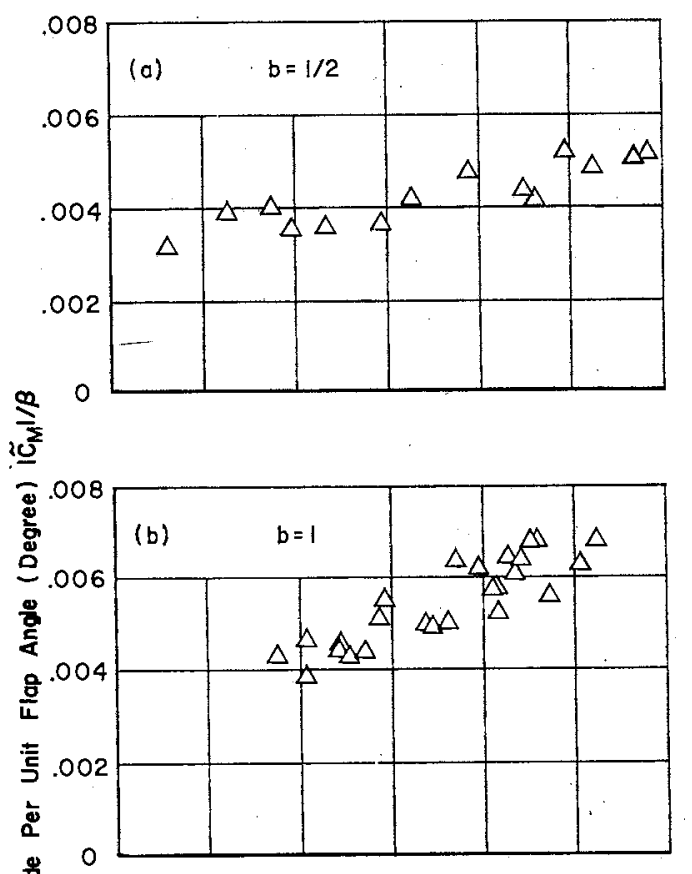

吝

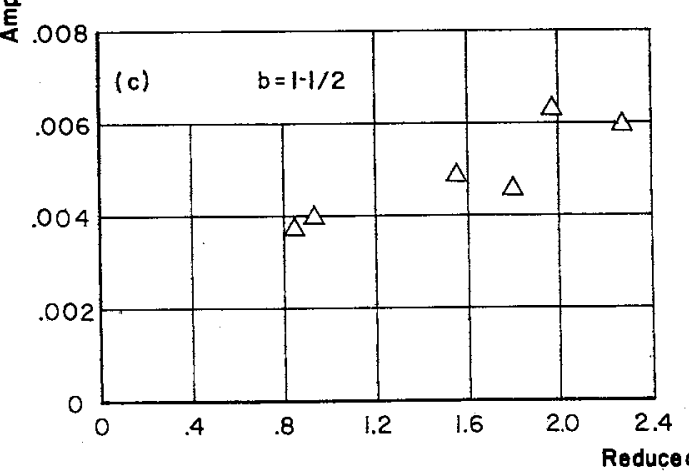

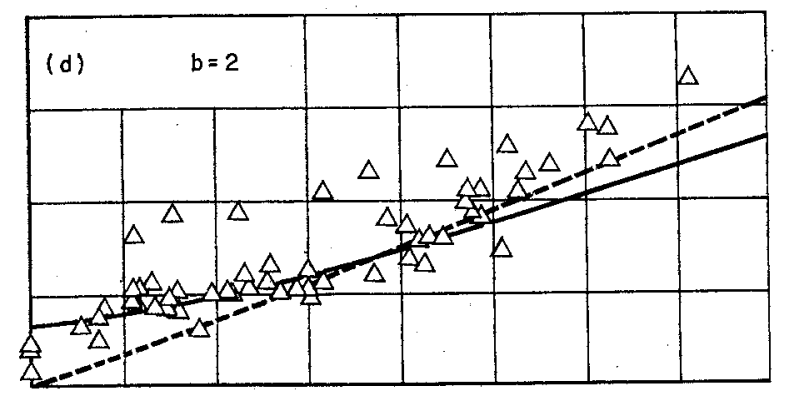

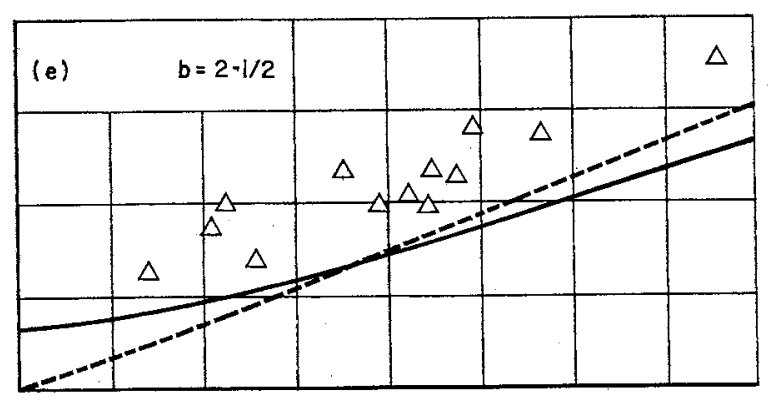

Note: Curves are from the infinite fluid theory;

- Axis of rototion at 0.45 chord,

--- Axis of rotation of 0.50 chord.

Fig. 24 - Amplitude of Oscillating Moment Coefficient in Symmetrical Jets 

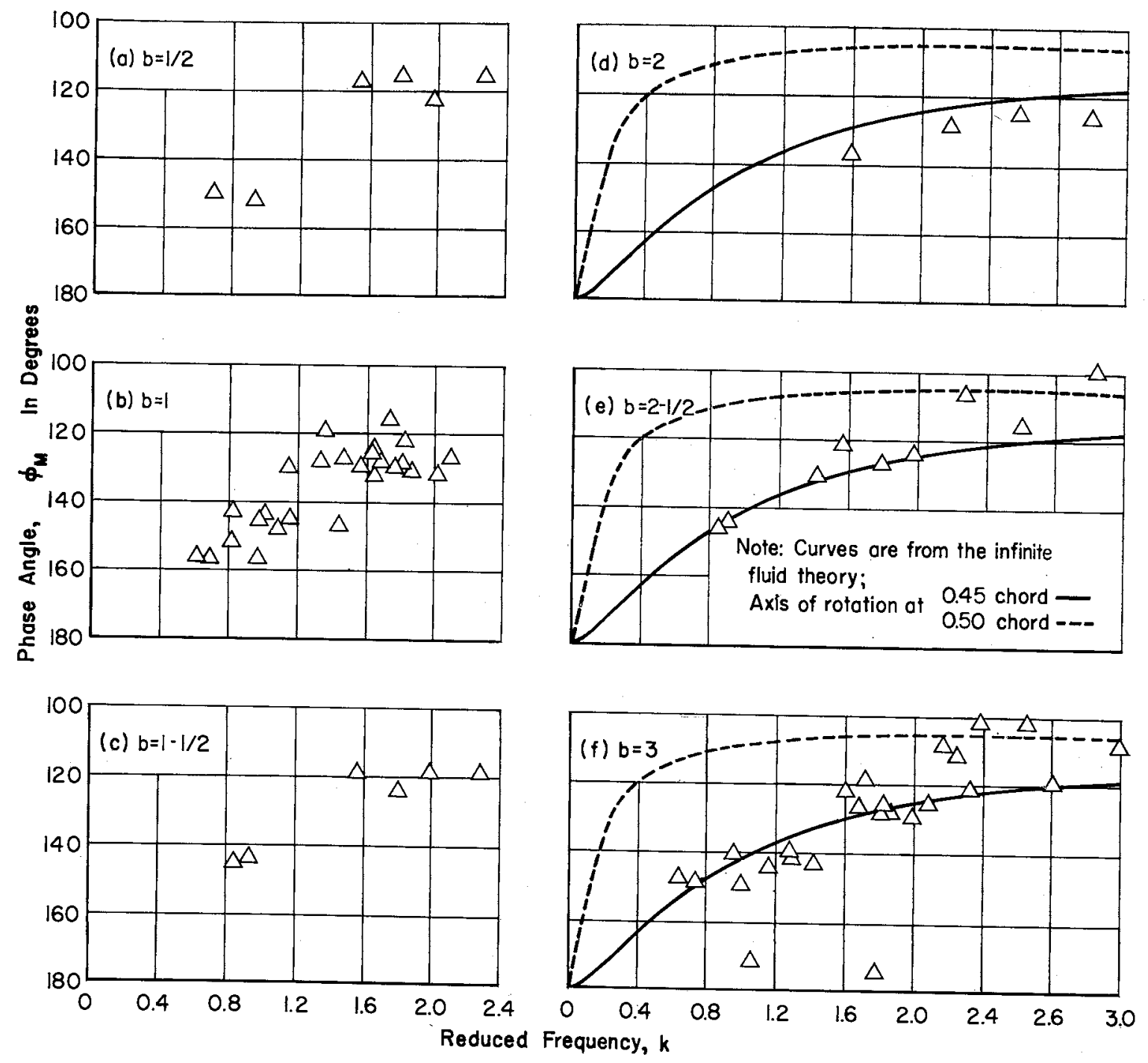

Fig。 25 - Phase Angle of Oscillating Moment Coefficient in Symmetrical 
$O=\left|\tilde{C}_{L}\right| / \beta$ Liff $\quad \square=\left|\tilde{C}_{D}\right| / \beta$ Drag $\quad \Delta=\left|\tilde{C}_{M}\right| / \beta$ Moment
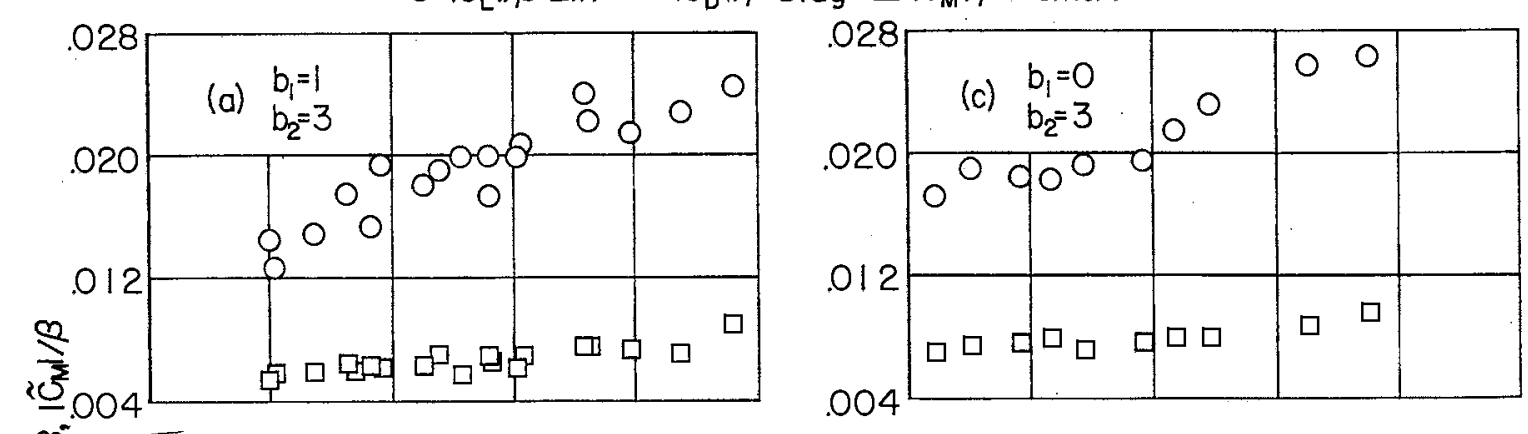

a
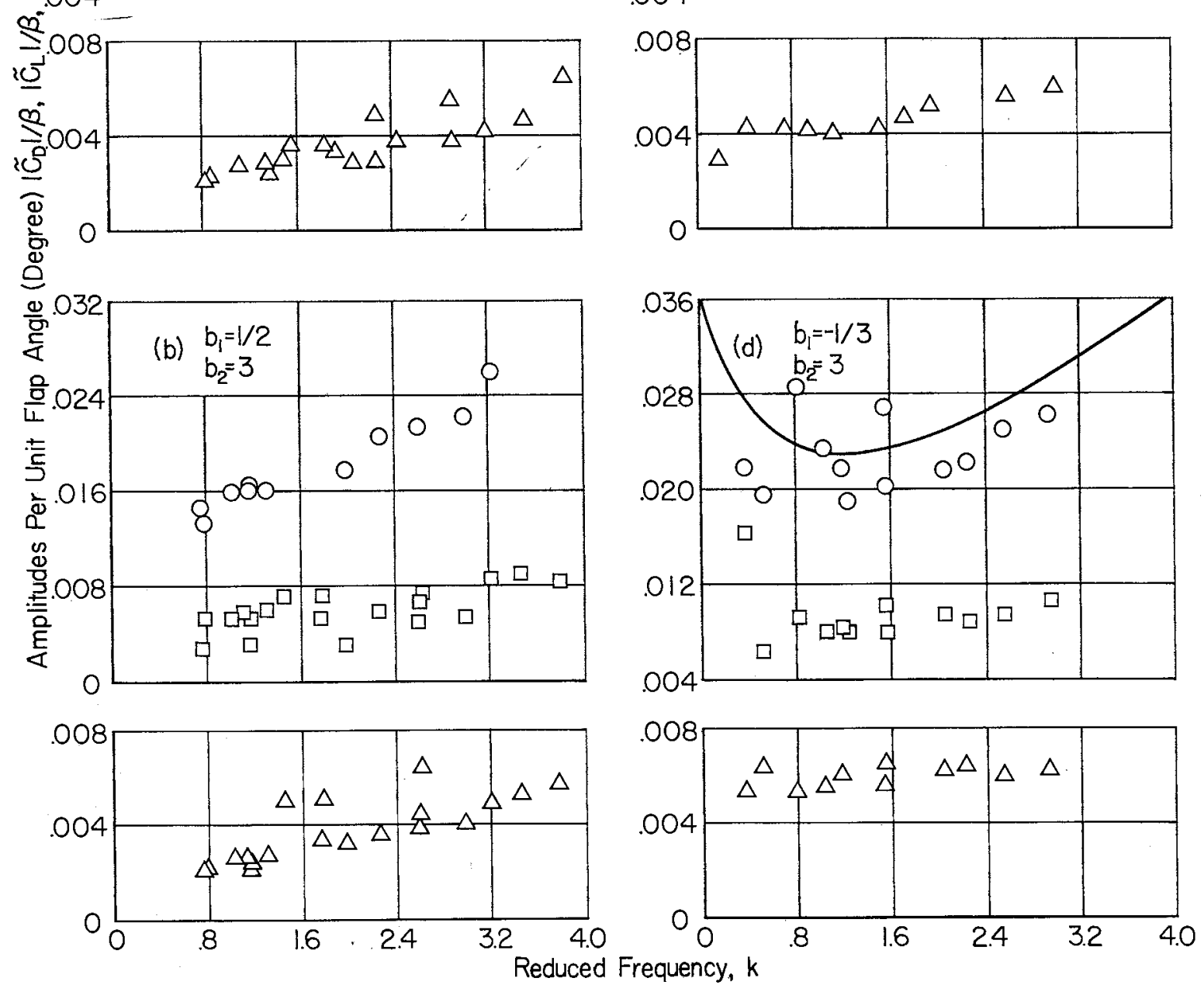

Fig. 26 - Effect of Suction-Side Free Surface on Amplitude of Oscillating Force and Moment 

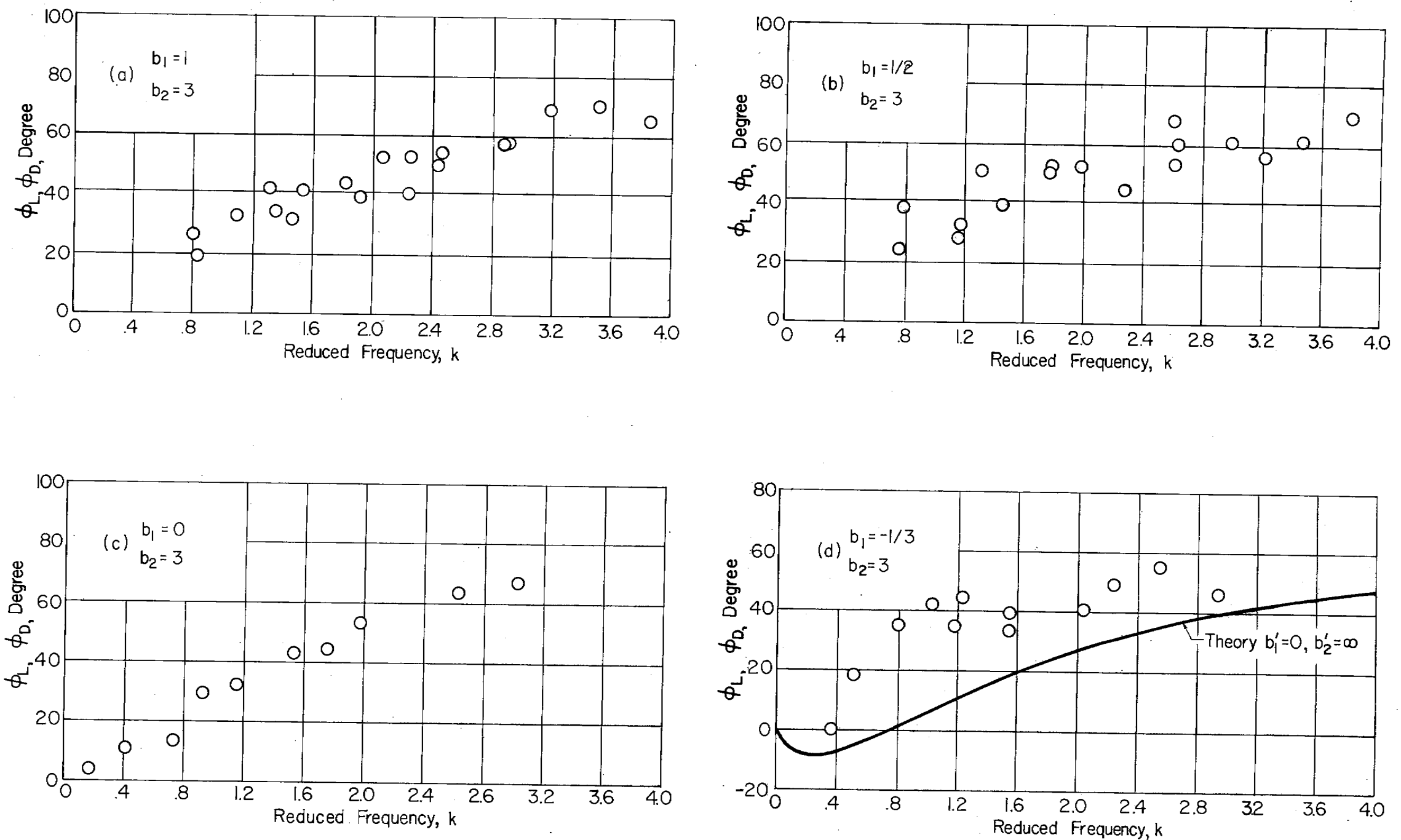
Fig. 27 - Effect of Suction-Side Free Surface on Phase Angle of Oscillating
Force and Moment 


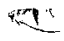
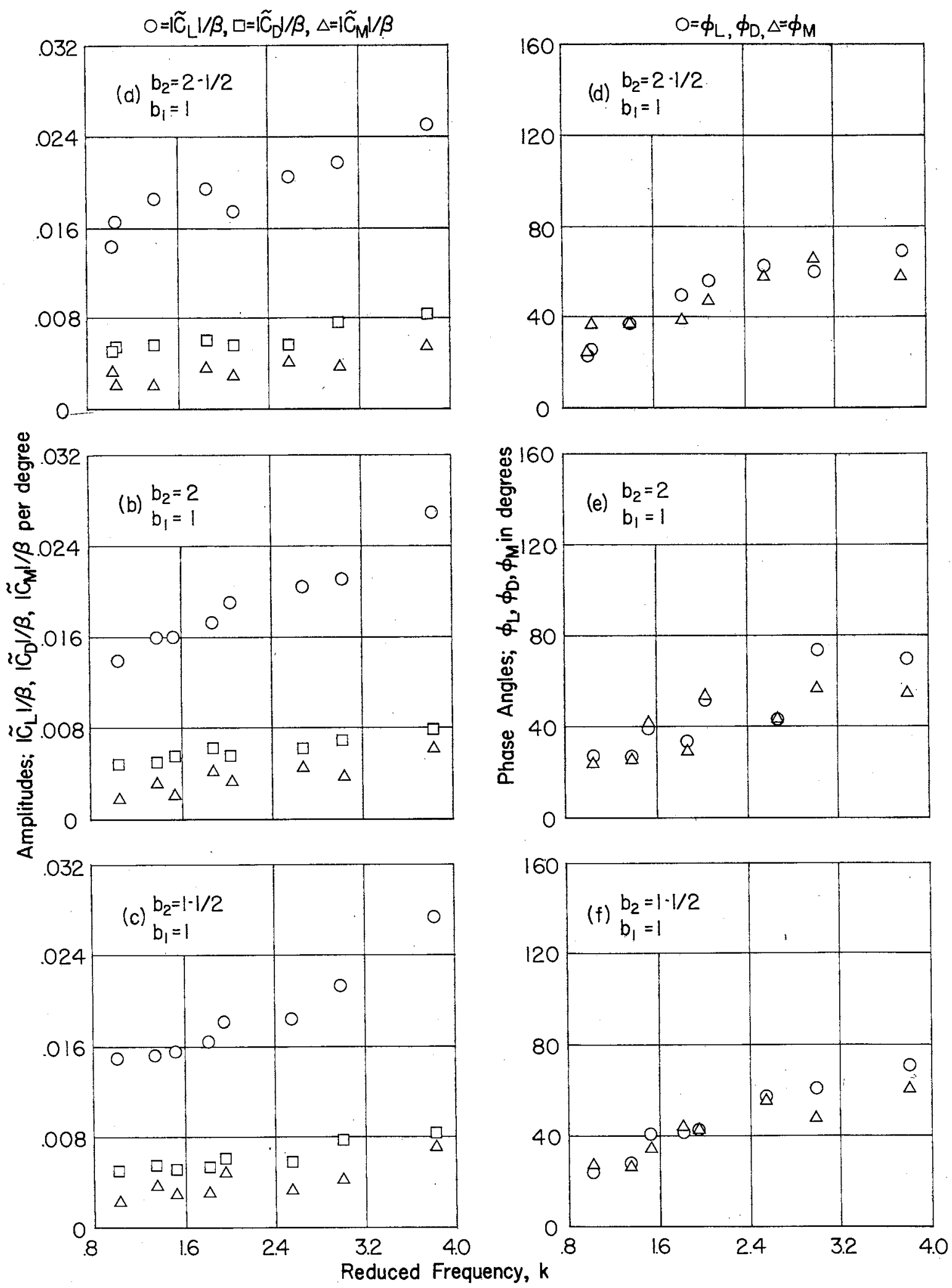

Fig. 28 - Effect of Pressure-Side Free Surface on Oscillatory Force and Moment 
SPONSOR'S DISTRIBUTION LIST FOR TECHNICAL PAPER 52-B

of the St. Anthony Falls Hydraulic Laboratory

Copies

6

1

1

1

\section{Organization}

Chief of Naval Research, Department of the Navy, Washington, D. C. 20360, Attn:

$$
\begin{aligned}
& 3 \text { - Code } 438 \\
& 1 \text { - Code } 461 \\
& 1 \text { - Code } 463 \\
& 1 \text { - Code } 466
\end{aligned}
$$

1 Commanding Officer, Office of Naval Research, Branch Office, 495 Summer Street, Boston 10, Massachusetts.

1 Commanding Officer, Office of Naval Research, Branch Office, 219 S. Dearborn St., Chicago, Illinois 60604.

Commanding Officer, Office of Naval Research, Branch Office, 207 West 24th Street, New York 11, New York.

Commanding Officer, Office of Naval Research, Branch Office, Navy No. 100, Box 39, Fleet Post Office, New York, New York.

Commanding Officer, Office of Naval Research, Branch Office, 1030 East Green Street, Pasadena 1, California.

Commanding Officer, Office of Naval Research, Branch Office, 1000 Geary Street, San Francisco 9, California.

Director, Naval Research Laboratory, Washingt on 25, D. C., Attn: Code 2027.

Chief, Bureau of Naval Weapons, Department of the Navy, Washington 25, D. C., Attn:

1 - Code RRRE

1 - Code RAAD

1 - Code RAAD-222

Chief, Bureau of Ships, Department of the Navy, Washington 25, D. C., Attn:

$$
\begin{aligned}
& 1 \text { - Code } 312 \\
& 1 \text { - Code } 335 \\
& 1 \text { - Code } 420 \\
& 1 \text { - Code } 421 \\
& 1 \text { - Code } 440 \\
& 1 \text { - Code } 442 \\
& 1 \text { - Code } 449
\end{aligned}
$$

Chief, Bureau of Yards and Docks, Department of the Navy, Washington 25, D. C., Attn: Code D-400.

Commanding Officer and Director, David Taylor Model Basin, Washington ?, D. C., Attn:

$$
\begin{aligned}
& 1 \text { - Code } 500 \\
& 1 \text { - Code } 513 \\
& 1 \text { - Code } 520 \\
& 1 \text { - Code } 525 \\
& 1 \text { - Code } 526
\end{aligned}
$$




$$
\begin{aligned}
& 1 \text { - Code } 526 \mathrm{~A} \\
& 1 \text { - Code } 530 \\
& 1 \text { - Code } 533 \\
& 1 \text { - Code } 580 \\
& 1 \text { - Code } 585 \\
& 1 \text { - Code } 589 \\
& 1 \text { - Code } 700
\end{aligned}
$$

I Commander, Naval Ordnance Test Station, China Lake, California, Attn: Code 753.

1 Commander, Naval Ordnance Test Station, Pasadena Annex, 3202 E. Foothill Boulevard, Pasadena 8, Colifornia, Attn: Code P508.

1 Commander, Portsmouth Naval Shipyard, Portsmouth, New Hampshire, Attn: Planning Department.

Commander, Boston Naval Shipyard, Boston, Massachusetts, Attn: Planning Department.

$1 \quad$ Commander, Pearl Harbor Naval Shipyard, Navy No. 128, Fleet Post Office, San Francisco, California, Attn: Planning Department.

1 Commander, San Francisco Naval Shipyard, San Francisco, California, Attn: Planning Department.

Commander, Mare Island Naval Shipyard, Vallejo, California, Attn: Planning Department.

Commander, New York Naval Shipyard, Brooklyn 1, New York, Attn: Planning Department.

Commander, Puget Sound Naval Shipyard, Bremerton, Washington, Attn: Planning Department.

Commander, Philadelphia Naval Shipyard, Philadelphia, Pennsylvania, Attn: Planning Department.

Commander, Norfolk Naval Shipyard, Portsmouth, Virginia, Attn: Planning Department.

Commander, Charleston Naval Shipyard, Charleston, South Carolina, Attn: Planning Department.

Commander, Long Beach Naval Shipyard, Long Beach 2, California, Attn: Planning Department.

Cormander, US Naval Weapons Laboratory, Dahlgren, Virginia, Attn: Planning Department.

Commander, JS Naval Ordnance Laboratory, White Oak, Maryland. Computation and'Exterior Ballistics Laboratory (Dr. A. V. Hershey). Superintendent, US Naval Academy, Annapolis, Maryland, Attn: Library. 
Secretary, Ship Structure Committee, US Coast Guard Headquarters, 1300 E Street NW, Nashington, D. C.

I Commander, Military Sea Transportation Service, Department of the Navy, Washington 25, D. C.

1 Division of Ship Design, Maritime Administration, 441 G Street NW, Washington 25, D. C.

1 Superintendent, US Merchant Marine Academy, Kings Point, Long Island, New York, Attn: Captain L. S. McCready.

1 Commanding Officer and Director, US Navy Mine Defense Laboratory, Panama City, Florida.

I Commanding Officer, NROTC and Naval Administrative Unit, Massachusetts Institute of Technology, Cambridge 39, Massachusetts.

1 Commander, Hdqs. US Army Transportation Research and Development Command, Transportation Corps, Fort Eustis, Virginia, Attn: Marine Transportation Division.

1 Air Force Office of Scientific Research, Mechanics Division, Washington 25, D. C.

1 Commander, Wright Air Development Division, Aircraft Laboratory, Wright-Patterson Air Force Base, Ohio, Attn: Mr. W. Mykytow, Dynamies Branch.

I Director of Research, Code RR, National Aeronautics and Space Administration, 600 Independence Avenue SW, Washington, D. C. 20546.

I Director, Langley Research Center, Langley Station, Hampton, Virginia, Attn: Mr. I. E. Garrick.

1 Director, Langley Research Center, Langley Station, Hampton, Virginia, Attn: Mr. D. J. Marten.

1 Director, Engineering Science Division, National Science Foundation, Washington, D. C.

I Director, National Bureau of Standards, Washington 25, D. C., Attn: Mr. J. M. Franklin.

I Dr. G. B. Schubauer, Fluid Mechanics Section, National Bureau of Standards, Washington 25, D. C.

20 Defense Documentation Center, Cameron Station, Alexandria, Virginia. I Clearinghouse, 5285 Port Royal Road, Springfield, Virginia, 22151.

$1 \quad$ Mr. Alfonso Alcadan L., Director, Laboratorio Nacional de Hydraulica, Antiguo Camino A Ancon, Casilla Postal 682, Lima, Peru.

$1 \quad \mathrm{Mr} . \mathrm{T}$. A. Duncan, Lycoming Division, AVCO Corporation, $1701 \mathrm{~K}$ Street NW, Apartment 904, Washington, D. C.

I Baker Manufacturing Company, Evansville, Wisconsin.

I Professor S. Siestrunck, Bureau D'Analyse et de Recherche Appliquees, 47, Avenue Victor Cresson, Issy-Les-Moulineaux, Seine, France. 
Professor A. Acosta, California Institute of Technology, Pasadena 4, California.

1 Professor M. Plesset, California Institute of Technology, Pasadena 4, California.

1 Professor T. Y. Wu, California Institute of Technology, Pasadena 4, California.

1 Professor A. Powell, University of California, Los Angeles, California.

$1 \quad$ Dr. Maurice L. Albertson, Professor of Civil Engineering, Colorado State University, Fort Collins, Colorado 80521.

1 Professor J. E. Cermak, Colorado State University, Department of Civil Engineering, Fort Collins, Colorado.

1 - Dr. Blaine R. Parkin, General Dynamics - Convair, P. O. Box 1950, San Diego 12, California.

1 Robert H. Oversmith, Chief of ASW/Marine Sciences, Mail Zone 6-107, General Dynamics - Convair, San Diego, California 92112.

$1 \quad$ Dr. Irving C. Statler, Head, Applied Mechanics Department, Cornell Aeronautical Laboratory, Inc., P. O. Box 235, Buffalo, New York 14221.

1 Mr. Richard P. White, Jr., Cornell Aeronautical Laboratory, 4455 Genesee Street, Buffalo, New York.

1 Professor W. R. Sears, Graduate School of Aeronautical Engineering, Cornell University, Ithaca, New York.

$1 \quad$ Mr. George H. Pedersen, Curtiss-Wright Corporation, Wright Aeronautical Division, Wood-Ridge, New Jersey, Location CC-1 Engrg. Mezz.

1 Mr. G. Tedrew, Food Machinery Corporation, P. O. Box. 367, San Jose, California.

1 General Applied Science Laboratory, Merrick and Stewart Avenues, Westbury, Long Island, New York, Attn: Dr. Frank Lane.

1 Mr. R. McCandliss, Electric Boat Division, General Dynamics Corporation, Groton, Connecticut.

I Dr. A. S. Iberall, President, General Technical Services, Inc., 2640 Whiton Road, Cleveland 18, Ohio.

I Gibbs and Cox, Inc., 21 West Street, New York, New York 10006.

I Mr. Eugene F. Baird, Chief of Dynamic Analysis, Grumman Aircraft Engineering Corporation, Bethpage, Long Island, New York.

I Mr. Robert E. Bower, Chief, Advanced Development, Grumman Aircraft Engineering Corporation, Bethpage, Long Island, New York.

1 Mr. William P. Carl, Grumman Aircraft Engineering Corporation, Bethpage, Long Island, New York.

1 Grumman Aircraft Engineering Corporation, Research Department, Plant 25, Bethpage, Long Island, New York 11714, Attn: Mr. Kenneth Keen. 
Dr. O. Grim, Hamburgische Schiffbau-Versuchsanstalt, Bramfelder Strasse 164, Hamburg 33, Germany.

1 Dr. H. W. Lerbs, Hamburgische Schiffbau-Versuchsanstalt, Bramfelder Strasse 164, Hamburg 33, Germany.

I Dr. H. Schwanecke, Hamburgische Schiffbau-Versuchsanstalt, Bramfelder Strasse 164, Hamburg 33, Germany.

I Professor G. P. Weinblum, Director, Institute for Schiffbau, University of Hamburg, Berliner Tow 21, Hamburg, Germany.

I Professor G. F. Carrier, Harvard University, Cambridge 38, Massachusetts.

Dr. S. F. Hoerner, 148 Busteed Drive, Midland Park, New Jersey.

Mr. P. Eisenberg, President, Hydronautics, Incorporated, Pindell School Road, Howard County, Laurel, Maryland.

Professor Carl Prohaska, Hydro-og Aerodynamisk Laboratorium, Lyngby, Denmark.

Professor L. Landweber, Iowa Institute of Hydraulic Research, State University of Iowa, Iowa City, Iowa.

Professor H. Rouse, Iowa Institute of Hydraulic Research, State University of Iowa, Iowa City, Iowa.

Professor S. Corrsin, Department of Mechanics, The Johns Hopkins University, Baltimore 18, Maryland.

Professor 0. M. Phillips, Division of Mechanical Engineering, Institute for Cooperative Research, The Johns Hopkins University, Baltimore 18, Maryland.

Mr. Bill East, Lockheed Aircraft Corporation, California Division, Hydrodynamics Research, Burbank, California.

Mr. R. W. Kermeen, Lockheed Missiles and Space Company, Department 81-73/Bldg 538, P. O. Box 504, Sunnyvale, California.

Department of Naval Architecture and Marine Engineering, Room 5-228, Massachusetts Institute of Technology, 77 Massachusetts Avenue, Cambridge, Massachusetts 02139.

Professor M. A. Abkowitz, Massachusetts Institute of Technology, Cambridge 39, Massachusetts. Professor H. Ashley, Mas
bridge 39, Massachusetts.

Professor A. T. Ippen, Massachusetts Institute of Technology, Cambridge 39, Massachusetts.

Professor M. Landahl, Massachusetts Institute of Technology, Cambridge 39, Massachusetts.

Dr. H. Reichardt, Director, Max-Planck Institut fur Stromungsforschung, Bottingerstrasse 6-8, Gottingen, Germany.

Professor R. B. Couch, University of Michigan, Ann Arbor, Michigan. 
Copies

1

1

1

1

1

1

1

1

1

1

1

\section{Organization}

Professor W. W. Willmarth, University of Michigan, Ann Arbor, Michigan.

Midwest Research Institute, 425 Volker Boulevard, Kansas City, Missouri, Attn: Library.

Director, St. Anthony Falls Hydraulic Laboratory, University of Minnesota, Minneapolis 14, Minnesota.

Dr. C. S. Song, St. Anthony Falls Hydraulic Laboratory, University of Minnesota, Minneapolis 14, Minnesota.

Mr. J. M. Wetzel, St. Anthony Falls Hydraulic Laboratory, University of Minnesota, Minneapolis 14, Minnesota.

Head, Aerodynamics Division, National Physical Laboratory, Teddington, Middlesex, England.

Mr. A. Silverleaf, National Physical Laboratory, Teddington, Middlesex England.

The Aeronautical Library, National Research Council, Montreal Road, Ottawa 2, Canada.

Dr. J. B. Van Manen, Netherlands Ship Model Basin, Wageningen, The Netherlands.

Professor John J. Foody, Chairman, Engineering Department, State University of New York, Maritime College, Bronx, New York 10465.

Professor J. Keller, Institute of Mathematical Sciences, New York University, 25 Waverly Place, New York 3, New York.

Professor J. J. Stoker, Institute of Mathematical Sciences, New York University, 25 Waverly Place, New York 3, New York.

Dr. T. R. Goodman, Oceanics, Incorporated, Technical Industrial Park, Plainview, Long Island, New York.

Professor J. William Holl, Department of Aeroxautical Engineering, The Pennsylvania State University, Ordnance Research Laboratory, P. 0. Box 30, University Park, Pennsylvania.

Dr. M. Sevik, Ordnance Research Laboratory, Pennsylvania State University, University Park, Pennsylvania.

Dr. George F. Wislicenus, Garfield Thomas Water Tunnel, Ordnance Research Laboratory, The Pennsylvania State University, Post Office Box 30, University Park, Pennsylvania 16801.

Mr. David Wellinger, Hydrofoil Projects, Radio Corporation of America, Burlington, Massachusetts.

The RAND Corporation, 1700 Main Street, Santa Monica, California 90406, Attn: Library.

Professor R. C. DiPrima, Department of Mathematics, Rensselaer Polytechnic Institute, Troy, New York.

Mr. L. M. White, U. S. Rubber Company, Research and Development Department, Wayne, New Jersey.

Professor J. K. Lunde, Skipsmodelltanken, Trondheim, Norway. 
Editor, Applied Mechanics Review, Southwest Research Institute, 8500 Culebra Road, San Antonio 6, Texas.

Dr. H. N. Abramson, Southwest Research Institute, 8500 Culebra Road, San Antonio 6, Texas.

Mr. G. Ransleben, Southwest Research Institute, 8500 Culebra Road, San Antonio 6, Texas.

Professor E. Y. Hsu, Stanford University, Stanford, California.

Dr. Byrne Perry, Department of Civil Engineering, Stanford University, Stanford, California 94305

Dr. J. P. Breslin, Stevens Institute of Technology, Davidson Laboratory, Hoboken, New Jersey.

Mr. D. Savitsky, Stevens Institute of Technology, Davidson Laboratory, Hoboken, New Jersey.

Mr. S. Tsakonas, Stevens Institute of Technology, Davidson Laboratory, Hoboken, New Jersey.

Dr. Jack Kotik, Technical Research Group, Inc., Route 110, Melvi.lle, New York.

1 Dr. R. Timman, Department of Applied Mathematics, Technological University, Julianalaan 132, Delft, Holland.

The Transportation Technical Research Institute, Investigation office, Ship Research Institute, 700 Shinkawa, Mitaka, Tokyo-to, Japan.

Dr. Grosse, Versuchsanstalt fur Wasserbau und Schiffbau, Schleuseninsel im Tiergarten, Berlin, Germany.

Dr. S. Schuster, Director, Versuchsanstalt fur Wasserbau und Schiffbau, Schleuseninsel im Tiergarten, Berlin, Germany.

Technical Library, Webb Institute of Naval Architecture, G.len Cove, Long Island, New York.

Professor E. V. Lewis, Webb Institute of Naval Architecture, Glen Cove, Long Island, New York.

1 Mr. C. Wigley, Flat 103, 6-9 Charterhouse Square, London E. C. I, England.

1 Coordinator of Research, Maritime Administration, 44.1 G Street NW, Washington 25, D. C. 


\section{DOCUMENT CONTROL DATA - R\&D}

(Security classification of title, body of abstract and indexing annotation must be entered when the overall report is classified)

1. ORIGINATING ACTIVITY (Corporate author)

St. Anthony Falls Hydraulic Laboratory

2a. REPORT SECURITY CLASSIFICATION Unclassified 2b. GROUP

\section{REPORT TITLE}

SUPERCAVITATING FLAT-PLATE WITH AN OSCILLATING FLAP AT ZERO CAVITATION NUMBER

\section{DESCRIPTIVE NOTES (Typo of roport and inclusive datos)}

Final report on this aspect of study.

5. ALTHOR(S) (Last namo, first namo, initial)

Song, C. S.

\begin{tabular}{|c|c|}
\hline $\begin{array}{l}\text { 6. REPORT DATE } \\
\text { NoVember } 1965\end{array}$ & \begin{tabular}{c|c} 
7a. TOTAL NO. OF PAGES & 7b. NO. OF REFS \\
60 & 11
\end{tabular} \\
\hline $\begin{array}{l}\text { Ba. CONTRACT OR GRANT NO. } \\
\text { D. PROJECT NO. }\end{array}$ & $\begin{array}{l}\text { 9 A. ORIGINA TOR'S REPORT NUMBER(S) } \\
\text { Technical Paper No. 52-B }\end{array}$ \\
\hline $\begin{array}{ll}\text { c. } & \mathrm{NR} 062-052 \\
\text { d. } & \end{array}$ & $\begin{array}{l}\text { 9b. OTHER REPORT NO(S) (A ny othor numbors that may bo assienod } \\
\text { this roport) }\end{array}$ \\
\hline
\end{tabular}

10. AVAILABILITY/LIMITATION NOTICES

Qualified requestors may obtain copies of this report from DDC.

11. SUPPL EMENTARY NOTES

12. SPONSORING MILITARY ACTIVITY

Office of Naval Research

13. ABSTRACT

The results of experimental and theoretical investigations on a supercavitating flat-plate with an oscillating flap at zero cavitation number are presented. The experiment was carried out in a vertical free-jet water tunnel using 3 in. chord and 2 in. chord flat-plate hydrofoils, both having flap-chord ratios of 0.29 . Various relative locations of the free surfaces were used and the reduced frequency range of zero to four was covered. Amplitude and phase angle of lift, drag, and moment as well as the surface wave speed were measured. The problem was also solved analytically by means of a first order perturbation theory and the results were compared with the experimental data. 
Unclassified

Security Classification

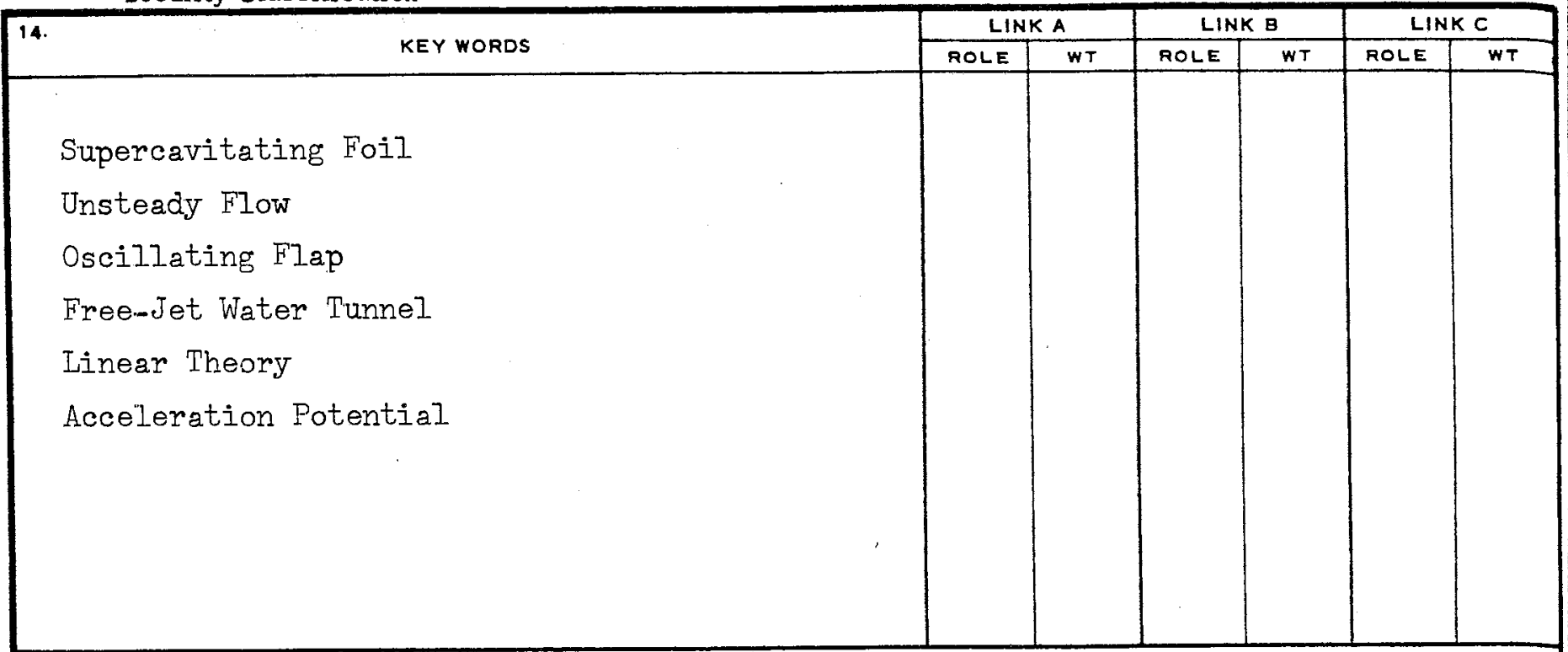

\section{INSTRUCTIONS}

1. ORIGINATING ACTIVITY: Enter the name and address of the contractor, subcontractor, grantee, Department of Defense activity or other organization (corporate author) issuing the report.

2a. REPORT SECURTY CLASSIFICATION: Enter the overall security classification of the report. Indicate whether "Restricted Data" is included. Marking is to be in accordance with appropriate security regulations.

2b. GROUP: Automatic downgrading is specified in DoD Directive 5200.10 and Armed Forces Industrial Manual. Enter the group number. Also, when applicable, show that optional markings have been used for Group 3 and Group 4 as authorized.

3. REPORT TITLE: Enter the complete report title in all capital letters. Titles in all cases should be unclassified. If a meaningful title cannot be selected without classification, show title classification in all capitals in parenthesis immediately following the title.

4. DESCRIPTIVE NOTES: If appropriate, enter the type of report; e. g. , interim, progress, summary, annual, or finàl.

Give the inclusive dates when a specific reporting period is covered.

5. AUTHOR(S): Enter the name(s) of author(s) as shown on or in the report. Entel last name, first name, middle initial. If military, show rank and branch of service. The name of the principal author is an ahsolute minimum requirement.

6. REPORT DATE: Enter the date of the report as day, month, year; or month, year. If more than one date appears on the report, use date of publication.

7a. TOTAL NUMBER OF PAGES: The total page count should follow normal pagination procedures, i.e., enter the number of pages containing information.

7b. NUMBER OF REFERENCES: Enter the total number of references cited in the report.

8a. CONTRACT OR GRANT NUMBER: If appropriate, enter the applicable number of the contract or grant under which the report was written.

$8 b, 8 c, 8 c 8 d$. PROJECT NUMBER: Enter the appropriate military department identification, such as project number, subproject number, system numbers, task number, etc.

9a. ORIGINATOR'S REPORT NUMBER(S): Enter the official report number by which the document will be identified and controlled by the originating activity. This number must be unique to this report.

9b. OTHER REPORT NUMBER(S): If the report has been assigned any other report numbers (either by the originator or by the sponsor), also enter this number(s).

10. AVAIL ABILITY/LIMITATION NOTICES: Enter any limitations on further dissemination of the report, other than those imposed by security classification, using standard statements such as:

(1) "Qualified requesters may obtain copies of this report from DDC."

(2) "Foreign announcement and dissemination of this report by DDC is not authorized."

(3) "U. S. Government agencies may obtain copies of this report directly from DDC. Other qualified DDC users shall request through

(4) "U. S. military agencies may obtain copies of this report directly from DDC. Other qualified users shall request through

(5) "All distribution of this report is controlled Qualified DDC users shall request through ."

If the report has been furnished to the Office of Technical Services, Department of Commerce, for sale to the public, indicate this fact and enter the price, if known.

11. SUPPLEMENTARY NOTES: Use for additional explanatory notes.

12. SPONSORING MILITARY ACTIVITY: Enter the name of the departmental project of fice or laboratory sponsoring (pay ing $f \circ r)$ the research and development. Include address.

13. ABSTRACT: Enter an abstract giving a brief and factual summary of the document indicative of the report, even though it may also appear elsewhere in the body of the technical report. If additional space is required, a continuation sheet shall be attached.

It is highly desirable that the abstract of classified reports be unclassified. Each paragraph of the abstract shall end with an indication of the military security classification of the information in the paragraph, represented as $(T S),(S)$, (C), or (U).

There is no limitation on the length of the abstract. However, the suggested length is from 150 to 225 words.

14. KEY WORDS: Key words are technically meaningful terms or short phrases that characterize a report and may be used as index entries for cataloging the report. Key words must be selected so that no security classification is required. Identifiers, such as equipment model designation, trade name, military project code name, geographic location, may be used as key words but will be followed by an indication of technical context. The assignment of links, roles, and weights is optional. 
Technical Paper No. 52, Series B

St. Anthony Falls Hydraulic Laboratory

SUPERCAVITATING FLAT-PLATE WITH AN OSCLLLATING FLAP AT ZERO CAVITATION NUMBER, by C.S. Song. November 1965, 60 pages incl. 28 illus. Contract Non $710(24)$.

The results of experimental and theoretical investigations on a supercavitating flat-plate with an oscillating flap a zero cavitation number are presented. The experiment wa carried out in a vertical free-jet water tunnel using 3 in. chord and 2 in. chord flat-plate hydrofoils, both having flapchord ratios of 0.29 . Various relative locations of the free surfaces were used and the reduced frequency range of zero to four was covered. Amplitude and phase angle of lift, drag, and moment as well as the surface wave speed were measured. The problem was also solved analytically by means of a first order perturbation theory and the results were compared with the experimental data.

Available from St. Anthony Falls Hydraulic Laboratory, University of Minnesota, at $\$ 1.75$ per copy.
1. Supercavitating Foil 2. Unsteady Flow 3. Oscillating Flap 4. Free-Jet Water Tunnel
5. Linear Theory 5. Linear Theory

. Acceleration Potential

I. Title

II. Song, C. S

III. St. Anthony Falls

Hydraulic Laboratory

IV. Contract No. $710(24)$

Unclassified
Technical Paper No. 52, Serïes B

St. Anthony Falls Hydraulic Laboratory

SUPERCAVITATING FLAT-PLATE WITH AN OSCILLATING FLAP AT ZERO CAVITATION NUMBER, by C. S. Song. November 1965. 60 pages incl. 28 illus. Contract Nonr $710(24)$.

The results of experimental and theoretical investigations on a supercavitating flat-plate with an oscillating flap at zero cavitation number are presented. The experiment was carried out in a vertical free-jet water tunnel using 3 in. chord and 2 in. chord flat-plate hydrofoils, both having flapchord ratios of 0.29 . Various relative locations of the free surfaces were used and the reduced frequency range of zero to four was covered. Amplitude and phase angle of lift, drag, and moment as well as the surface wave speed were measured. The problem was also solved analytically by means of a first order perturbation theory and the results were compared with the experimental data.

Available from St. Anthony Falls Hydraulic Laboratory, University of Minnesota, at $\$ 1.75$ per copy.
1. Supercavitating Foi

2. Unsteady Flow

4. Free-Jet Water Tunnel

5. Linear Theory

6. Acceleration Potential

I. Title

II. Song, C. S.

III. St. Anthony Falls Hydraulic Laboratory

IV. Contract No. $710(24)$
Technical Paper No. 52, Series B

St. Anthony Falls Hydraulic Laboratory

SUPERCAVITATING FLAT-PLATE WITH AN OSCILLATING FLAP AT ZERO CAVITATION NUMBER, by C.S. Song. November 1965 . 60 pages incl. 28 illus. Contract Nonr $710(24)$.

The results of experimental and theoretical investigations on a supercavitating flat-plate with an oscillating flap at zero cavitation number are presented. The experiment was carried out in a vertical free-jet water tunnel using 3 in. chord and 2 in. chord flat-plate hydrofoils, both having flapchord ratios of 0.29 . Various relative locations of the free surfaces were used and the reduced frequency range of zer to four was covered. Amplitude and phase angle of lift, drag, and moment as well as the surface wave speed were measured. The problem was also solved analytically by means of a first order perturbation theory and the results were compared with the experimental data.

Available from St. Anthony Falls Hydraulic Laboratory, University of Minnesota, at $\$ 1,75$ per copy.
1. Supercavitating Foil 2. Unsteady Flow 4. Free-Jet Water Tunne 4. Free-Jet Water 6. Acceleration Potential

I. Title

II. Song, C. S.

III. St. Anthony Falls

Hydraulic Laboratory

IV. Contract No. $710(24)$

Unclassified
Technical Paper No, 52 , Series B

St. Anthony Falls Hydraulic Laboratory

SUPERCAVITATING FLAT-PLATE WITH AN OSCILLATING FLAP AT ZERO CAVITATION NUMBER, by C. S. Song. November 1965. 60 pages incl. 28 illus. Contract Nonr 710 (24).

The results of experimental and theoretical investigations on a supercavitating flat-plate with an oscillating flap at zero cavitation number are presented. The experiment was carried out in a vertical free-jet water tunnel using 3 in. chord and 2 in. chord flat-plate hydrofoils, both having flapchord ratios of 0.29 . Various relative locations of the free surfaces were used and the reduced frequency range of zero to four was covered. Amplitude and phase angle of lift, drag, and moment as well as the surface wave speed were measured. The problem was also solved analytically by means of a first order perturbation theory and the results were coma first order perturbation theory and the results were compared with the experimental data.

Available from St. Anthony Falls Hydraulic Laboratory, Univer sity of Minnesota, at $\$ 1.75$ per copy.
1. Supercavitating Foil

2. Unsteady Flow

3. Oscillating Flap

5. Linear Theory

5. Linear Theory

I. Title

II. Song, C. S.

III. St. Anthony Falls

Hydraulic Laboratory

IV. Contract No. $710(24)$ 
Technical Paper No. 52, Series B

St. Anthony Falls Hydraulic Laboratory

SUPERCAVITATING FLAT-PLATE WITH AN OSCILLATING FLAP AT ZERO CAVITATION NUMBER, by C. S. Song. November 1965. 60 pages incl. 28 illus. Contract Nonr 710 (24)

The results of experimental and theoretical investigations on a supercavitating flat-plate with an oscillating flap at zero cavitation number are presented. The experiment was carried out in a vertical free-jet water tunnel using 3 in. chord and 2 in. chord flat-plate hydrofoils, both having flapchord ratios of 0.29 . Various relative locations of the free surfaces were used and the reduced frequency range of zero to four was covered. Amplitude and phase angle of lift, drag, and moment as well as the surface wave speed were measured. The problem was also solved analytically by means of a first order perturbation theory and the results were compared with the experimental data.

Available from St. Anthony Falls Hydraulic Laboratory, University of Minnesota, at $\$ 1.75$ per copy.
1. Supercavitating Foil 2. Unsteady Flow 3. Oscillating Flap 4. Free-Jet Water Tunnel
5. Linear Theory

6. Acceleration Potential

I. Title

II. Song, C. S.

III. St. Anthony Falls Hydraulic Laboratory IV. Contract No. $710(24)$

Unclassified
Technical Paper No. 52, Series B

St. Anthony Falls Hydraulic Laboratory

SUPERCAVITATING FLAT-PLATE WITH AN OSCILLATING FLAP AT ZERO CAVITATION NUMBER, by C.S. SOng. November 1965. 60 pages incl. 28 illus. Contract Nonr $710(24)$.

The results of experimental and theoretical investigations on a supercavitating flat-plate with an oscillating flap at on a supercavitating flat-plate with an oscillating flap at zero cavitation number are presented. The experiment was carried out in a vertical free-jet water tunnel using 3 in. chord and 2 in. chord flat-plate hydrofoils, both having flapchord ratios of 0.29 . Various relative locations of the free surfaces were used and the reduced frequency range of zero to four was covered. Amplitude and phase angle of lift, drag, and moment as well as the surface wave speed were measured. The problem was also solved analytically by means of a first order perturbation theory and the results were compared with the experimental data.

Available from St. Anthony Falls Hydraulic Laboratory, University of Minnesota, at $\$ 1.75$ per copy.
1. Supercavitating Foil

2. Unsteady Flow

4. Free-Jet Water Tunnel

5. Linear Theory

6. Acceleration Potential

I. Title

II. Song, C. S.

III. St. Anthony Falls

Hydraulic Laboratory

IV. Contract No. $710(24)$
Technical Paper No. 52, Series B

St. Anthony Falls Hydraulic Laboratory

SUPERCAVITATING FLAT-PLATE WITH AN OSCILLATNG FLAP AT ZERO CAVITATION NUMBER, by C. S. Song. ING FLAP AT ZERO CAVITATION NUMBER, by C. S. Song. Novembe
$710(24)$.

The results of experimental and theoretical investigations on a supercavitating flat-plate with an oscillating flap at on a supercavitating flat-plate with an oscillating flap at zero cavitation number are presented. The experiment was carried out in a vertical free-jet water tunnel using 3 in. chord and 2 in. chord flat-plate hydrofoils, both having flapchord ratios of 0.29 . Various relative locations of the free surfaces were used and the recuced frequency range of zero to four was covered. Amplitude and phase angle of lift, drag, and moment as well as the surface wave speed were measured. The problem was also solved analytically by means of a first order perturbation theory and the results were compared with the experimental data.

Available from St. Anthony Falls Hydraulic Laboratory, University of Minnesota, at $\$ 1.75$ per copy.
1. Supercavitating Foil

2. Unsteady Flow

4. Oscillating Flap

5. Linear Theory

6. Acceleration Potential

I. Title

II. Song, C. S.

III. St. Anthony Falls

Hydraulic Laboratory

IV. Contract No. $710(24)$

Unclassified
Technical Paper No. 52, Series B

St. Anthony Falls Hydraulic Laboratory

SUPERCAVITATING FLAT-PLATE WITH AN OSCILLATING FLAP AT ZERO CAVITATION NUMBER, by C.S. Song. November 1965. 60 pages incl. 28 illus. Contract Non 710 (24).

The results of experimental and theoretical investigation on a supercavitating flat-plate with an oscillating flap a zero cavitation number are presented. The experiment was carried out in a vertical free-jet water tunnel using 3 in. chord and 2 in. chord flat-plate hydrofoils, both having flapchord ratios of 0.29 . Various relative locations of the free surfaces were used and the reduced frequency range of zero to four was covered. Amplitude and phase angle of lift, drag, and moment as well as the surface wave speed were measured. The problem was also solved analytically by means of a first order perturbation theory and the results were compared with the experimental data.

Available from St. Anthony Falls Hydraulic Laboratory, University of Minnesota, at $\$ 1.75$ per copy.
1. Supercavitating Foil

2. Unsteady Flow

3. Oscillating Flap

5. Linear Theor

6. Acceleration Potential

I. Title

II. Song, C. S.

III. St. Anthony Falls

Hydraulic Laboratory

IV. Contract No. $710(24)$ 
Technical Paper No. 52, Series B

St. Anthony Falls Hydraulic Laboratory

SUPERCAVITATING FLAT-PLATE WITH AN OSCILLAT ING FLAP AT ZERO CAVITATION NUMBER, by C.S. Song. November 1965. 60 pages incl. 28 illus. Contract Nonr 710 (24).

The results of experimental and theoretical investigation on a supercavitating flat-plate with an oscillating flap at zero cavitation number are presented. The experiment was carried out in a vertical free-jet water tunnel using 3 in. chord and 2 in. chord flat-plate hydrofoils, both having flapchord ratios of 0.29 . Various relative locations of the free surfaces were used and the reduced frequency range of zero to four was covered. Amplitude and phase angle of lift, dras, and moment as well as the surface wave speed were measured. The problem was also solved analytically by means of a first order perturbation theory and the results were compared with the experimental data.

Available from St. Anthony Falls Hydraulic Laboratory, University of Minnesota, at $\$ 1.75$ per copy.
1. Supercavitating Foil 2. Unsteady Flow

3. Oscillating Flap

5. Linear Theory

6. Acceleration Potential

I. Title

II. Song, C. S.

III. St. Anthony Falls

Hydraulic Laboratory

IV. Contract No. $710(24)$

Unclassified
Technical Paper No. 52, Series B

St. Anthony Falls Hydraulic Laboratory

SUPERCAVITATING FLAT-PLATE WITH AN OSCILLATING FLAP AT ZERO CAVITATION NUMBER, by C.S. Song. November 1965. 60 pages incl. 28 illus. Contract Nonr 710 (24).

The results of experimental and theoretical investigations on a supercavitating flat-plate with an oscillating flap at zero cavitation number are presented. The experiment was carried out in a vertical free-jet water tunnel using 3 in. chord and 2 in. chord flat-plate hydrofoils, both having flapchord ratios of 0.29 . Various relative locations of the free surfaces were used and the reduced frequency range of zero to four was covered. Amplitude and phase angle of lift, drag, and moment as well as the surface wave speed were measured. The problem was also solved analytically by means of a first order perturbation theory and the results were compared with the experimental data.

Available from St. Anthony Falls Hydraulic Laboratory, University of Minnesota, at $\$ 1.75$ per copy.
1. Supercavitating Foil 2. Unsteady Flow 3. Oscillating Flap 4. Free-Jet Water Tunnel 5. Linear Theory

6. Acceleration Potential

I. Title

II. Song, C. S.

III. St. Anthony Falls Hydraulic Laboratory

IV. Contract No. $710(24)$
Technical Paper No. 52, Series B

St. Anthony Falls Hydraulic Laboratory

SUPERCAVITATING FLAT-PLATE WITH AN OSCILLATING FLAP AT ZERO CAVITATION NUMBER, by C. S. Song. November 1965 . 60 pages incl. 28 illus. Contract Non 710 (24). The results of experimental and theoretical investigations on a supercavitating flat-plate with an oscillating flap at zero cavitation number are presented. The experiment was carrled out in a vertical free jet water tunnel using 3 in. chord and 2 in. chord hat-plate hydrofolls, both having flapchord ratios of 0.29 . Various relative locations of the surfaces were used and the reduced frequency range of zero to four was cover. Ar and moment as well as the surface wave speed were meas ured. The problem was also solved analytically wy means of pared with the experimental data.

Available from St. Anthony Falls Hydraulic Laboratory, University of Minnesota, at $\$ 1.75$ per copy.
1. Supercavitating Foil

2. Unsteady Flow

4. Free-Jet Water Tunne

5. Linear Theory

6. Acceleration Potential

I. Title

II. Song, C. S.

III. St. Anthony Falls

Hydraulic Laboratory

IV. Contract No. $710(24)$

Unclassified
Technical Paper No. 52, Series B

St. Anthony Falls Hydraulic Laboratory

SUPERCAVITATING FLAT-PLATE WITH AN OSCILLATING FLAP AT ZERO CAVITATION NUMBER, by C.S. Song. November 1965. 60 pages inc1. 28 illus. Contract Nonr 710 (24).

The results of experimental and theoretical investigations on a supercavitating flat-plate with an oscillating flap at zero cavitation number are presented. The experiment was carried out in a vertical free-jet water tunnel using 3 in. chord and 2 in. chord flat-plate hydrofoils, both having flapchord ratios of 0.29 . Various relative locations of the free surfaces were used and the reduced frequency range of zero to four was covered. Amplitude and phase angle of lift zero and moment as well as the surface wave speed were meas and moment as well as the surface wave speed were meas-
ured. The problem was also solved analytically by means of a first order perturbation theory and the results were compared with the experimental data.

Available from St. Anthony Falls Hydraulic Laboratory, University of Minnesota, at $\$ 1.75$ per copy.
1. Supercavitating Foil 2. Unsteady Flow 3. Oscillating Flap 4. Free-Jet Water Tunnel 5. Linear Theory 6. Acceleration Potential

I. Title

II. Song, C. S

III. St. Anthony Falls

Hydraulic Laboratory

IV. Contract No, 710 (24) 